\title{
A Parametric Study and Economic Evaluation of Drilling Patterns in Deep, Thick CBM Reservoirs
}

\author{
Ali Omran Ali Nasar \\ West Virginia University
}

Follow this and additional works at: https://researchrepository.wvu.edu/etd

\section{Recommended Citation}

Nasar, Ali Omran Ali, "A Parametric Study and Economic Evaluation of Drilling Patterns in Deep, Thick CBM Reservoirs" (2011). Graduate Theses, Dissertations, and Problem Reports. 584.

https://researchrepository.wvu.edu/etd/584

This Thesis is protected by copyright and/or related rights. It has been brought to you by the The Research Repository @ WVU with permission from the rights-holder(s). You are free to use this Thesis in any way that is permitted by the copyright and related rights legislation that applies to your use. For other uses you must obtain permission from the rights-holder(s) directly, unless additional rights are indicated by a Creative Commons license in the record and/ or on the work itself. This Thesis has been accepted for inclusion in WVU Graduate Theses, Dissertations, and Problem Reports collection by an authorized administrator of The Research Repository @ WVU. For more information, please contact researchrepository@mail.wvu.edu. 
A Parametric Study and Economic Evaluation of Drilling Patterns in Deep, Thick CBM Reservoirs

\section{Ali Omran Ali Nasar}

Thesis Submitted to the College of Engineering and Mineral Resources at West Virginia University

In partial fulfillment of the requirements for the degree of Master of Science in Petroleum and Natural Gas Engineering

Dr. Shahab Mohaghegh, Committee Chair

Samuel Ameri, Prof.

Razi Gaskari, PhD.

Department of Petroleum and Natural Gas Engineering Morgantown, West Virginia 2011

Keywords: Petroleum and Natural Gas Engineering, CBM Production and Sensitivity Analysis

\section{Copyright 2011 Ali Omran Ali Nasar}




\title{
ABSTRACT \\ A Parametric Study and Economic Evaluation of Drilling Patterns in Deep, Thick CBM Reservoirs
}

\begin{abstract}
Ali O. Nasar
Over the past decade, the production from unconventional reservoirs such as coalbed methane has increased dramatically. The focal driving force for this growth in coalbed methane production was the development and promulgation of reservoir engineering and completion technology.

There have been many studies performed on the well configuration and production optimization techniques in the coal seams. According to many of these studies horizontal, deviated and multi-lateral wells are of more benefits compared to the vertical wells. However, the targets of these studies have mostly been the thin coal seams while this result might not hold for the thick CBM reservoirs. The experience has proved that one thick coal is better than an equivalent thickness of multiple thin coals. Samples of the deep thickest accumulation of coal in the world can be found in some of the areas of the United States such as Uintah basin and Piceance basin in Colorado, Black Warrior basin in Alabama and Arkoma basin in Oklahoma and Alaska. The thickness of coal beds in these areas can reach up to $150 \mathrm{ft}$ and they can be as deep as $9000 \mathrm{ft}$.
\end{abstract}

Although horizontal drilling will result in higher gas production and consequently more revenue, the drilling cost in these wells are significantly higher than the vertical wells. When the coal beds are thick enough that the contact of wellbore and formation is not a limiting issue, the practicality of drilling horizontally versus multiple vertical wells might be questioned.

In this work, the most appropriate drilling patterns in thick and deep CBM reservoirs have been identified. A sensitivity analysis has been performed with the intention of addressing the effect of different reservoir parameters and well configurations germane to methane production from CBM. These characteristics include fracture permeability, fracture porosity, gas content, and desorption time. The yardstick for comparing the economical practicality of different drilling configurations under diverse reservoir properties is the Net Present Value (NPV). 
This work is dedicated to my parents Omran Nasar and Fajr Abdullah. They always have given me the confidence and have encouraged me to reach all of my goals, and also to my Brothers and Sisters. 


\section{Acknowledgments}

I would like to express my deepest gratitude and special thanks to Dr. Shahab Mohaghegh for his guidance and support. Dr Shahab is not only my advisor, but he is also my closest friend who helped me a lot.

I would like to extend my thanks to Department Chair Sam Ameri for his willingness to express and extend a warm sense of confidence towards me.

Additionally, I would like to extend my gratitude to Dr. Razi Gaskari for his valuable information and feedback.

Also, I would like to thank my Mother and Father for their support while I studied abroad from them and my Sisters and Brothers.

Immense thanks to my research assistant Vida Gholami for believing in my abilities during study at WVU.

Special thanks to my professors in the Department of Petroleum and Natural Gas Engineering at West Virginia University for their support during my study. Also, as I am a member of the Pearl group, I would like to thank every of the member group for their contribution and support while I worked with the team: Abdullahi Yusuf, Vida Gholami, Alireza Shahkarami ,Ognjen Grujic, Yasaman Khazaeni, Amirmasoud Kalantari, Shohreh Amini, Soodabeh Esmaili, Najmeh Borzouei, Seyed Alireza, Haghighat, Ike Eleanya Onuoha, Qin He, where I had spent a wonderful time which I will never forget.

Special thanks go to my best friends Essa. Tabar and Ahmed. Abuseta who support me while studying at WVU. Besides them, also I would like to thank my brother in law Hassan Abuzaid.

Finally, I would like to acknowledge Computer Modeling Group (CMG) for providing the software for this study. 


\section{Table of Contents}

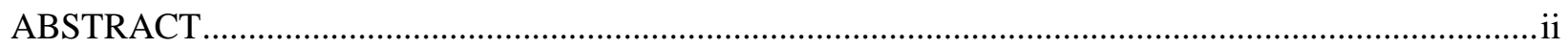

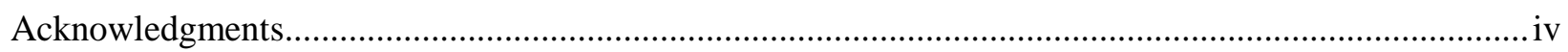

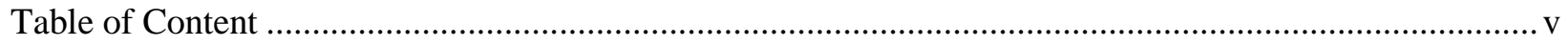

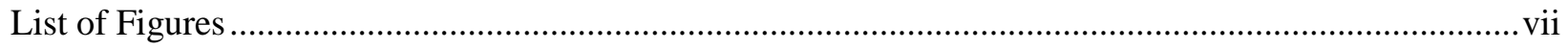

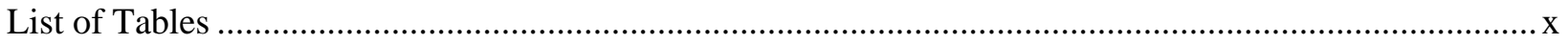

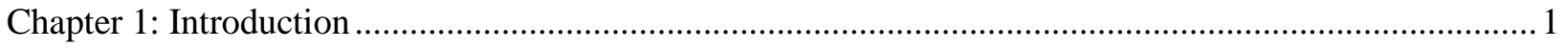

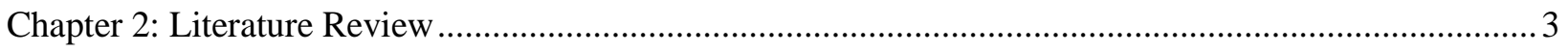

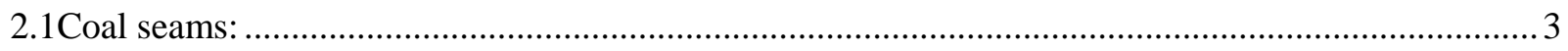

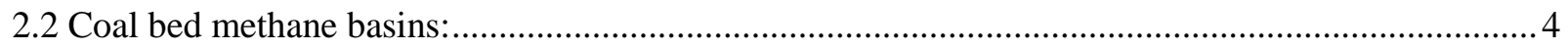

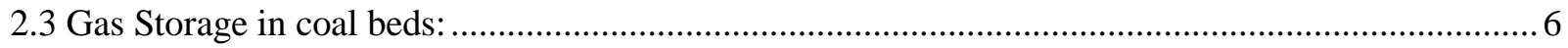

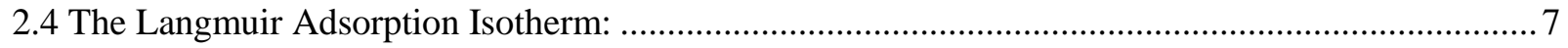

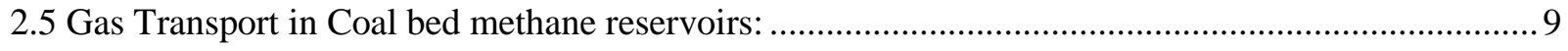

2.6 Coalbed methane Reservoir Characteristics: .....................................................................

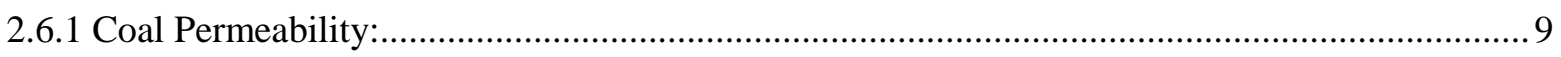

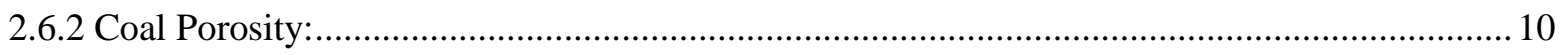

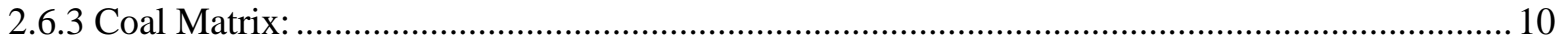

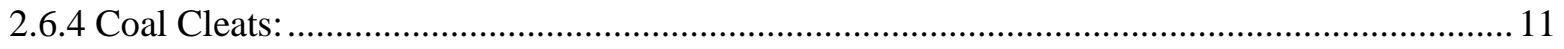

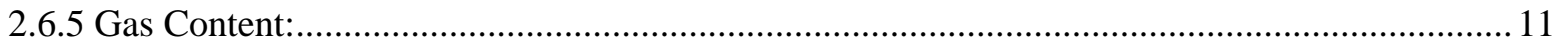

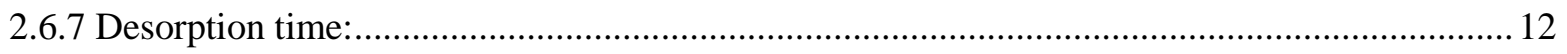

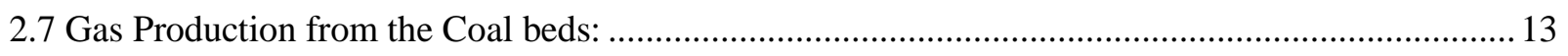

2.8 Saturated and Under-Saturated Coalbed Methane Reservoirs: ................................................. 13

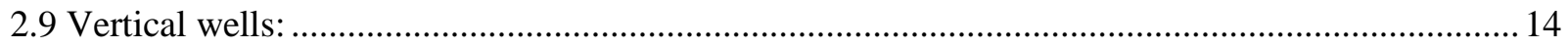

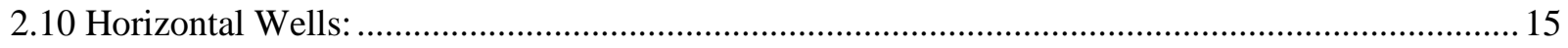

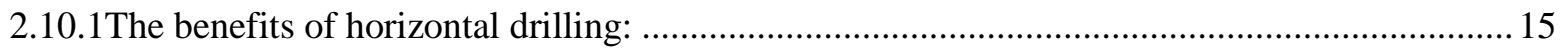

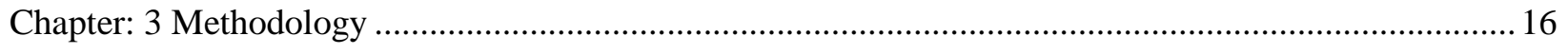

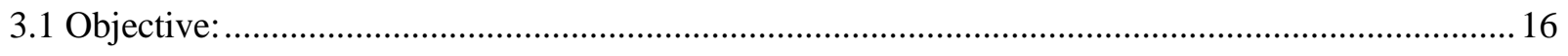




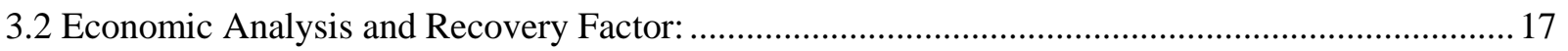

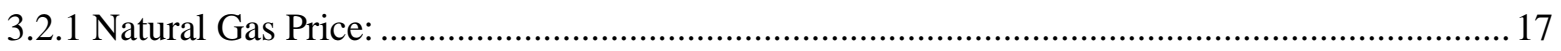

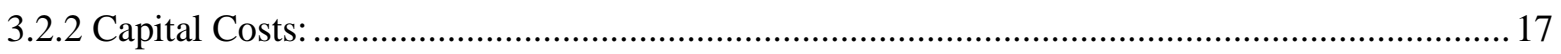

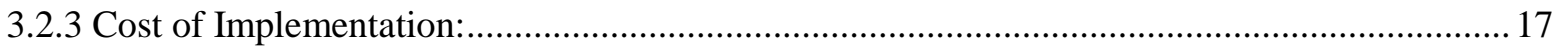

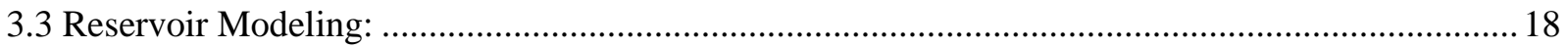

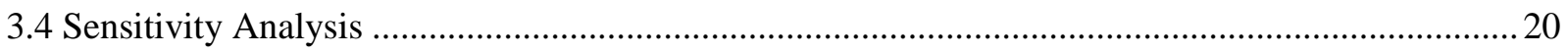

3.4.1Effect of Reservoir Parameters on Coalbed Methane Production: ........................................ 20

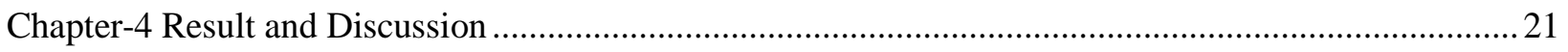

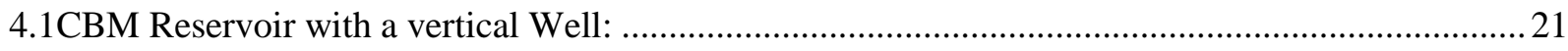

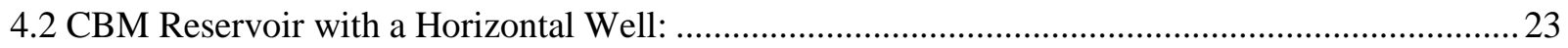

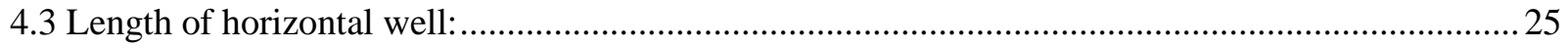

4.4 Comparison of Vertical and Horizontal Well Performance: ....................................................26

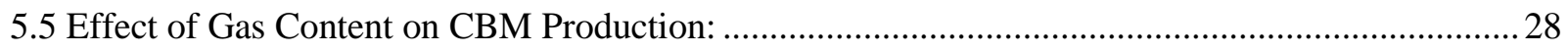

4.6 Effect of Desorption Time on CBM Production: .................................................................. 31

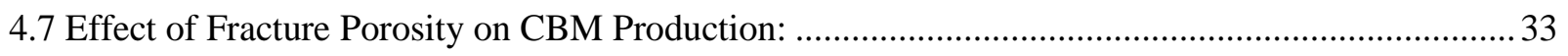

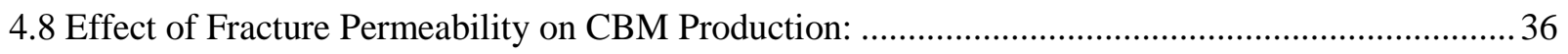

4.9 Effect of Permeability Anisotropy on CBM Production:............................................................. 39

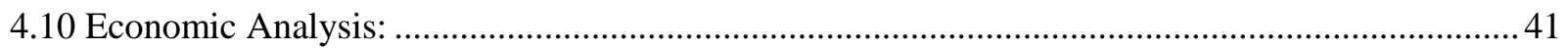

4.10.1Economic Analysis of the Desorption time: ..................................................................... 46

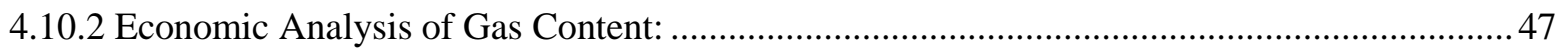

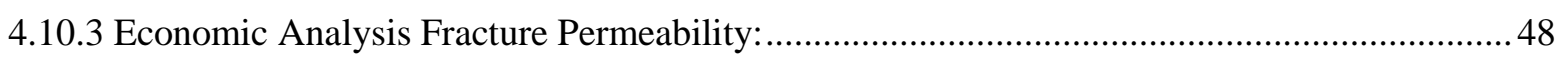

4.10.4 Economic Analysis of Fracture Porosity: ....................................................................... 49

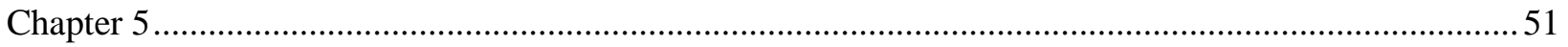

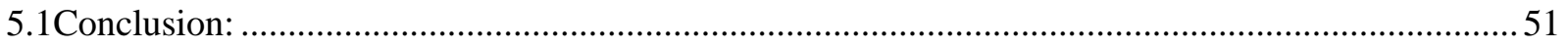

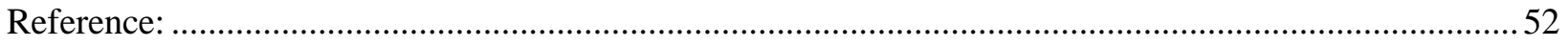




\section{List of Figures}

Figure 1 The annual production of the coalbed methane reservoirs ............................................. 1

Figure 2 Illustrates the steps of the coal deposition and coal rank ............................................. 4

Figure 3 Major Coal bed methane basins in United State ........................................................... 4

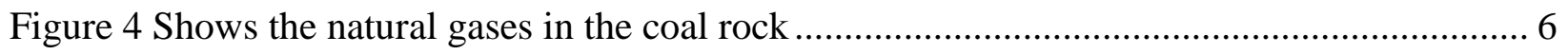

Figure 5 Relationship between rank, depth, and sorptive capacity ............................................... 7

Figure 6 Example of Langmuir Isotherm Relationship ......................................................... 8

Figure 7 The mechanism of gas desorption and flow through coal bed ...................................... 9

Figure 8 CBM reservoir model and CBM reservoir model ...................................................... 10

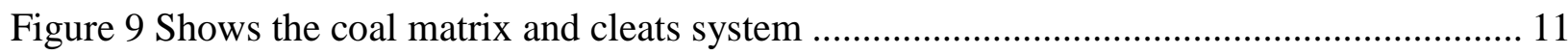

Figure 10 Coalbed methane storage capacities ………….................................................... 12

Figure 11 Production profiles for conventional and unconventional reservoir ........................... 13

Figure 12 Desorption behavior of under-saturated and saturated coalbed methane reservoir ..... 14

Figure 13 Shows horizontal well and vertical well configuration .............................................. 15

Figure 14 Reservoir simulation model of thick and deep coal bed methane reservoir .................. 19

Figure $15 \mathrm{Gas}$ and water production profile from the vertical well............................................... 22

Figure 16 Pressure distribution from vertical well in 2D and 3D view ..................................... 22

Figure 17 Cumulative gas production of perforating different layers of the vertical well ........... 23

Figure $18 \mathrm{Gas}$ and water production from the horizontal well ................................................... 24

Figure 19 Pressure distribution from horizontal well in 2D and 3D view................................ 24

Figure 20 Gas cumulative production of perforating first, second and third layer of the horizontal

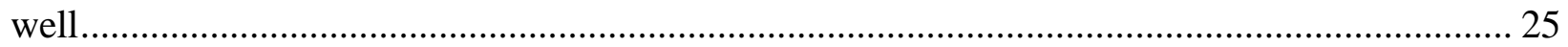

Figure 21 Gas cumulative production from horizontal well with different lateral length ............. 26

Figure 22 Cumulative gas production from vertical and horizontal well .................................... 27

Figure 23 Gas Recovery factor result of one vertical well and one horizontal well.................... 27

Figure 24 Effect of gas content on cumulative gas and on gas rate for varying gas content of the

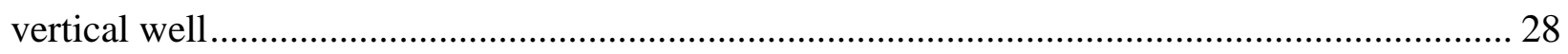

Figure 25 Effect of gas content on gas recovery factor of the vertical well ................................. 29 Figure 26 Effect of gas content on cumulative gas and on gas rate for varying gas content of the

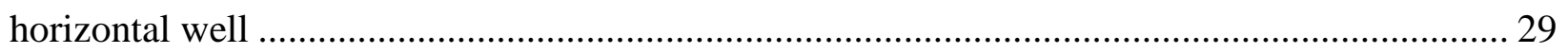

Figure 27 Effect of gas content on gas recovery factor of the horizontal well .............................. 30 
Figure 28 Effect of desorption time on cumulative gas and on gas rate for varying desorption

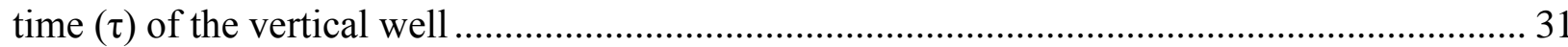

Figure 29 Effect of desorption time on gas recovery factor of the vertical well ...................... 32

Figure 30 Effect of desorption time on cumulative gas and on gas rate for varying desorption

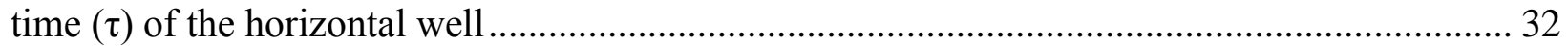

Figure 31 Effect of desorption time on gas recovery factor of the vertical well ....................... 33

Figure 32: Effect of fracture porosity on cumulative gas and on gas rate for varying cleats

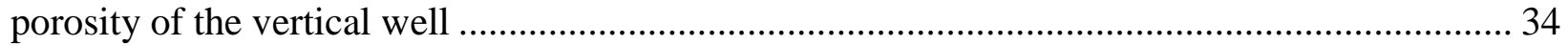

Figure 33: Effect of fracture porosity on gas recovery factor of the vertical well..................... 35

Figure 34: Effect of fracture porosity on cumulative gas and on gas rate for varying cleats

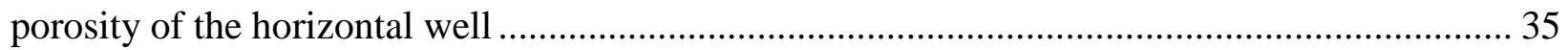

Figure 35: Effect of fracture porosity on gas recovery factor of the horizontal well ................. 36

Figure 36 Effect of fracture permeability on cumulative gas and on gas rate for varying cleats

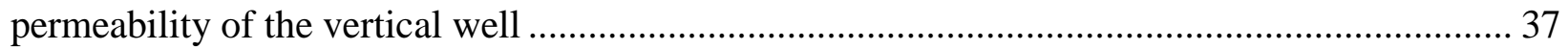

Figure 37 Effect of fracture permeability on gas recovery factor of the vertical well................ 37

Figure 38 Effect of fracture permeability on cumulative gas and on gas rate for varying cleats

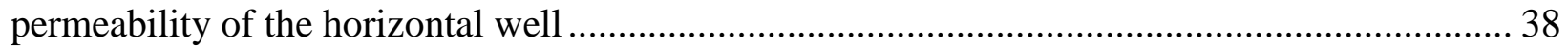

Figure 39 Effect of fracture permeability on gas recovery factor of the horizontal well ........... 38 Figure 40 Effect of the permeability anisotropy on the cumulative production from the vertical

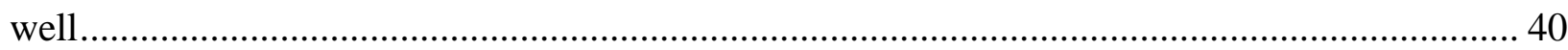
Figure 41 Effect of the permeability anisotropy on the cumulative production from the horizontal well 40

Figure 42 Net Present Value (NPV) result of one vertical well and one horizontal well 43 Figure 43 Net Present Value (NPV) result of one Horizontal well and different number of vertical well 44

Figure 44 Net Present Value (NPV) of gas price 3\$..........................................................45

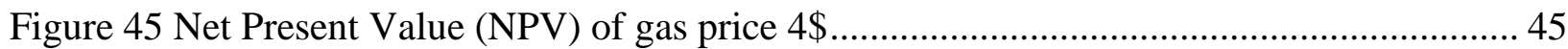

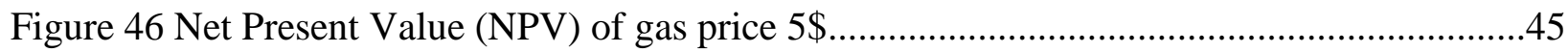

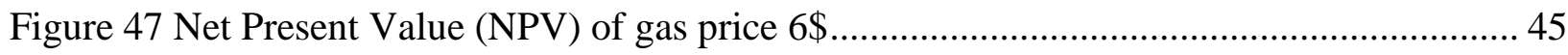

Figure 48 Effect of gas content on NPV of the Horizontal well............................................ 46

Figure 49 Effect of gas content on NPV of the vertical well .............................................. 46 


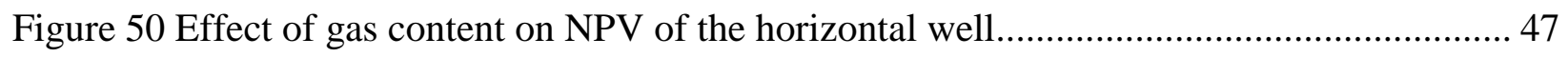

Figure 51 Effect of gas content on NPV of the vertical well ................................................ 47

Figure 52 Effect of fracture permeability on NPV of the horizontal ................................... 48

Figure 53 Effect of fracture permeability on NPV of the vertical well ................................... 48

Figure 54 Effect of fracture porosity on NPV of the horizontal well ..................................... 49

Figure 55 Effect of fracture porosity on NPV of the vertical well ........................................ 49 


\section{List of Tables}

Table 1 Depth and thickness of coal bed methane basins in United State................................ 5

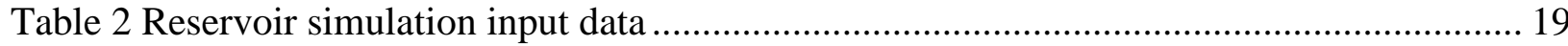

Table 3 The change in the reservoir parameters for sensitivity analysis .................................. 20

Table 4 Shows different in gas content with change in the Langmuir pressure and volume. ...... 28

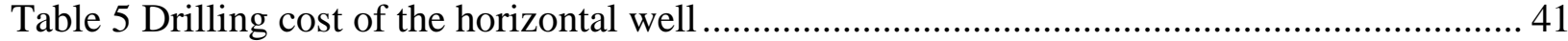

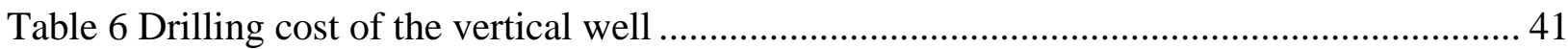

Table 7 Sample of the calculation and the result of the horizontal well and the vertical Well .... 42 


\section{Nomenclature}

\begin{tabular}{|c|c|}
\hline$C B M$ & Coal Bed Methane \\
\hline$C M G$ & Computer Group Modeling \\
\hline $\mathrm{CH}_{4}$ & Methane \\
\hline $\mathrm{CO} 2$ & Carbon Dioxide \\
\hline$F t$ & Feet \\
\hline$S c f$ & Standard Cubic Feet \\
\hline$T c f$ & Trillion Cubic Feet \\
\hline$G_{s}$ & Gas Storage Capacity, scf/ton \\
\hline$G_{S L}$ & Dry, Ash Langmuir Storage Capacity scf/ton \\
\hline$W_{a}$ & Ash Content, Weight Fraction \\
\hline$W_{e}$ & Equilibrium Moisture Content, Weight Fraction \\
\hline$P_{L}$ & Langmuir Pressure, Psia \\
\hline$P$ & Pressure, Psia \\
\hline$V_{L}$ & Langmuir Volume \\
\hline$S_{f}$ & Cleat Spacing \\
\hline$D_{m i}$ & Micropore Diffusion Coefficient \\
\hline$G$ & Gas-In-Place Volume, scf \\
\hline$A$ & Reservoir Area, acres \\
\hline$h$ & Reservoir Thickness, feet \\
\hline $\bar{\rho}$ & Average in-Situ Rock Density at the Average In-Situ Rock Composition, $\mathrm{g} / \mathrm{cm}^{3}$ \\
\hline $\bar{G}_{c}$ & Average Gas Content at the Average In-Situ Rock Composition, scf/ton \\
\hline$K_{\mathrm{f}}$ & Fracture Permeability \\
\hline$\varphi_{\mathrm{f}}$ & Fracture Porosity \\
\hline$\tau$ & Desorption Time \\
\hline
\end{tabular}




\section{Chapter 1: Introduction}

In recent years, the demand for energy from unconventional reservoirs has increased all over the world. The increased dependence is because of the depletion of conventional reservoirs. As a result, the industry has moved toward the exploration and exploitation of unconventional reservoirs to support the ever-increasing demand for energy. Unconventional reservoirs differ from conventional reservoirs in their methods of production. In unconventional reservoirs, we cannot produce at economic flow rates or at economic volumes of oil and gas without having assistance from massive stimulation treatments or special recovery processes and technologies ${ }^{1}$. Typical unconventional reservoirs include tight gas sands, Coal bed methane, Gas hydrate deposition, Heavy oil, Tar Sands, Gas Shales, and Reservoirs with high pressure and high temperature ${ }^{1}$. These reservoirs exist in different places around the world such as United States, Canada, China and Australia.

The coalbed methane (CBM) reservoirs are an important source of natural gas in the United States. In the late 90's the production from coalbed methane reservoirs was around 6 Bcf coming from 165 coal bed methane wells ${ }^{2}$. The number of drilled wells and the production rate has increased over many years as shown in Figure 1. In 2007, Energy Information Administration (EIA) shows that the reserve and production from the coalbed methane in U.S is $21,875 \mathrm{Bcf}$ and 1,754 Bcf respectively.

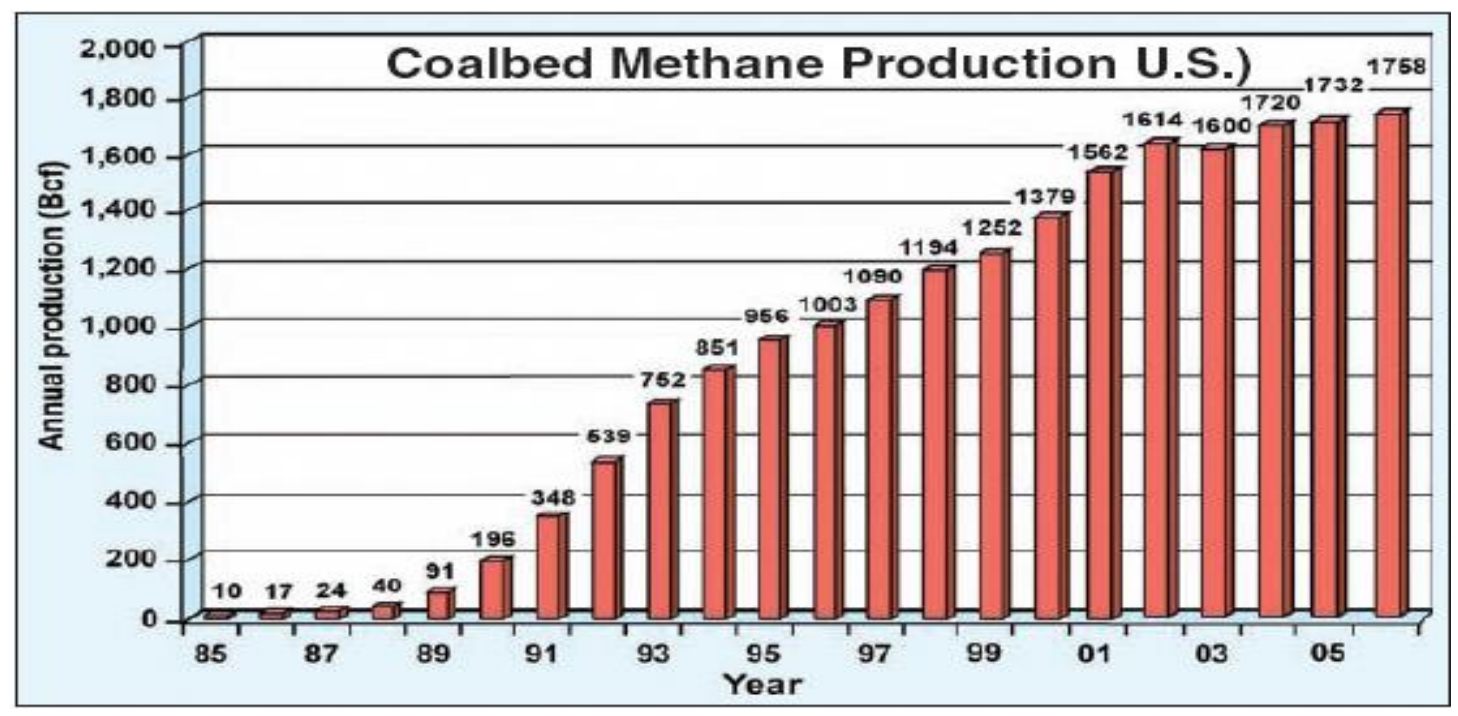

Figure 1 The annual production of the coalbed methane reservoirs ${ }^{1}$ 
The production from coalbed methane $(\mathrm{CBM})$ reservoirs is not the same as that from conventional reservoirs. The difficulty of production from coal bed methane reservoirs arises from the complexity in the reservoir characteristics. The coal rock, which is a sedimentary rock, is different from any other source rocks in their way of holding gases and releasing them. In conventional reservoirs, one rock plays the role of the source rock and another rock represents the reservoir rock, while the coal rock represents both the source and the reservoir rock ${ }^{4}$. Another difference is that, in the conventional sandstone reservoirs the gas is found in free state within the pore structure of the rock. However, in coalbed methane reservoir gas is adsorbed onto the internal structure of the coal, which allows a significant amount of gas to be stored in the coal rock.

The production from coalbed methane reservoirs is dependent on the fracture system, since the fracture system plays a significant role to convey the desorpted gas from the matrix system. The parameters that govern the fracture system are fracture spacing and porosity. Most coal bed methane reservoirs undergo the process of dewatering, which leads to a reduction in the reservoir pressure and the production of gas. The dewatering process can take anywhere from a few days to several months which are different from one reservoir to another. For example, in saturated coalbed methane reservoirs, gas production starts from the first day of the production with small amount of water.

Getting help from reservoir simulators is one of the most important tools in dealing with coal bed methane reservoirs. It will aid the reservoir engineer to forecast the production and have a better understanding of the reservoir behavior under different circumstances. In this study a commercial reservoir simulator was used in order to create a replica of the reservoir and study different scenarios for producing gas from deep and thick coal bed methane reservoirs. This study has been performed in order to compare drilling vertical and horizontal wells in deep and thick CBM reservoirs. Many researchers have shown the success of drilling horizontal wells in CBMs while some others have claimed the opposite. 


\section{Chapter 2: Literature Review}

\subsection{Coal seams:}

Coal by definition, is a sedimentary rock that contains more than 50 percent of weight and 70 percent of the organic material, predominantly carbon hydrogen and oxygen ${ }^{5}$. The coal is formed from organic materials after they have been buried and compressed over time and under suitable condition. The coal is also a carbonaceous rock which is formed from buried plants in ancient forests or swamps and also from ancient sea deposits. The coal begins as layers of plant matter accumulate over long periods of time. These plant materials convert to coal in two steps. First, is peat which is a brown organically rich soil and the second is lignite which is a soft brown fuel.

As the number of the deposition layers increase, it leads to an increase in the temperature under the ground. This increase in temperature will decrease the amount of oxygen and hydrogen but will increase the carbon content ${ }^{5}$. At the same time, the buried peat is affected by pressure and temperature which will convert peat into lignite or sub-bituminous coal or anthracite and form the coal rock. Lignite, sub-bituminous coal, and anthracite are used to rank coal which is classified based on the degree of conversion of the original plant material into carbon as shown in Figure 2. Moreover, the coal rank is an important factor used to classify the amount of the carbon content in the coal rock. The ranks of the coal from most to least carbon content can be classified as: anthracite, bituminous coal, sub bituminous coal, and lignite ${ }^{6}$.

- Lignite is the brown coal, which is the first type to form when plant matter is compacted, has an energy value of 9 to 17 million Btu/ton.

- Sub-bituminous is dark black and soft coal, with an energy value of 16 to 24 million Btu/ton.

- Bituminous coal (19 to 30 million Btu/ton) is also dark black and represents the most important coal grade for energy.

- Anthracite coal is black and hard, is metallic gray and has very high energy content, typically 22 to 28 million Btu per ton. 


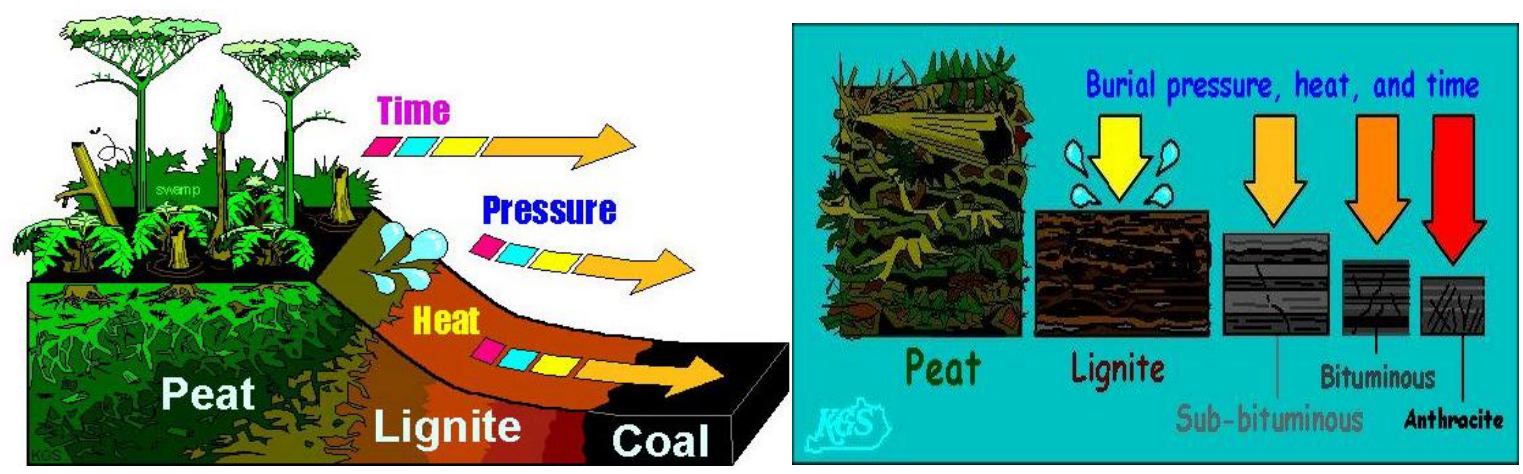

Figure 2 Illustrates the steps of the coal deposition and coal rank ${ }^{6}$

\subsection{Coal bed methane basins:}

Coal bed methane basins form after the plant matter is buried and forms coal seams. The coal basins are depression in the earth's crust formed when the crust buckles as a result of movements of the tectonic plates ${ }^{7}$. This happened in the end of the Silurian Period, about 400 million years ago. Therefore, coal is only found in rocks deposited about 400 million years ago 5 . The greatest deposits of coal occur in basins containing rocks of the Carboniferous and Permian.

Since the period between 250 and 350 million years ago, coal has continued to form in basins all around the world since the Silurian Period ${ }^{7}$. The major coalbed methane resources in the United States are located in twelve basins: San Juan, Warrior, Wind River, Greater Green River, Illinois, Piceance, Arkoma, Central and Northern Appalachian, Uinta, Power River and Raton. Figure 3 shows all the coalbed methane basins in U.S.

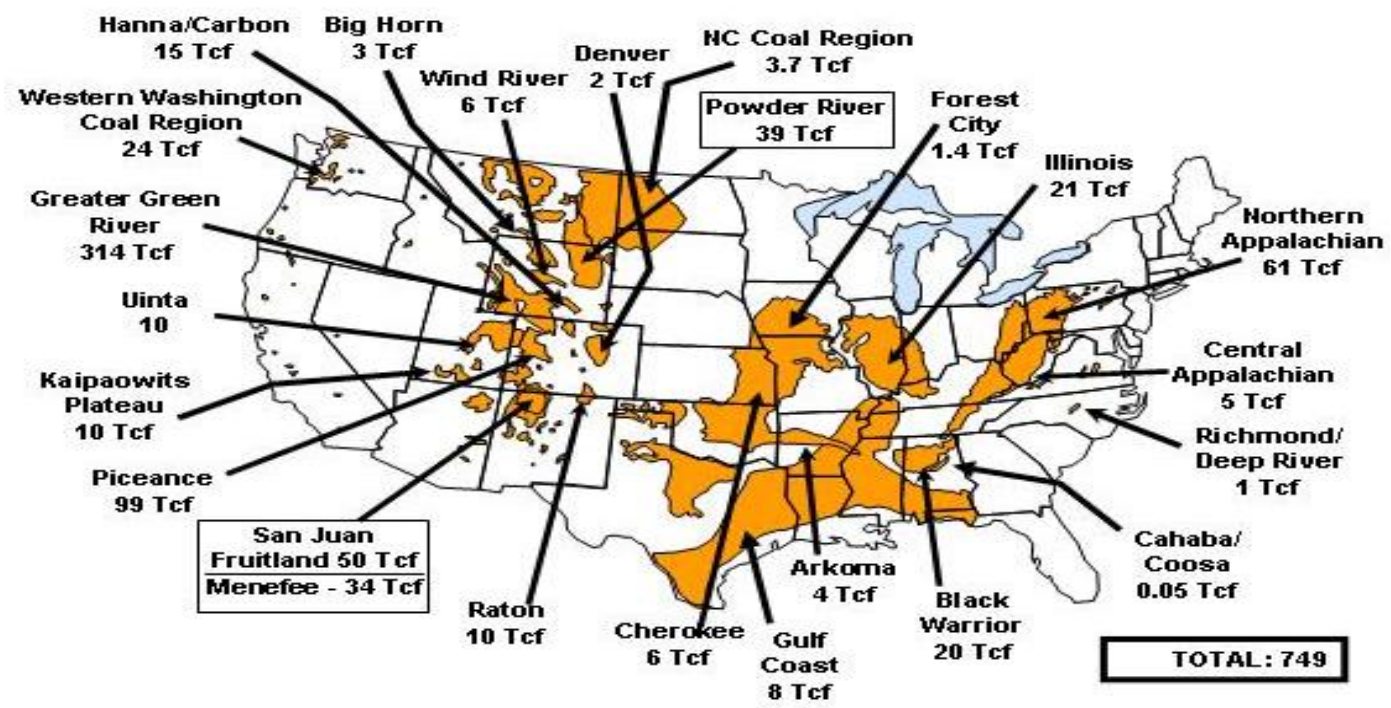

Figure 3 Major Coal bed methane basins in United State ${ }^{7}$ 
The depth and the thickness of coal bed methane seams are different from one basin to another. The deepest coal bed methane basins in the U.S are located in the western part of the United States. Table1 shows the distribution of coal bed methane basins with their depth and thickness in the United States.

Table 1 Depth and thickness of coal bed methane basins in United State ${ }^{8}$

\begin{tabular}{|l|c|c|c|c|}
\hline Basin & $\begin{array}{c}\text { Black Warrior } \\
\text { Basin }\end{array}$ & $\begin{array}{c}\text { Central Appalachian } \\
\text { Basin }\end{array}$ & $\begin{array}{c}\text { North Appalachian } \\
\text { Basin }\end{array}$ & $\begin{array}{c}\text { Cahaba } \\
\text { Basin }\end{array}$ \\
\hline Minimum depth (ft) & 800 & 100 & 1030 & 2500 \\
\hline Maximum depth (ft) & 3500 & 3500 & 6570 & 9000 \\
\hline Minimum thickness of coal formation (ft) & 10 & 1 & 2 & 2 \\
\hline Maximum thickness of coal formation (ft) & 66 & 10 & 12 & 20 \\
\hline
\end{tabular}

\begin{tabular}{|l|c|c|c|c|}
\hline Basin & $\begin{array}{c}\text { Arkoma } \\
\text { Basin }\end{array}$ & $\begin{array}{c}\text { Cherokee } \\
\text { Basin }\end{array}$ & $\begin{array}{c}\text { Forest City } \\
\text { Basin }\end{array}$ & $\begin{array}{c}\text { Powder River } \\
\text { Basin }\end{array}$ \\
\hline Minimum depth (ft) & 2500 & 611 & 400 & 720 \\
\hline Maximum depth (ft) & 9000 & 2300 & 1350 & 2096 \\
\hline Minimum thickness of coal formation (ft) & 7 & 3 & 2 & 2.1 \\
\hline Maximum thickness of coal formation (ft) & 45 & 7 & 25 & 22 \\
\hline
\end{tabular}

\begin{tabular}{|l|c|c|c|c|}
\hline Basin & $\begin{array}{l}\text { San Juan } \\
\text { Basin }\end{array}$ & $\begin{array}{l}\text { Uinta } \\
\text { Basin }\end{array}$ & $\begin{array}{c}\text { Piceance } \\
\text { Basin }\end{array}$ & $\begin{array}{c}\text { Raton } \\
\text { Basin }\end{array}$ \\
\hline Minimum depth (ft) & 500 & 1200 & 2300 & 1500 \\
\hline Maximum depth (ft) & 5000 & 4400 & 6500 & 2500 \\
\hline Minimum thickness of coal formation (ft) & & 4 & 80 & 2 \\
\hline Maximum thickness of coal formation (ft) & & 48 & 150 & 35 \\
\hline
\end{tabular}

The depth of the coal seams has an influence on drilling methods. In most CBM reservoirs, the horizontal wells that have been drilled were in coal seams between 500 and 4000 $\mathrm{ft}$ deep ${ }^{8}$. CBM horizontal wells have not been demonstrated successfully produced from seams deeper than $6000 \mathrm{ft}$, because of very low coalbed permeability. CBM horizontal wells can be economically produced from depths greater than $6000 \mathrm{ft}$ only if sweet spots can be identified ${ }^{8}$. 


\subsection{Gas Storage in coal beds:}

The coal bed has an extensive storage capacity for natural gases (methane). Coal is known to have small pores, however these small structures have very high capacity for the storage of methane. Furthermore, the methane in the coal is present in two states. The first state is the "free gas" and the second state is "adsorbed gas" as illustrated in Figure 4. The first state "free gas" is found in the coal in two states. The free gas is in fractures and dissolved gas is in water. The second state "adsorbed gas" is found on the coal surface. The adsorption of methane molecules means "that one substance becomes attached to the surface of another substance, which is different from the absorption". In absorption, one substance becomes trapped inside another substance, such as a sponge soaking up water ${ }^{9}$. The coal matrix has larger internal surface area for methane to the adsorbed. Most of the gas is stored on the surface of coal within the micropores of the coal matrix. In other words, the gas is found on the surface of the coal as a single layer of molecules in a condensed, near liquid state.

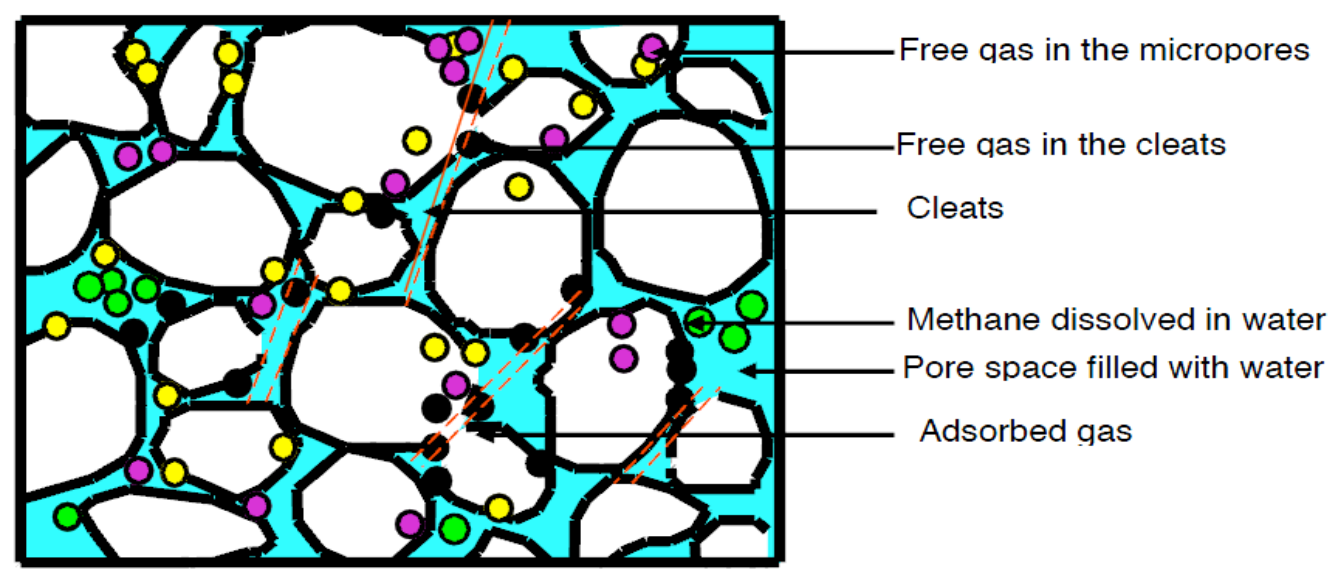

Figure 4 Shows the natural gases in the coal rock ${ }^{9}$

The difference between the free gas and the adsorbed gas in coal is that, free gas is compressed in the fractures (cleats) and Macropores (matrix) of the coal, but the adsorbed gas adheres to the large internal surface of the coal ${ }^{7}$. Most gases in the coal bed methane are found in adsorbed state. Daines found that the amount of gas in the adsorbed state at pressures of 300 psi is ten times as great as the amount of free gas ${ }^{9}$. Since the coal seams have the capacity to adsorb large amounts of gases on their internal surface area, some gases have higher ability to desorb on the coal surface than others. The gases that industry is most interested in are $\mathrm{CH} 4 \&$ 
$\mathrm{CO} 2$, because of methane's inherent value as a fuel, and carbon dioxide's purported effect on global warming ${ }^{9}$.

The coal storage capacity of methane depends on some factors like coal rank and coal depth. It is has been observed that coal capacity is increased with increase in the coal rank and coal depth. Figure 5 shows the increase in the capacity of coal with ranks and depth.

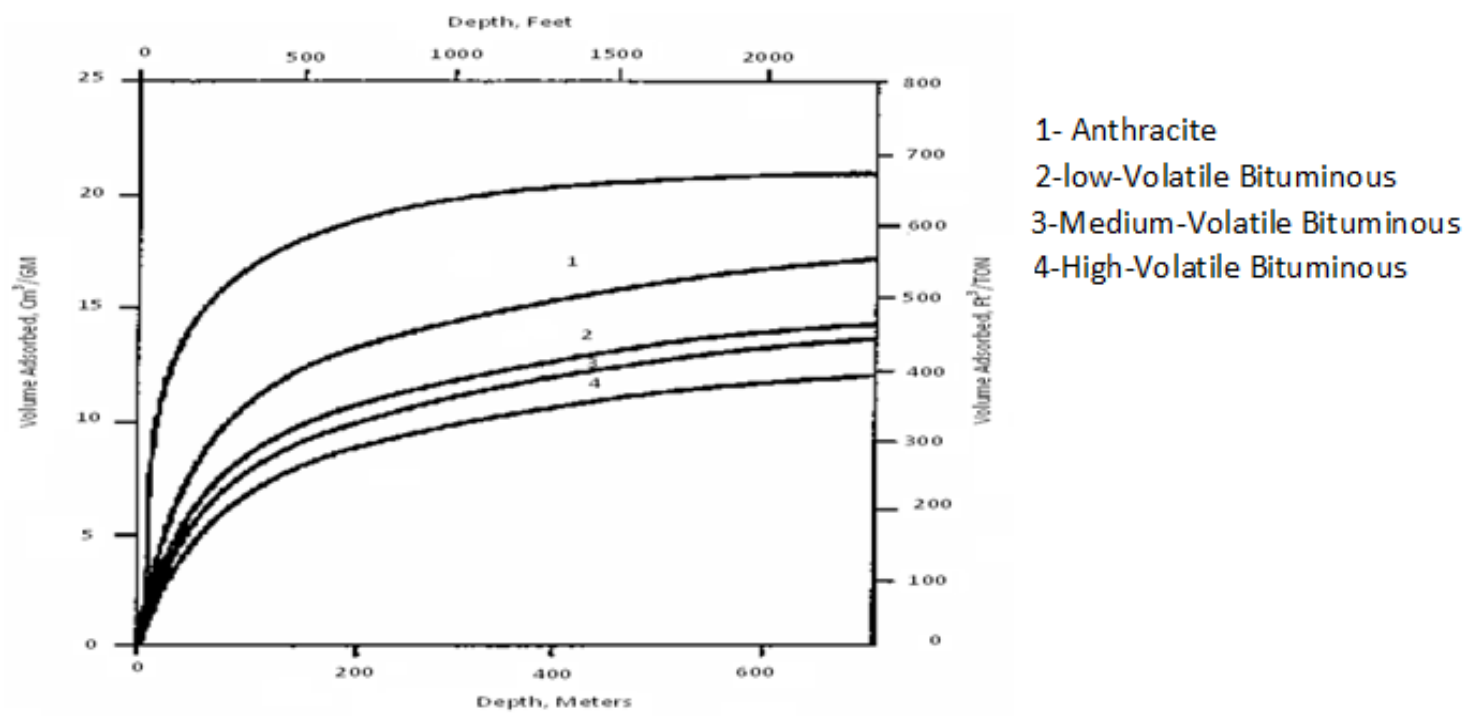

Figure 5 Relationship between rank, depth, and sorptive capacity ${ }^{11}$

The most production from coal is generally methane which is adsorbed at the coal matrix; however, there are some ethane and traces of propane, butane and heavier hydrocarbons along with nitrogen and carbon dioxide. The adsorbed gas is recovered by desorption from the matrix as the pressure is reduced during production. Finally, the desorption of gas from the matrix is typically described by the Langmuir isotherm.

\subsection{The Langmuir Adsorption Isotherm:}

The adsorbed gas on the coal surface is recovered by reducing the pressure during the production time. The Langmuir Adsorption Isotherm is the most common model that is used to relate the storage capacity to organic content, moisture content and pressure ${ }^{10}$. Furthermore, the Langmuir adsorption isotherm assumes that the gas attaches to the surface of the coal and covers the surface as a single layer of gas (a monolayer). The equation that is used to describe the relationship between storage capacity to organic content, moisture content and pressure is: 
$G_{s}=G_{S L}=\left[1-W_{a}+W_{e}\right] \frac{P}{P+P_{L}}$

Where:

$G_{s} \quad$ Gas storage capacity, scf/ton.

$G_{S L} \quad$ Dry, ash Langmuir storage capacity scf/ton.

$W_{a} \quad$ Ash content, weight fraction.

$W_{e} \quad$ Equilibrium moisture content, weight fraction.

$P_{L} \quad$ Langmuir pressure, psia.

$P \quad$ Pressure, psia.

Isotherm relationship is very important for the reservoir engineers; it can be used to estimate three factors which essential illustrated in Figure 6:

- The pressure at which gas released (desorption) begins.

- The amount of the gas released as the pressure is reduced.

- The gas remaining in the reservoir at the abandonment.

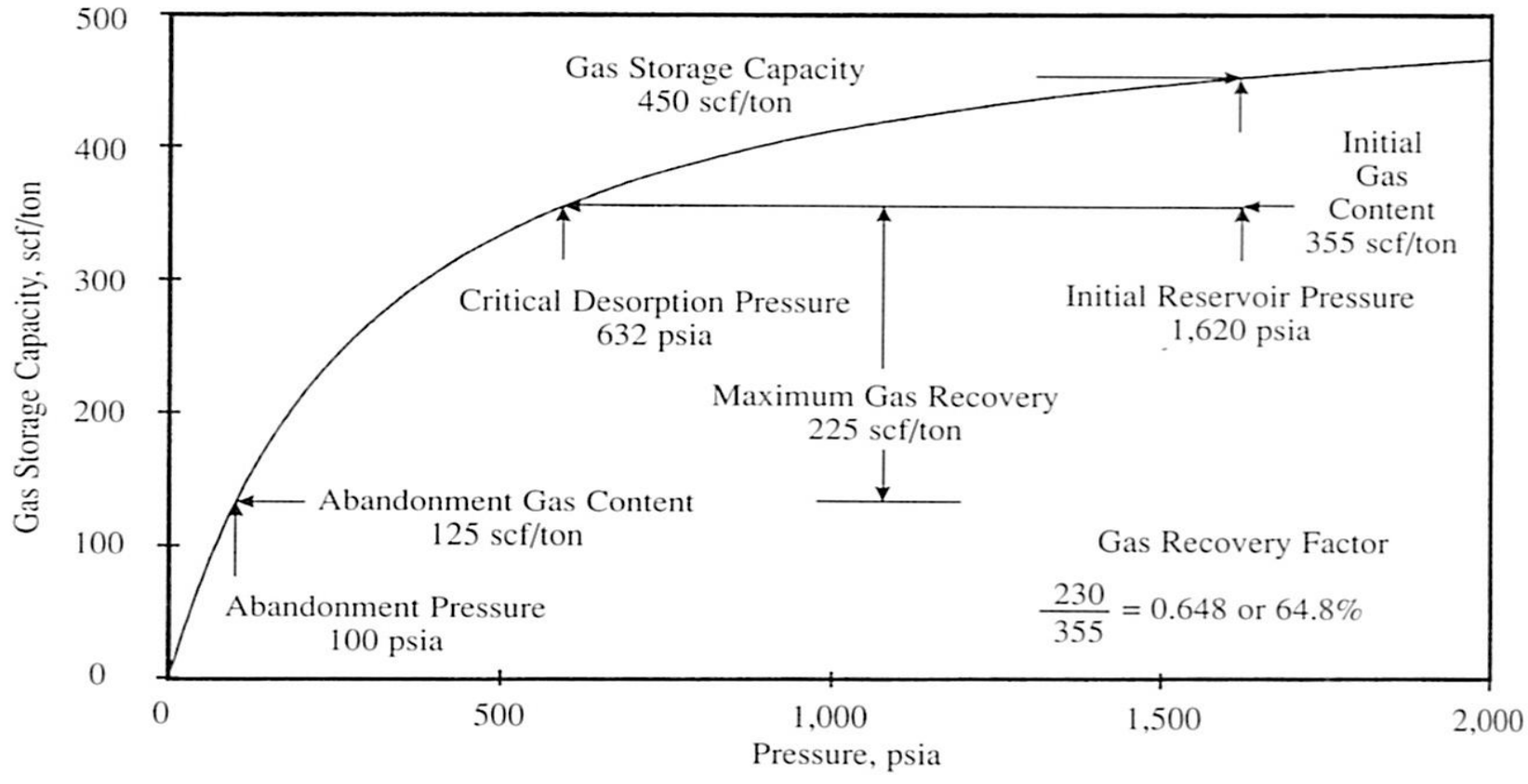

Figure 6 Example of Langmuir Isotherm Relationship ${ }^{10}$ 


\subsection{Gas Transport in Coal bed methane reservoirs:}

The mechanism of flow of natural gas through coal is usually described by Darcy's Law in the cleats and diffusion in the matrix ${ }^{11}$. The flow of natural gas which occurs in the cleats after desorption starts is a complex process. The coal matrix, where most of the gas is stored, is characterized by diffusion of gas through the matrix, which is controlled by a concentration gradient, and modeled by Fick's Law ${ }^{11}$. In initial production of a CBM well, the rates of fluid and free gas are mainly a function of the permeability of the cleat system. As dewatering continues and a drop in reservoir pressures occurs, gas desorption begins, the rate of gas production becomes more of a function of the rate of diffusion of the coal matrix rather than the permeability of the cleat system ${ }^{11}$.

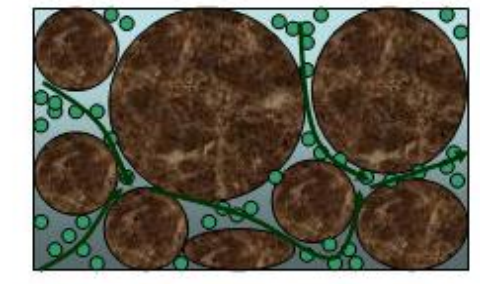

Free gas flow in matrix pore system

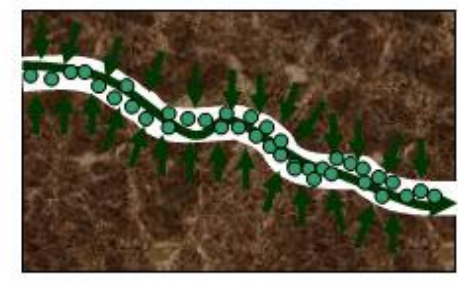

Free gas flow in fracture system

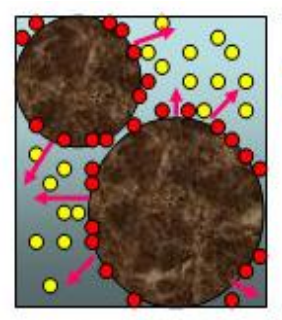

Gas desorption in matrix pores and fractures

- Adsorbed gas

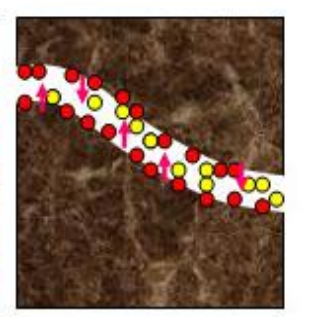

- Free gas

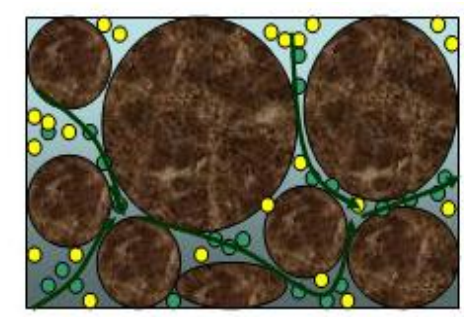

Adsorbed gas \& free gas flow in matrix pores

- Desorbed gas

Desorption

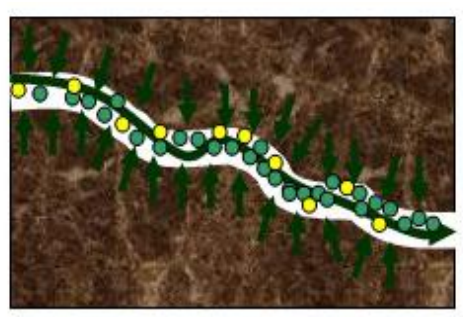

Adsorbed gas \& free gas flow in fractures $\longrightarrow$ Flow in porous media

Figure 7 The mechanism of gas desorption and flow through coal bed

\subsection{Coalbed methane Reservoir Characteristics:}

\subsubsection{Coal Permeability:}

The permeability is the most critical reservoir parameter that has an obvious effect on the gas production from coal. The coal bed methane formations are considered to be dualporosity and dual-permeability systems. The term "dual" in the previous context refers to the fact that the Coal Bed Seam has two different permeability and porosity values, one for the matrix and the other for the cleat. These two systems are presented by the matrix and the cleats 
of the coal which illustrate in Figure 8. The matrix stores the gas by adsorption and flow of gas in the matrix is by diffusion. In CBM production, permeability refers to the permeability of the cleats and not the matrix. The permeability of the cleats is always higher than the permeability in the matrix and is around eight times of the matrix permeability ${ }^{12}$.
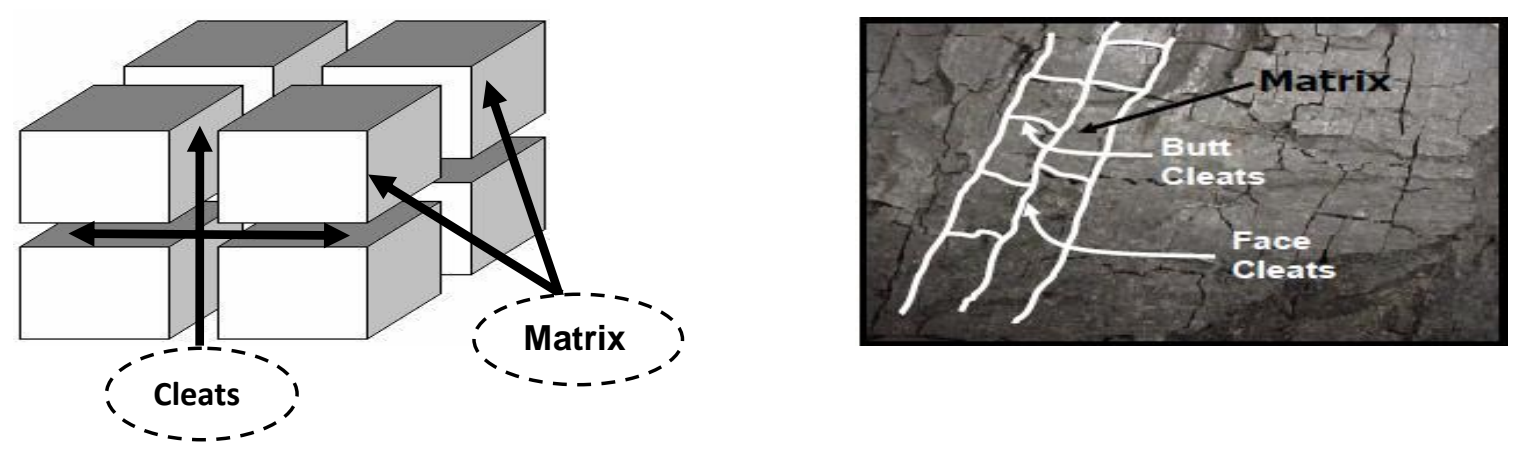

Figure 8 CBM reservoir model and CBM reservoir model

\subsubsection{Coal Porosity:}

Essentially, the coal is a dual porosity system. A coalbed has two different types of porosities which are called the primary porosity and the secondary porosity. The primary porosity is the porosity of the matrix which is composed of fine pores, which are called Micropores, with extremely low permeability ${ }^{13}$. These Micropores contain a large internal surface area where the gas is adsorbed. This adsorbed gas transports through the primary porosity by diffusion process. The second type of the coal porosity is called the secondary porosity which refers to the cleats porosity. This type of porosity is also called the Macropores, which consists of the natural fracture of the cracks and fissures inherent in all coal ${ }^{13}$. These Macropores which are bigger than Micropores, provides a place for the fluid to flow from the matrix. The coal cleats are composed of two types of the components which are face cleats and butt cleats as they are shown in Figure 8.

\subsubsection{Coal Matrix:}

The coal matrix is composed of a network of pores varying in sizes. The smallest pores are located within the matrix and the pores become larger towards the surface of the coal. The smallest pores are (Micropores) and the largest are (Macropores). The Micropores are the primary sites for gas adsorption. The larger pores are considered to be important for the 
transmission (diffusion) of desorbed gas to the cleat system. The gas is stored on the surface of the coal within the Micropores of the matrix. The gas is found on the surface of the coal as a single layer of molecules in a condensed, near liquid state. The adsorbed gas is recovered by desorption from the matrix as the pressure is reduced during production.

\subsubsection{Coal Cleats:}

The Cleats are natural fractures that occurs nearly perpendicular to bedding. The cleat system consists of two fractures as they are shown in Figure 9. These two fractures are face cleats and butt cleats. The face cleats are the dominant through-going fracture set, and butt cleats are terminate upon their intersection with the face cleats. Both cleats are mainly a function of rank, ash content, and geological structural of the coal.
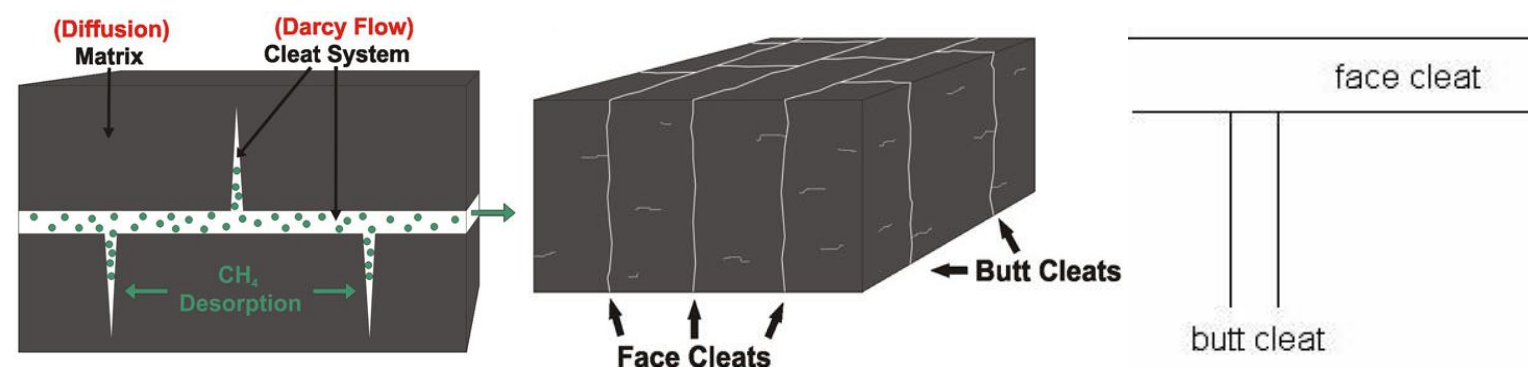

Figure 9 Shows the coal matrix and cleats system

\subsubsection{Gas Content:}

The gas content in the coal refers to the amount of gas that exists as adsorbed gas. The gas content has a great influence on gas production of CBM reservoirs. Moreover, Gas content of coal seam is dependent on the depth and rank of the coal. Usually the Gas content increases with the depth of the coal and the rank of the deposition. Please refer to Figures 4 and 10 for illustration. The higher ranks of coals (like antiheroic) are associated with increased gas generation, and deeper coal beds are associated with increased methane adsorption due to higher pressures and also it has a higher probability of gas containment. Therefore, the effect of depth on the gas content in coal seams is also associated with the variations in the pressure and temperature with depth. 


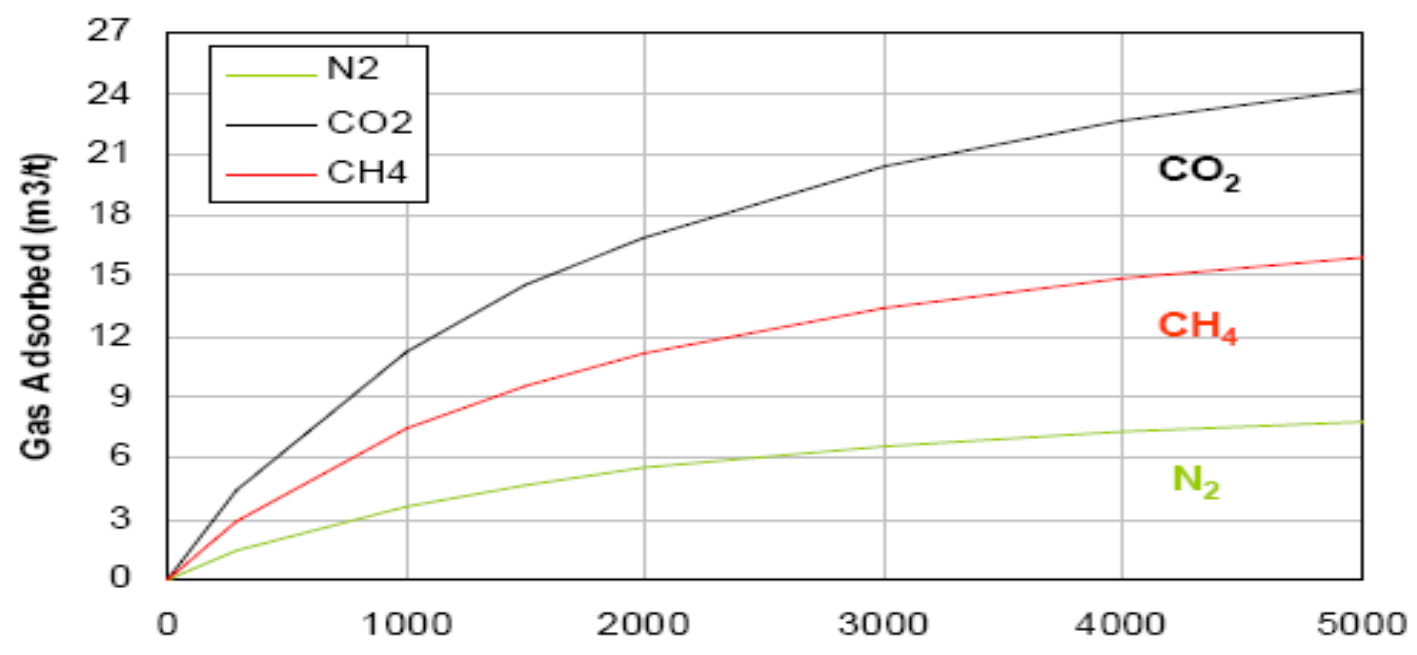

Figure 10 Coalbed methane storage capacities

\subsubsection{Desorption time:}

The desorption time, by definition, is the time which is required to release 63 present of the total amount of the gas which desorbed in the coal matrix ${ }^{9}$. The desorbed gas is the gas which exists in a desorption state within the coal matrix, and most of the gases which produce from the coal is desorbed gases. It is found that between 90-98 percent of the gas which is produced from CBM reservoirs is desorbed gas ${ }^{9}$. Moreover, the desorption time indicates how rapidly initial desorption from coal takes place, but does not describe the diffusion through the coal matrix. Thus, desorption time alone cannot be used as an indicator of coal bed gas production ${ }^{9}$.

Adsorption of gases by the internal surfaces of coal causes the coal matrix to swell and desorption of gases causes the coal matrix to shrink. The swelling or shrinkage of coal, as gas is adsorbed or desorbed is referred to as sorption-induced strain ${ }^{11}$. The desorption time is a function cleat space of cleat spacing and Micropore diffusion coefficient according to equation 2.2.

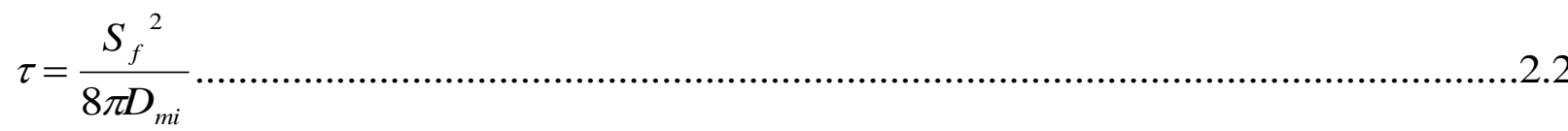

Where

$\mathrm{S}_{\mathrm{f}} \quad$ Cleat spacing

$\mathrm{D}_{\mathrm{mi}} \quad$ Micropore diffusion coefficient 


\subsection{Gas Production from the Coal beds:}

About $8 \%$ of total natural gas production in the United States is produced from coal beds ${ }^{14}$. The productions from coal bed methane reservoirs are different from conventional reservoir. In a conventional reservoir, the relationship between the pressure decline and gas production rate is a straight line as shown in Figure 11. However, in CBM reservoirs the decline curve is not a straight line. Please refer to Figure 11 for an illustration. In CBM reservoirs, the gas will start to desorb when the reservoir pressure starts decreasing. The first stage of producing in CBM reservoir requires removing water in order to decrease pressure on the coal matrix. So the first product from CBM reservoirs is mostly water and some free gas. The water production of the coal bed methane reservoirs might take a few days to three years depending on the geological condition (for example if the coal is under-saturated) ${ }^{14}$.
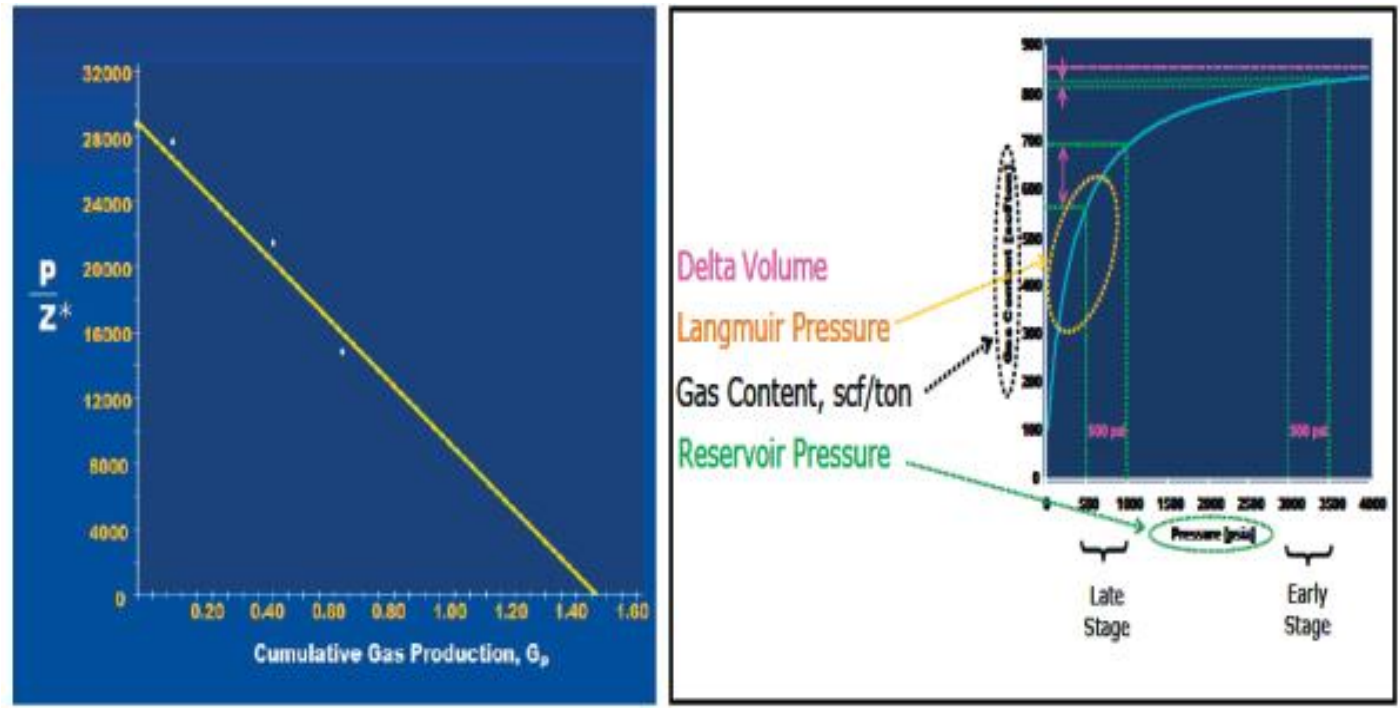

Figure 11 Production profiles for conventional and unconventional reservoir ${ }^{14}$

\subsection{Saturated and Under-Saturated Coalbed Methane Reservoirs:}

The desorption experiment is an important experiment for determining whether the coal is saturated or under saturated with respect to gas, at reservoir conditions. Understanding gas saturations can help to predict the gas production characteristics during pressure drawdown. The saturated reservoir is different from the under saturated reservoirs. First, if the initial reservoir pressure is significantly greater than the pressure required to initiate desorption that means the 
coal is under-saturated ${ }^{14}$. In the under-saturated coalbed methane reservoirs, the water is initially present in the cleat system, and the initial production is water and sometimes with a small amount of free gas. The period of producing water in this type of reservoirs may take a few months to a couple years without producing gas. This can significantly affect the economics of the project. Second, if initial reservoir pressure is equal to the critical desorption pressure, the coal is saturated ${ }^{14}$. In the saturated coal bed methane reservoirs the gas production will start as soon as reservoir pressure begins to decrease. Please refer to Figure 12 for illustration.

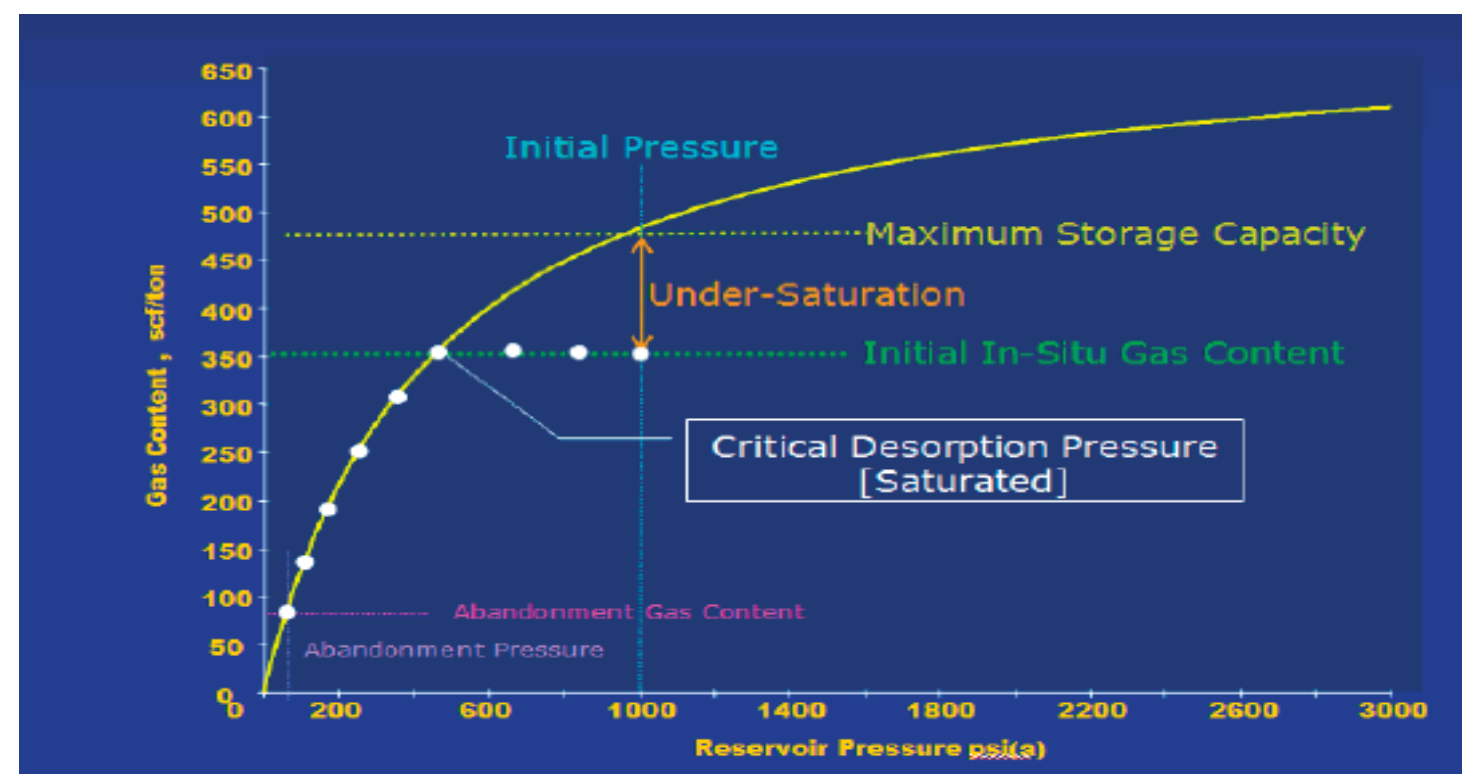

Figure 12 Desorption behavior of under-saturated and saturated coalbed methane reservoir ${ }^{14}$

\subsection{Vertical wells:}

In order to efficiently produce from CBM reservoirs, a well must be drilled. In most of the CBM reservoirs, the wells that have been drilled in the early life of the reservoir are vertical wells. The vertical well drilling technique is used in sandstone reservoirs and can be used in the $\mathrm{CBM}$ reservoir. However, there are some differences in drilling methods due to the complexity of the reservoir properties. In the vertical wells the type of formation will determine the technique of drilling ${ }^{8}$. The method which is used to drill vertical wells is called the rotary drilling technique. This technique works by rotating drill string from surface through formation. Drilling vertical wells in the thick coalbed methane formation has been proven to be more successful than drilling horizontal. The range of thickness in the thick coal bed methane reservoirs where most vertical wells are drilled is between 100 to $200 \mathrm{ft}^{8}$. 


\subsection{Horizontal Wells:}

In recent years, horizontal wells have been very successful in increasing productivity, and improving the overall cost-effectiveness of field operations. The horizontal drilling technique is the process of drilling a well from the surface to a subsurface location just above the target oil or gas reservoir called the "kickoff point as shown in Figure 13. After that, the well will deviate toward well bore from the vertical plane around a curve to intersect the reservoir at the "entry point" with a near-horizontal inclination, and remaining within the reservoir until the desired bottom hole location is reached ${ }^{8}$.
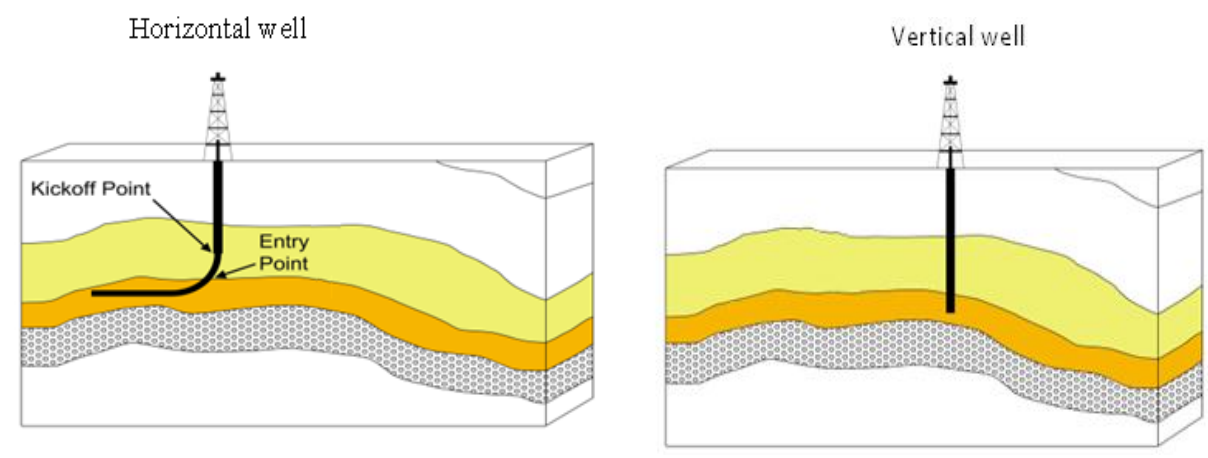

Figure 13 Shows horizontal well and vertical well configuration ${ }^{8}$

In the thick coal seams a horizontal well is not considered to be the best economic choice, as the wellbore may not access all parts of the reservoir. That is why vertical wells are anticipated to be successful ${ }^{8}$. One of the most important factors to be considered in drilling the horizontal well is the horizontal length. The length has the most influence on the production rate and the drilling cost of horizontal wells. Basically, the horizontal length is dependent on the drainage area of the reservoir. In most CBM reservoirs, the length of the horizontal wells usually ranges between $400 \mathrm{ft}$ to $6000 \mathrm{ft}^{8}$.

\subsubsection{The benefits of horizontal drilling:}

The horizontal well has many benefits when compared to the vertical well.

- Horizontal wells will increase production rates.

- Horizontal wells sometimes have lower cost than vertical wells in some area.

- Horizontal drilling considerably reduces the risk of bypassing vertically fractured reservoirs. 


\section{Chapter: 3 Methodology}

\subsection{Objective:}

The objective of this work is to identify the best drilling pattern in deep and thick coal bed methane reservoirs. Seam thickness affects the decision of whether to drill a vertical well or a horizontal well, which is the focus of this study. Moreover, it is known as rule of thumb that drilling a horizontal well is not a recipe for success in the thick coal bed methane from field experience. In order to prove that, economic analysis should be considered. The economic analysis will provide us a clear solution of whether drilling horizontal wells is an appropriate decision or not. As main part of the work using reservoir simulation, sensitivity analysis is conducted on various reservoir parameters to determine how each parameter would most affect gas flow of a coalbed methane reservoir. The reservoir characteristics that have been studied include gas content, desorption permeability, and porosity. To accomplish this objective a reservoir simulation model for thick and deep coal bed methane reservoirs has been built.

\section{In order to accomplish the objective of this study, the following procedure will be followed:}

- Building a reservoir model which is capable of producing methane (natural gases) from deep and thick coal bed methane reservoirs.

- Performing sensitivity analysis to address the impact of changing the reservoir properties such as Fracture permeabilities $\left(\mathrm{K}_{\mathrm{f}}\right)$, Fracture porosity $\left(\varphi_{\mathrm{f}}\right)$, Gas content $\left(\mathrm{G}_{\mathrm{c}}\right)$ and, desorption time $(\tau)$ on the gas production from CBM reservoirs. This will help us to identify which reservoir parameter has the most effect on coal.

- Performing economic analysis on the horizontal well and vertical well in order to identify the best drilling pattern in deep and thick CBM reservoirs, and to evaluate the recovery factor of the two wells. 


\subsection{Economic Analysis and Recovery Factor:}

Economic analysis is the application of basic financial analysis to a scientific project problem, the result of which shows either a profit or loss for the given scientific project undertaken. The yard-stick to determine the most appropriate drilling patterns in deep and thick CBM reservoir is the Net Present Value. This study also focuses on the recovery factor $\left(R_{F}\right)$ as it is critical factor in decision making.

The major factor affecting the economics of coal bed reservoirs are discussed as follows:

- Natural Gas Price

- Capital Costs

- Cost of Implementation

\subsubsection{Natural Gas Price:}

The Natural gas is the most important variable in terms of the drilling cost, because it changes with time based on demands. To make a proper forecast of Natural Gas price, different gas prices should be considered. As a result, gas price of $3 \$$ was considered in this study. Other scenarios considered, assumed gas prices of $4,5,6 \$$ in case the gas price increases with time.

\subsubsection{Capital Costs:}

The capital cost is the costs of drilling, maintenance and dewatering process. In our case, dewatering cost was not considered (saturated coalbed methane reservoir), however dewatering process has a significant impact on the economics of the project. The total capital costs for the subsurface and surface equipment to supply coal bed gas were estimated to be $\$ 3.7$ to $\$ 1.9$ million for the horizontal well and vertical well respectively.

\subsubsection{Cost of Implementation:}

Implementation costs include the operations \& maintenance costs. These costs were estimated to be $13000 \$ /$ month to $6000 \$$ /month for the horizontal well and vertical well respectively. 


\subsection{Reservoir Modeling:}

The necessity for reservoir simulation arises from the need for petroleum engineers to find accurate performance predictions for a hydrocarbon reservoir under different operating conditions. This is due to the fact that in a hydrocarbon recovery project the risk of the suggested development plan must be minimized. Similarly, reservoir simulation is use to assist Reservoir Engineers have a better understanding of reservoir behavior and make production forecasts to help engineers in making investment decisions.

In this study, a compositional reservoir simulator has been utilized with the intention of modeling and simulating the reservoir. CMG (Computer Modeling Group) is the reservoir simulation that has been used. This commercial software is computer software for reservoir simulation capable to determine reservoir capacities in order to maximize potential recovery. CMG is confirmed by six basic applications. They are BUILDER (Preprocessing Applications), IMEX (Black Oil Simulator, STARS (Steam Thermal Advanced Processes), GEM (Generalized Equation-of-State Model Compositional Reservoir Simulator), WINPROP (Phase Behavior Analysis) and RESULTS (Postprocessing Applications). In this study, we used a part of these applications adjusted for coalbed methane production. The applications used were BUIDER, GEM, and RESULTS. We built two basic reservoir simulation models using GEM builder. The first model has a vertical well and the second model has a horizontal well. The input data for the two models are the same, and they are listed in the Table-2. The data were collected from a literature review. These two models are synthetic models for coal bed methane, which are located at deepest depth and have one of the thickest coal bed methane reservoirs in United States. The formation depth is 8500 feet which consists of three layers with cross thickness of 300 feet. 


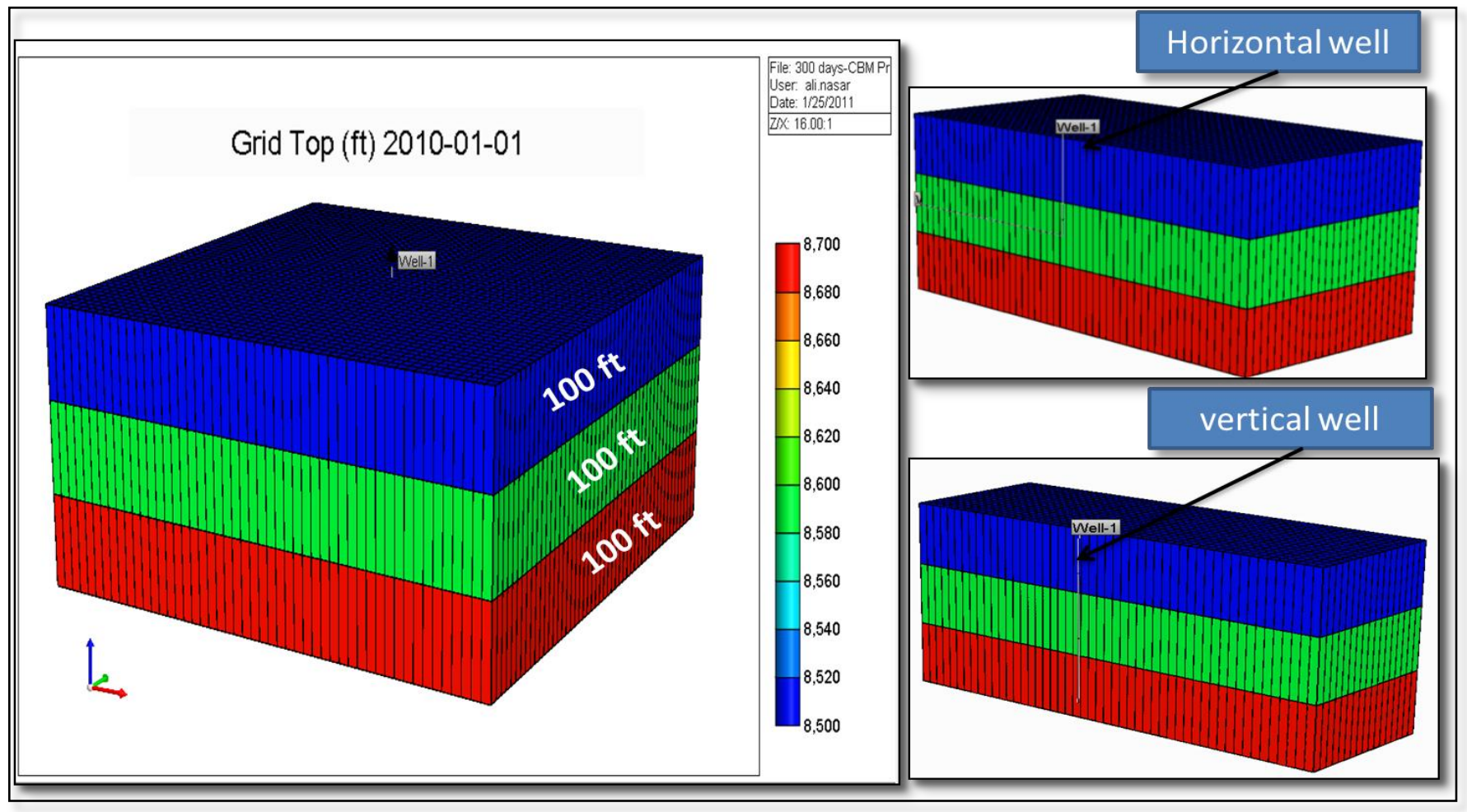

Figure 14 Reservoir simulation model of thick and deep coal bed methane reservoir

Table 2 Reservoir simulation input data

\begin{tabular}{|l|l|}
\hline Input Parameters & Value \\
\hline Grid top depth, feet & 8500 \\
\hline Thickness, feet & 300 \\
\hline Porosity, Matrix, fraction & 0.005 \\
\hline Porosity, Fracture, fraction & 0.02 \\
\hline Permeability Matrix, i , md & 0.001 \\
\hline Permeability Matrix, j, md & 0.001 \\
\hline Permeability Matrix, $\mathrm{k}, \mathrm{md}$ & 0.001 \\
\hline Permeability Fracture, i , md & 8 \\
\hline Permeability Fracture, j, $\mathrm{md}$ & 8 \\
\hline Permeability Fracture, $\mathrm{k}, \mathrm{md}$ & 8 \\
\hline Fracture Spacing, i , ft & 0.02 \\
\hline Fracture Spacing, $\mathrm{j}, \mathrm{ft}$ & 0.02 \\
\hline Fracture Spacing, $\mathrm{k}, \mathrm{ft}$ & 0.02 \\
\hline
\end{tabular}

\begin{tabular}{|l|l|}
\hline Coal Desorption Time, days & 300 \\
\hline Langmuir Pressure $\mathrm{P}_{\mathrm{L}}, \mathrm{psi}$ & 2700 \\
\hline Langmuir Volume $\mathrm{V}_{\mathrm{L}}, \mathrm{scf} / \mathrm{ton}$ & 700 \\
\hline Gas Content, scf/ton & 400 \\
\hline Temperature, ${ }^{\circ} \mathrm{F}$ & 200 \\
\hline Reservoir Pressure, psi & 3600 \\
\hline Bottom Hole Pressure & 500 \\
\hline Critical Desorption Pressure, psi & 3600 \\
\hline Production Time, years & 10 \\
\hline Area, acre & 2295.68 \\
\hline
\end{tabular}




\subsection{Sensitivity Analysis}

\subsubsection{Effect of Reservoir Parameters on Coalbed Methane Production:}

The overall goal of the sensitivity analysis section is to illustrate the effects of a variety of coal properties on gas production from a coal seam. In this study, a sensitivity analysis on the vertical well and horizontal well has been implemented. As a result, several reservoir simulation models had been built in order to investigate the impact of some reservoir properties on the cumulative gas production and gas rate production. This study focused on the four reservoir parameters, namely: Gas Content, Desorption Time, Fracture Permeability, and Fracture Porosity.

These reservoir parameters are found to have the greatest impact on production from coalbed methane reservoirs. Sensitivity analysis represents a set of simulation runs in which all parameters are kept constant, but only one is changed systematically according to Table 3 .

Table 3 The change in the reservoir parameters for sensitivity analysis

\begin{tabular}{|l|l|l|l|l|l|}
\hline Parameters & Basic Case & Case-1 & Case-2 & Case-3 & Case-4 \\
\hline Permeability, md & 8 & 4 & 6 & 10 & 12 \\
\hline Porosity, fraction & 0.08 & 0.01 & 0.0075 & 0.005 & 0.003 \\
\hline Gas content, scf/ton & 400 & 200 & 300 & 500 & 600 \\
\hline Desorption time, day & 300 & 200 & 100 & 10 & 1 \\
\hline
\end{tabular}




\section{Chapter-4 Result and Discussion}

In this Chapter, the simulation results of different reservoir models will be shown and discussed. Several reservoir models have been built and run in this study. The first scenarios illustrate the results of the vertical and horizontal wells that were drilled in the reservoir. The second scenarios show the impact of changing the reservoir parameters, such as fracture permeability, fracture porosity, gas content and desorption time of the vertical and horizontal well. The main objective of changing these reservoir parameters is to investigate their impact on the gas production of deep and thick CBM reservoirs. These reservoir parameters are obtained to be the most reservoir influential parameters, effecting gas production from CBM reservoirs.

\subsection{CBM Reservoir with a vertical Well:}

The first model has a vertical well which is located at 8500 feet and perforated through the three layers of coal seam. The well is located in the middle of the reservoir. The net pay thickness of these three layers is $300 \mathrm{ft}$ with $100 \mathrm{ft}$ for each individual. The reservoir is homogeneous in terms of reservoir properties. The model has been built in a Cartesian gridding system and it has a drainage area of 2295 acres. The result in Figure 15 shows the gas and water production of the vertical well. 


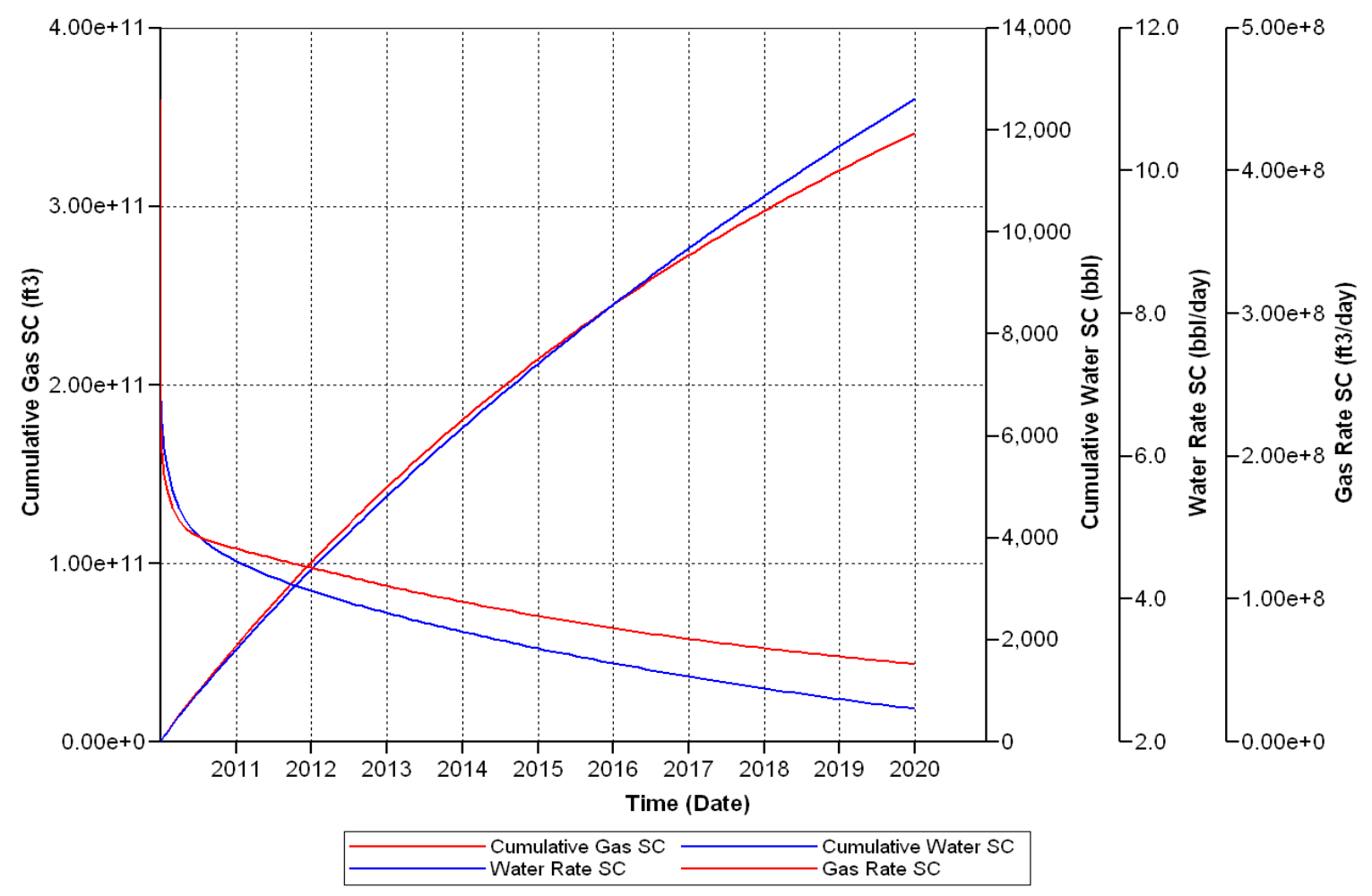

Figure 15 Gas and water production profile from the vertical well

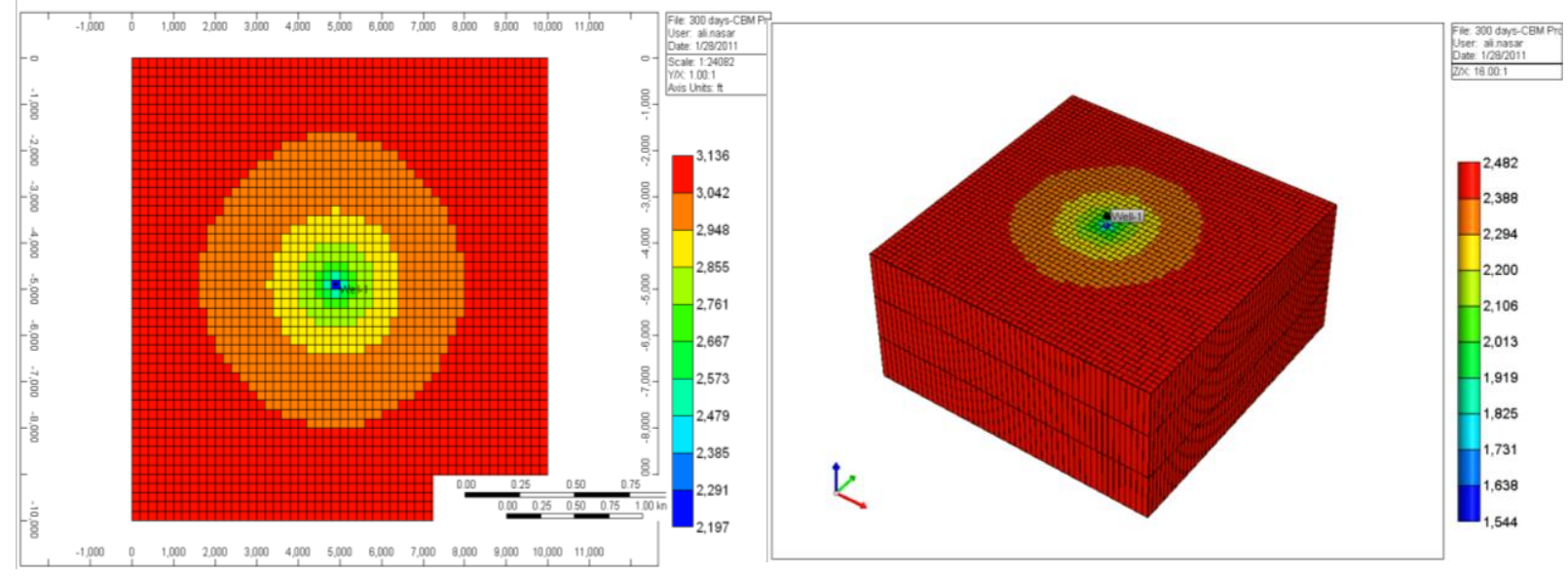

Figure 16 Pressure distribution from vertical well in 2D and 3D view

The vertical well itself has been tested in three different scenarios. In the first scenario we perforated the well in the three layers. While in the second and third scenario we only perforated in the two top layers and two bottom layers respectively. The point behind these three scenarios is to see how sensitive our model is and to address the difference in gas production between 
them. As a result, perforating three layers increases the gas production comparing with two others, due to the fact that we have more access to the whole reservoir since it is a homogeneous reservoir.

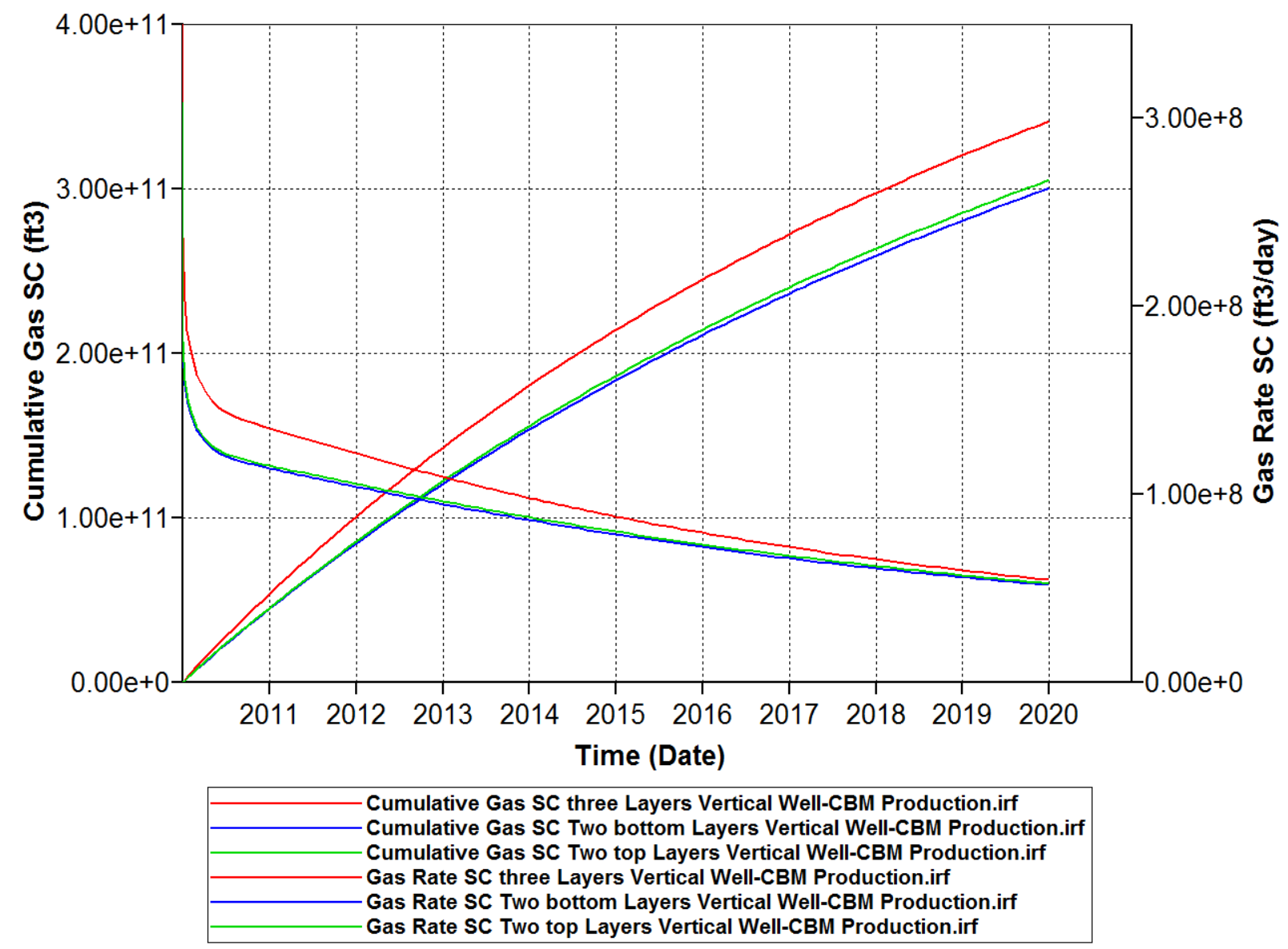

Figure 17 Cumulative gas production of perforating different layers of the vertical well

\subsection{CBM Reservoir with a Horizontal Well:}

The second model has a horizontal well with a single lateral of 5000 feet. That well is drilled at a depth of $8600 \mathrm{ft}$, which is basically located at the second layer and has been perforated through the entire $5000 \mathrm{ft}$ length of the lateral. The gas and water production of the horizontal well are shown in Figure 18. 


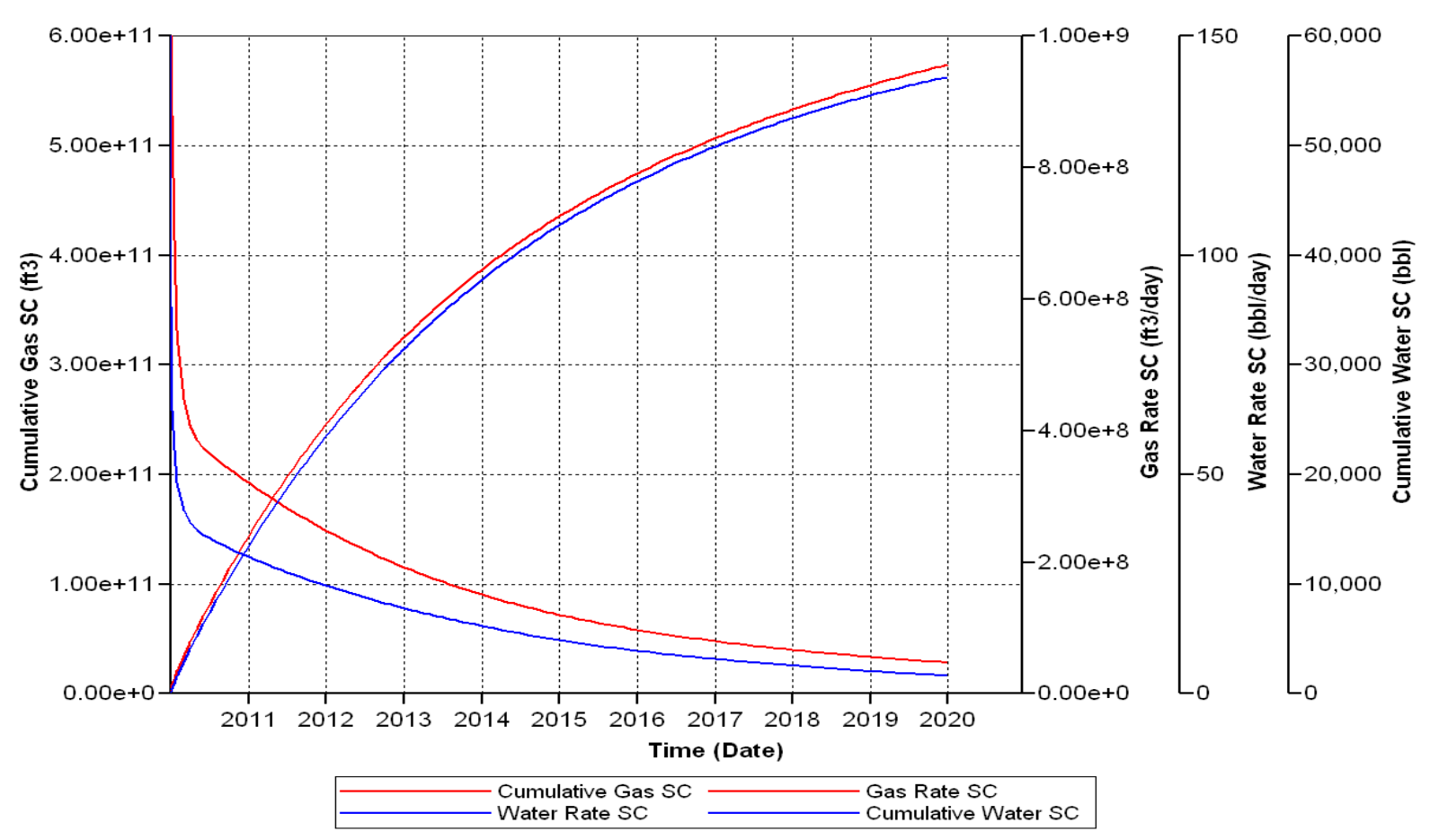

Figure 18 Gas and water production from the horizontal well

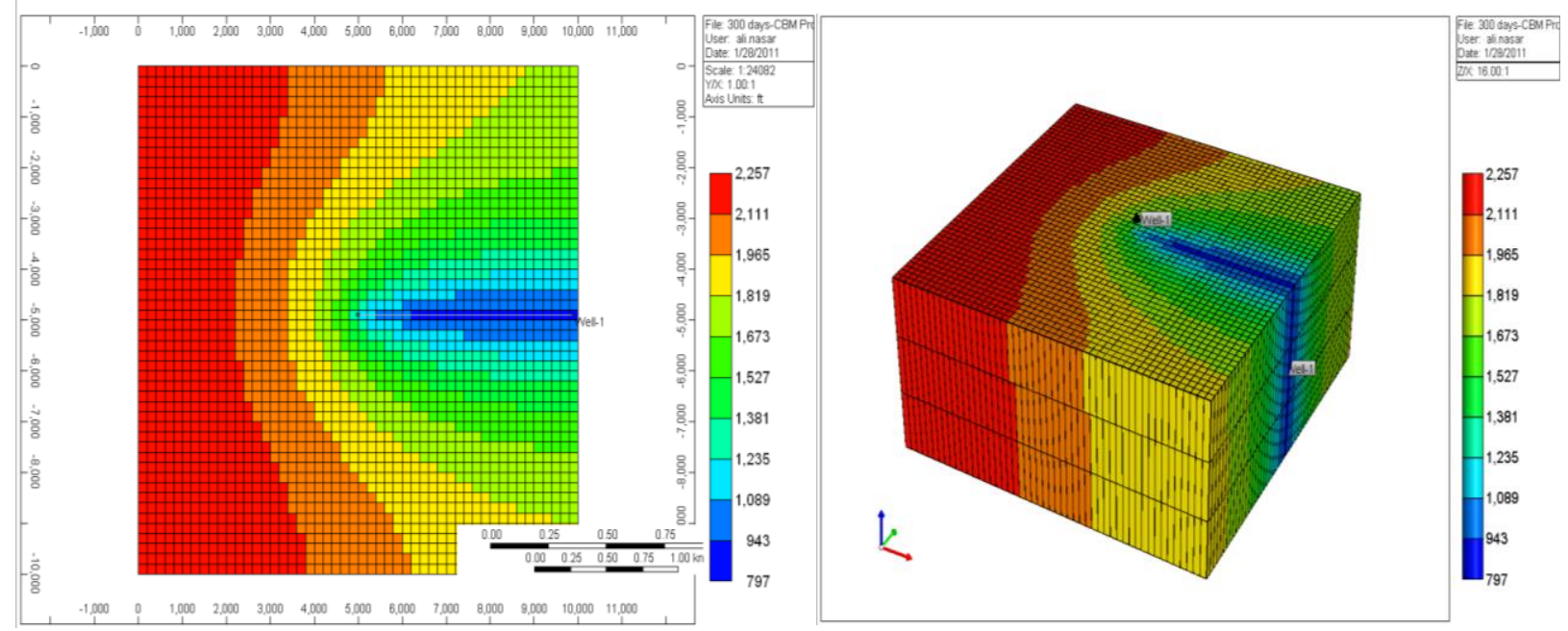

Figure 19 Pressure distribution from horizontal well in 2D and 3D view

In addition, the horizontal well is drilled in the second layer with 5000 feet length as it had mentioned before. We also drilled in the first and third layer. The purpose of drilling the horizontal well in different locations of coal seam is to see if is any change in the gas production. From the result below, we can notice that there is no significant change in the cumulative production whether we drilled in the first, second or even in the third layer. 


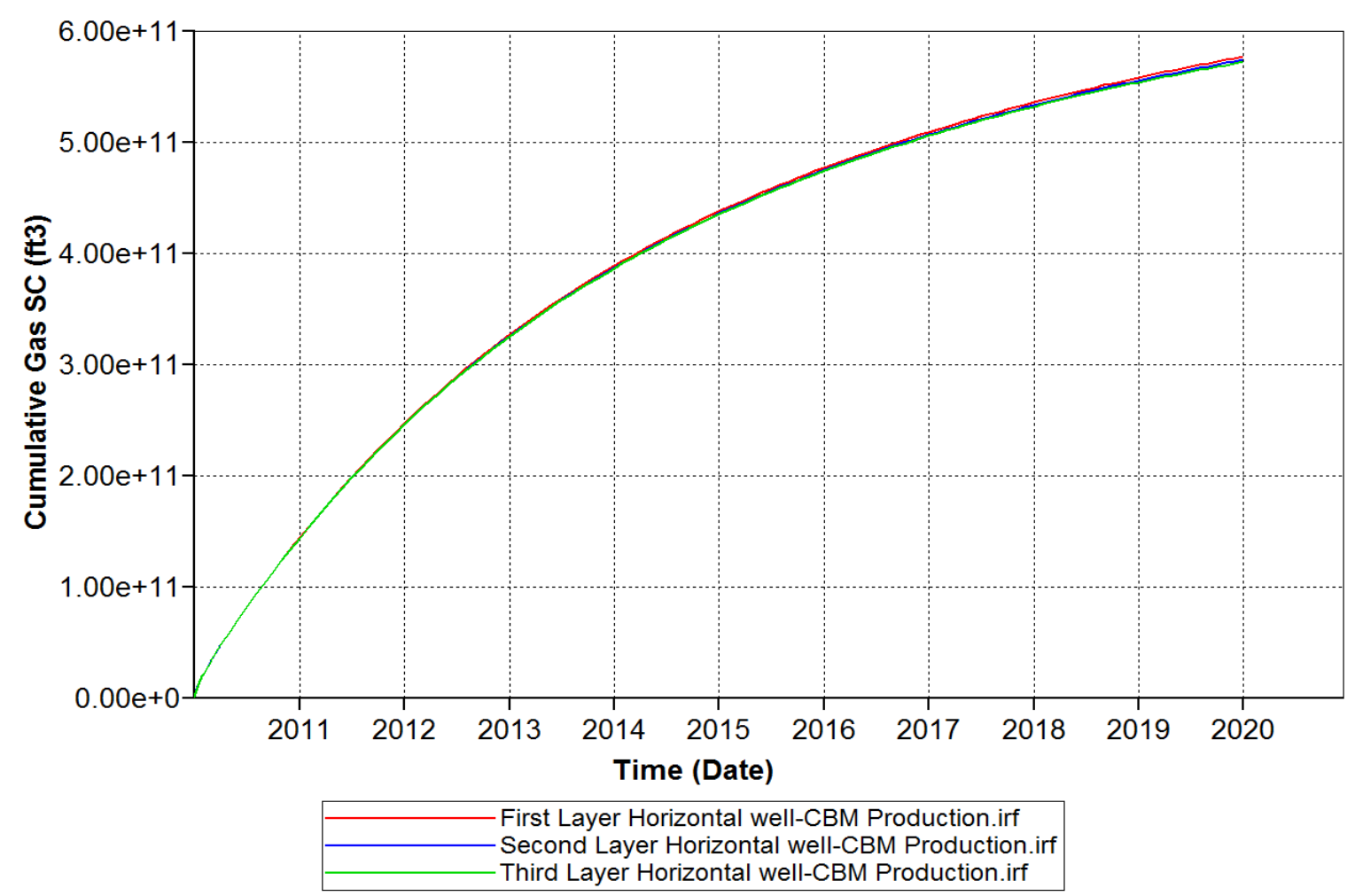

Figure 20 Gas cumulative production of perforating first, second and third layer of the horizontal well

\subsection{Length of horizontal well:}

The horizontal length is an important element which has an obvious effect on the production rate and the cost of horizontal completion. It is well known that with a higher horizontal length the total gas recovery increases, but drilling costs must be considered to find out the optimum length. The horizontal length depends on the drainage area of the reservoir. In this study, the horizontal length was varied between 1000 feet to 10000 feet. The cumulative gas production and gas production rate of different horizontal lengths are shown in Figure 21. 


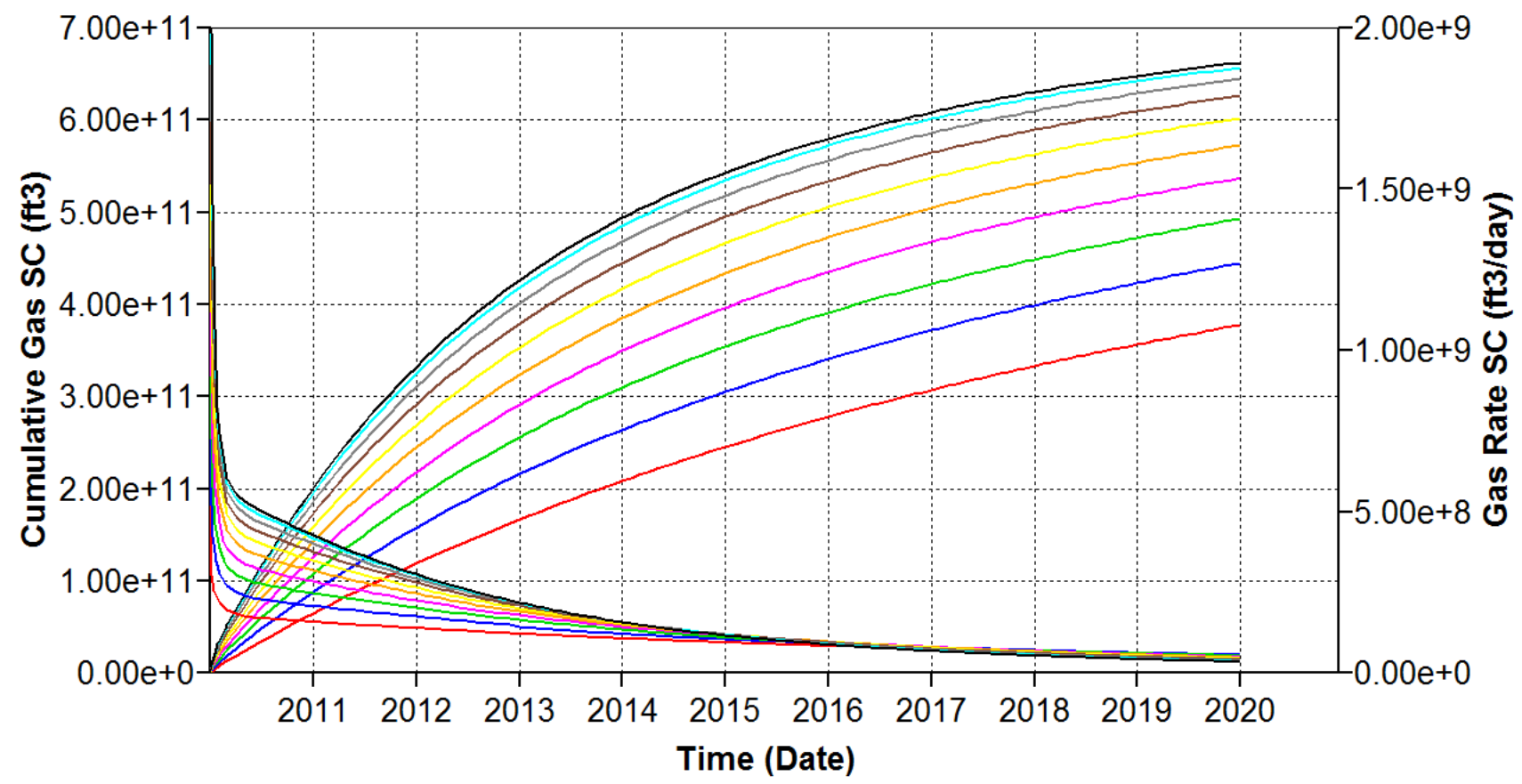

\begin{tabular}{|c|c|}
\hline $\begin{array}{c}\text { Cumulative Gas SC } 1000 \mathrm{Ft} \text { length -CBM Production.irf } \\
\text { Cumulative Gas SC } 3000 \mathrm{Ft} \text { length -CBM Production.irf } \\
\text { Cumulative Gas SC } 5000 \mathrm{Ft} \text { length -CBM Production.irf } \\
\text { Cumulative Gas SC } 7000 \mathrm{Ft} \text { length -CBM Production.irf } \\
\text { Cumulative Gas SC } 9000 \mathrm{Ft} \text { length -CBM Production.irf } \\
\text { Gas Rate SC } 1000 \mathrm{Ft} \text { length -CBM Production.irf } \\
\text { Gas Rate SC } 3000 \mathrm{Ft} \text { length -CBM Production.irf } \\
\text { Gas Rate SC } 5000 \mathrm{Ft} \text { length -CBM Production.irf } \\
\text { Gas Rate SC } 7000 \mathrm{Ft} \text { length -CBM Production.irf } \\
\text { Gas Rate SC } 9000 \mathrm{Ft} \text { length -CBM Production.irf }\end{array}$ & $\begin{array}{c}\text { Cumulative Gas SC } 2000 \text { Ft length -CBM Production.irf } \\
\text { Cumulative Gas SC } 4000 \text { Ft length -CBM Production.irf } \\
\text { Cumulative Gas SC } 6000 \text { Ft length -CBM Production.irf } \\
\text { Cumulative Gas SC } 8000 \text { Ft length -CBM Production.irf } \\
\text { Cumulative Gas SC } 10000 \text { Ft length -CBM Production.irf } \\
\text { Gas Rate SC } 2000 \text { Ft length -CBM Production.irf } \\
\text { Gas Rate SC } 4000 \text { Ft length -CBM Production.irf } \\
\text { Gas Rate SC } 6000 \mathrm{Ft} \text { length -CBM Production.irf } \\
\text { Gas Rate SC } 8000 \mathrm{Ft} \text { length -CBM Production.irf } \\
\text { Gas Rate SC } 10000 \text { Ft length -CBM Production.irf }\end{array}$ \\
\hline
\end{tabular}

Figure 21 Gas cumulative production from horizontal well with different lateral length

\subsection{Comparison of Vertical and Horizontal Well Performance:}

Usually, the gas production rates of vertical and horizontal wells will significantly differ from each other. It is known that drilling horizontal wells will increase the production rate and will decrease the overall cost of the well during its life. However, in thick coalbed methane reservoirs horizontal wells might not be the best option and drilling multiple vertical wells might be a better option. Gas production from the vertical well is compared to the horizontal well and the results are demonstrated in Figure 22. From the results, it can clearly be seen that there is a noteworthy difference in the cumulative production between a horizontal well and a vertical well. Nevertheless, without performing economic analysis the decision cannot be made whether drilling a horizontal well or multiple vertical well would be beneficial. Figure 22 and 23 show the benefit of drilling a horizontal well and the recovery factor obtained. According to the 
results, drilling one horizontal well increases overall profitability by $30 \%$ as compared to the vertical well.

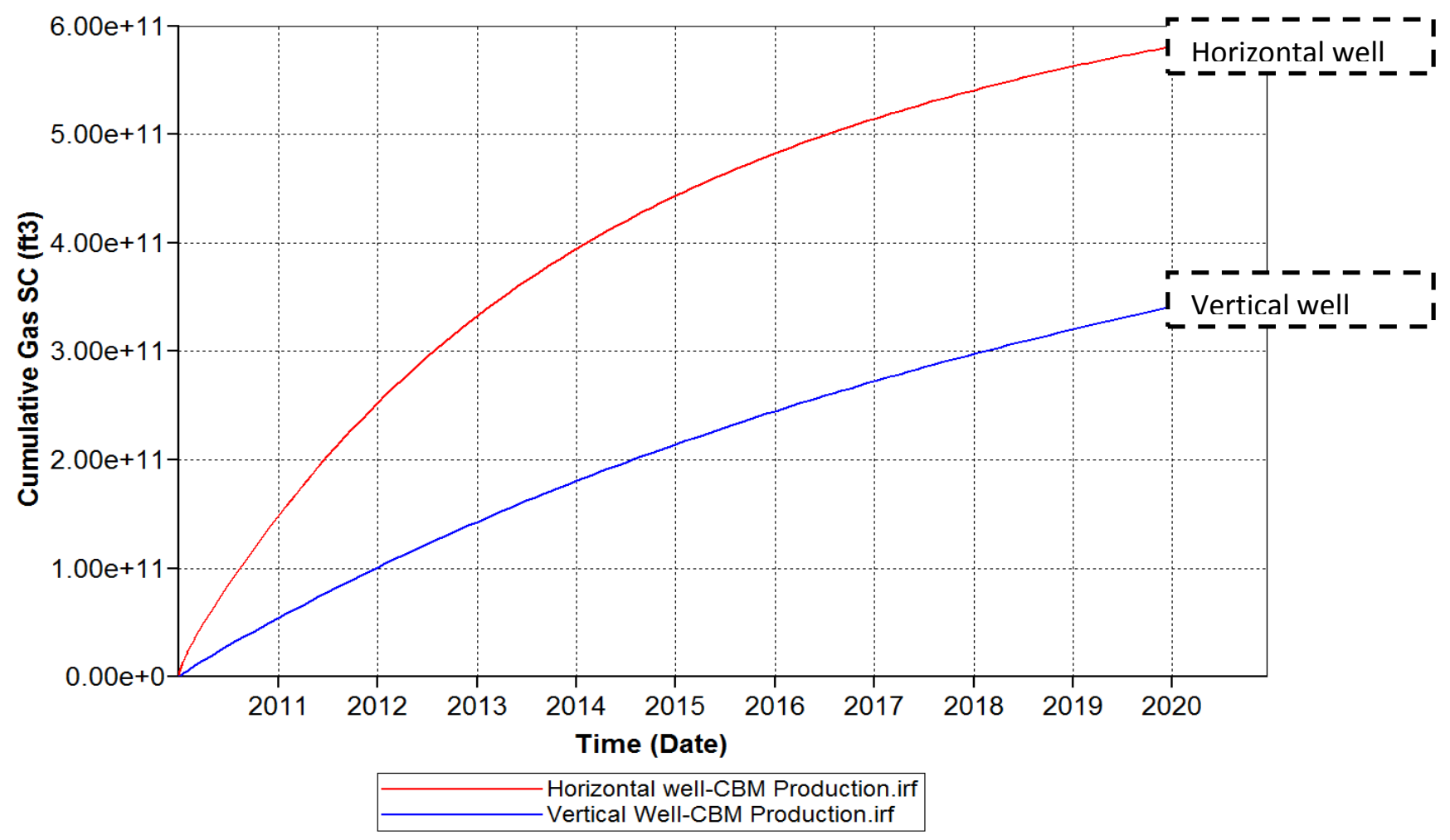

Figure 22 Cumulative gas production from vertical and horizontal well

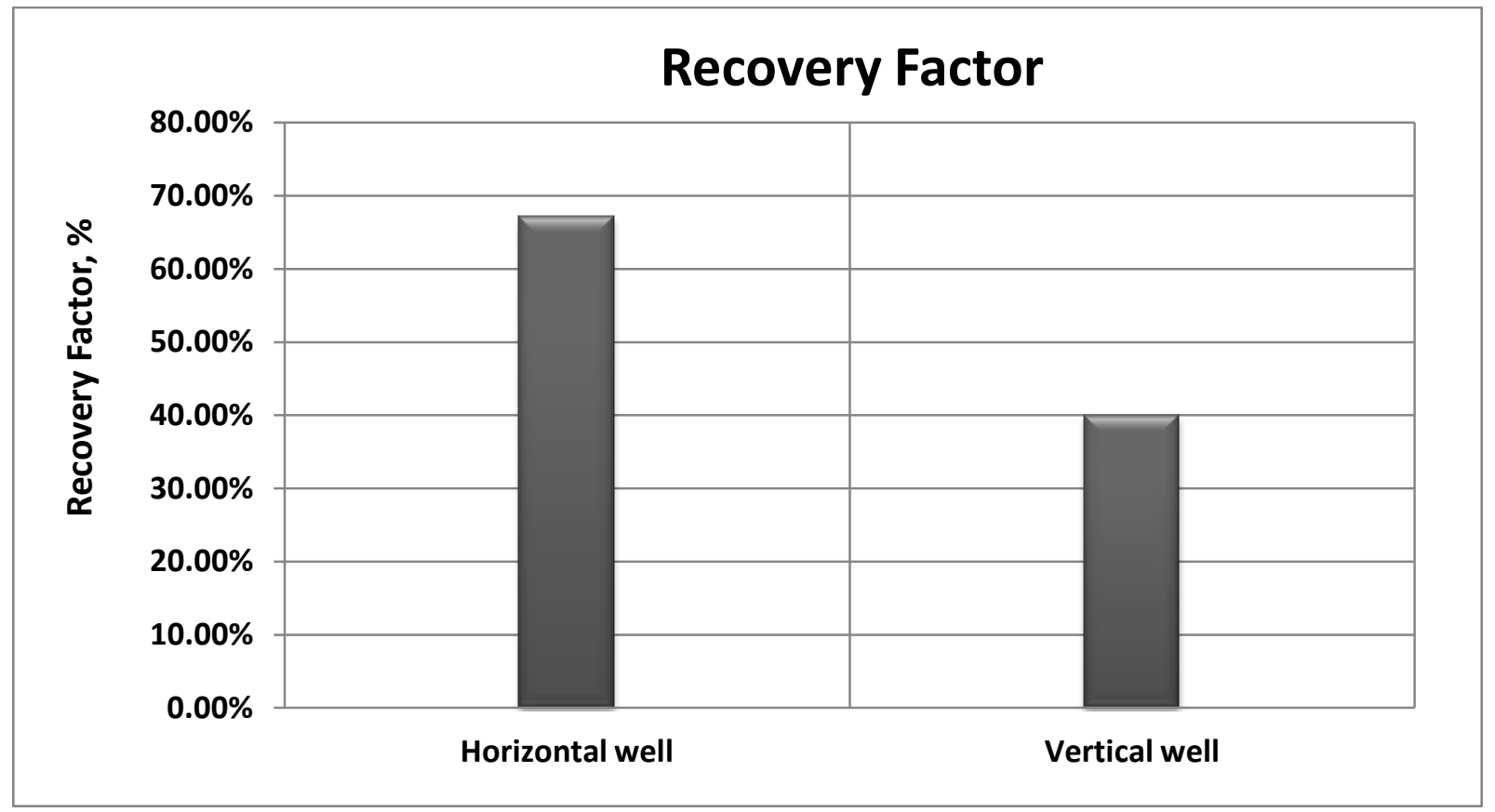

Figure 23 Gas Recovery factor result of one vertical well and one horizontal well 


\subsection{Effect of Gas Content on CBM Production:}

The Gas content is an important parameter that influences the production of coal bed methane reservoirs. The gas content is the amount of gas in the coal rock. This amount of the gas produced is dependent on the ability of the coal to store. The gas content is the first reservoir parameter that had been investigated in this study. The same system has been simulated with five different values of gas content as shown in Table 4. These values have been generated by changing the Langmuir volume and Langmuir pressure in order to keep the critical adsorbed pressure constant to have a saturated coalbed methane reservoir.

Table 4 Shows different in gas content with change in the Langmuir pressure and volume

\begin{tabular}{|l|c|c|c|}
\hline & Gas content, scf/ton & Langmuir volume $\left(\mathrm{V}_{\mathrm{L}}\right), \mathrm{scf} /$ ton & Langmuir pressure $\left(\mathrm{P}_{\mathrm{L}}\right), \mathrm{psi}$ \\
\hline Based model & 400 & 700 & 2700 \\
\hline First scenario & 200 & 400 & 3600 \\
\hline Second scenario & 300 & 550 & 3000 \\
\hline Third scenario & 500 & 840 & 2448 \\
\hline Fourth scenario & 600 & 1000 & 2400 \\
\hline
\end{tabular}

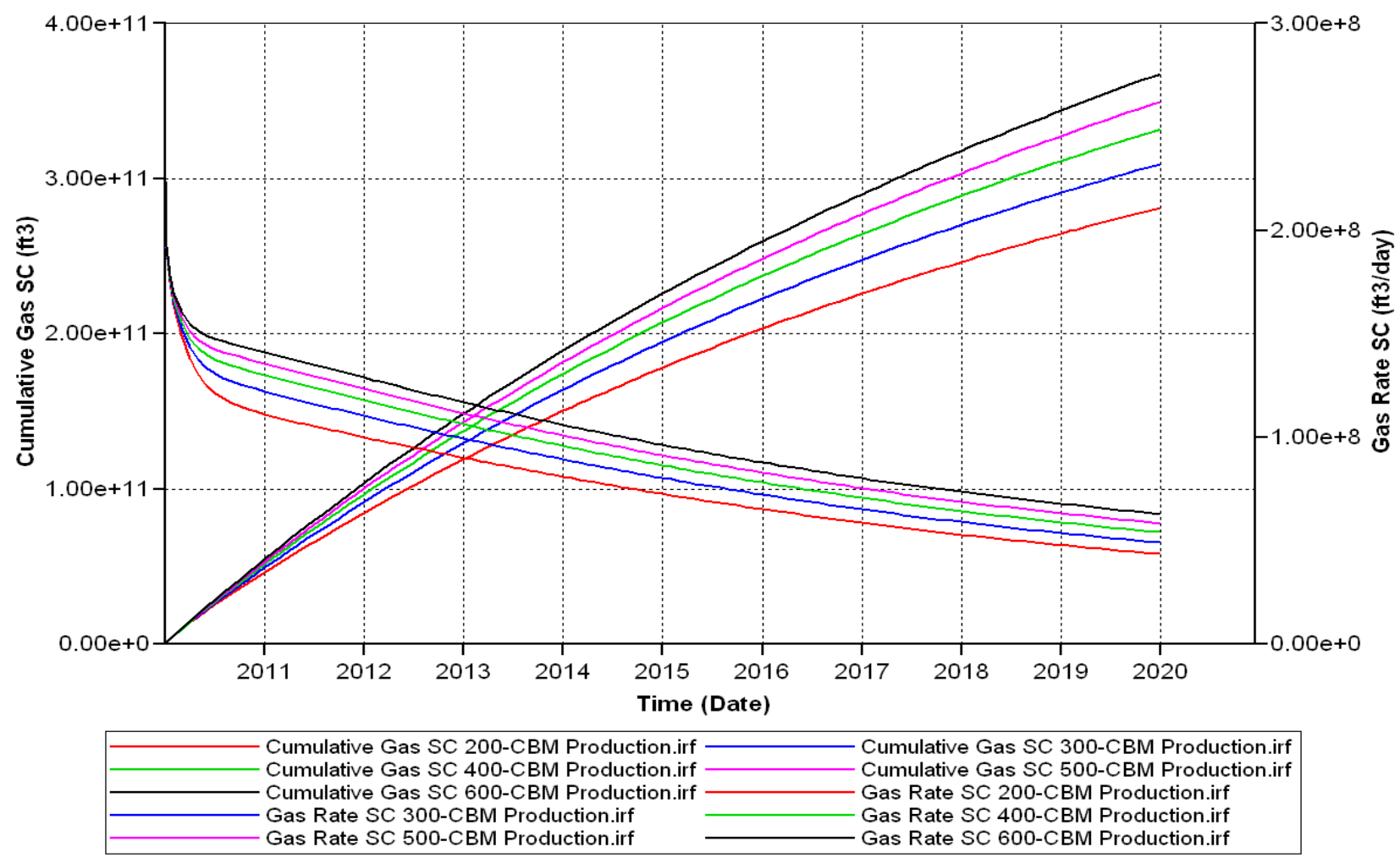

Figure 24 Effect of gas content on cumulative gas and on gas rate for varying gas content of the vertical well 


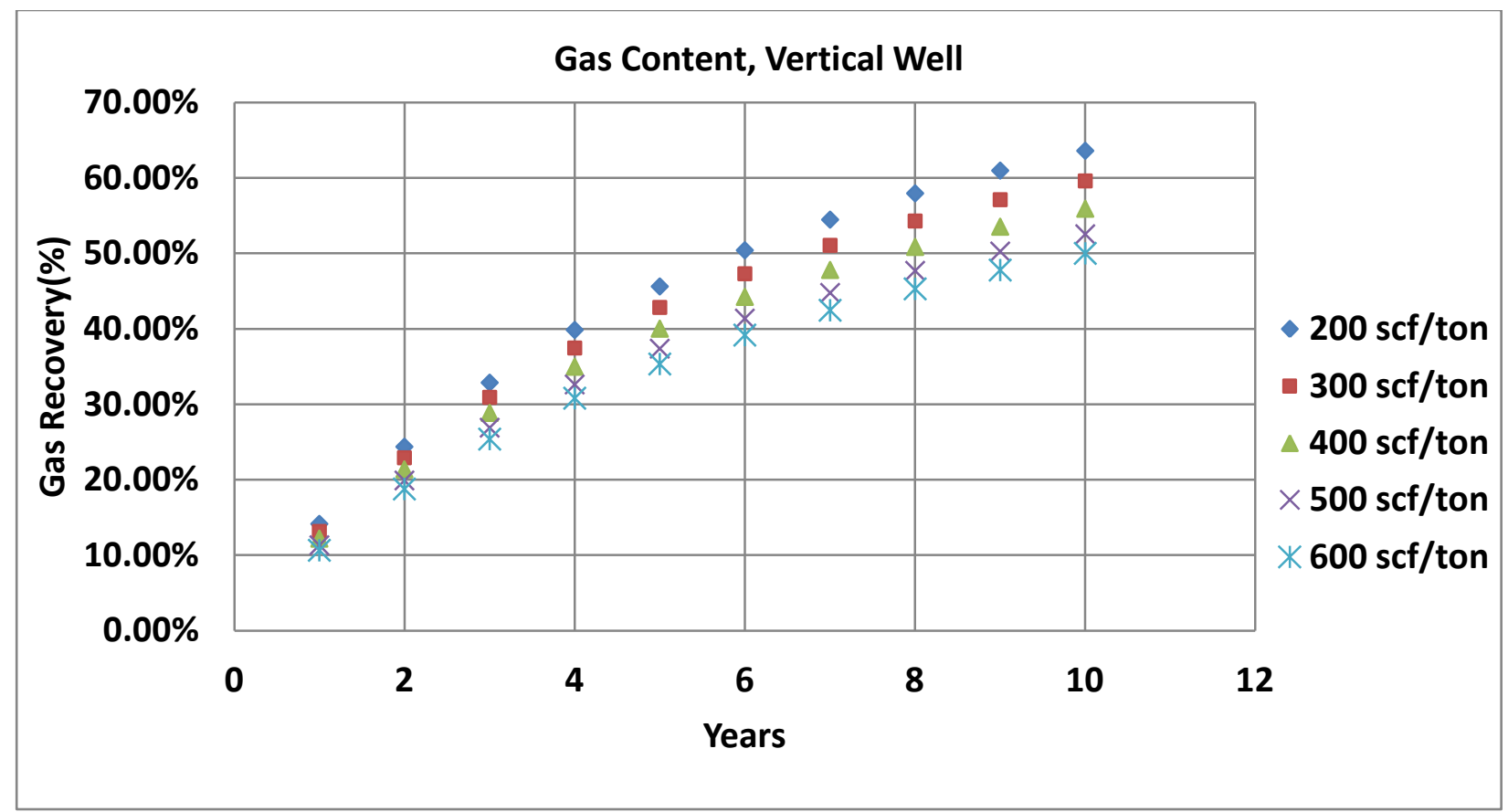

Figure 25 Effect of gas content on gas recovery factor of the vertical well

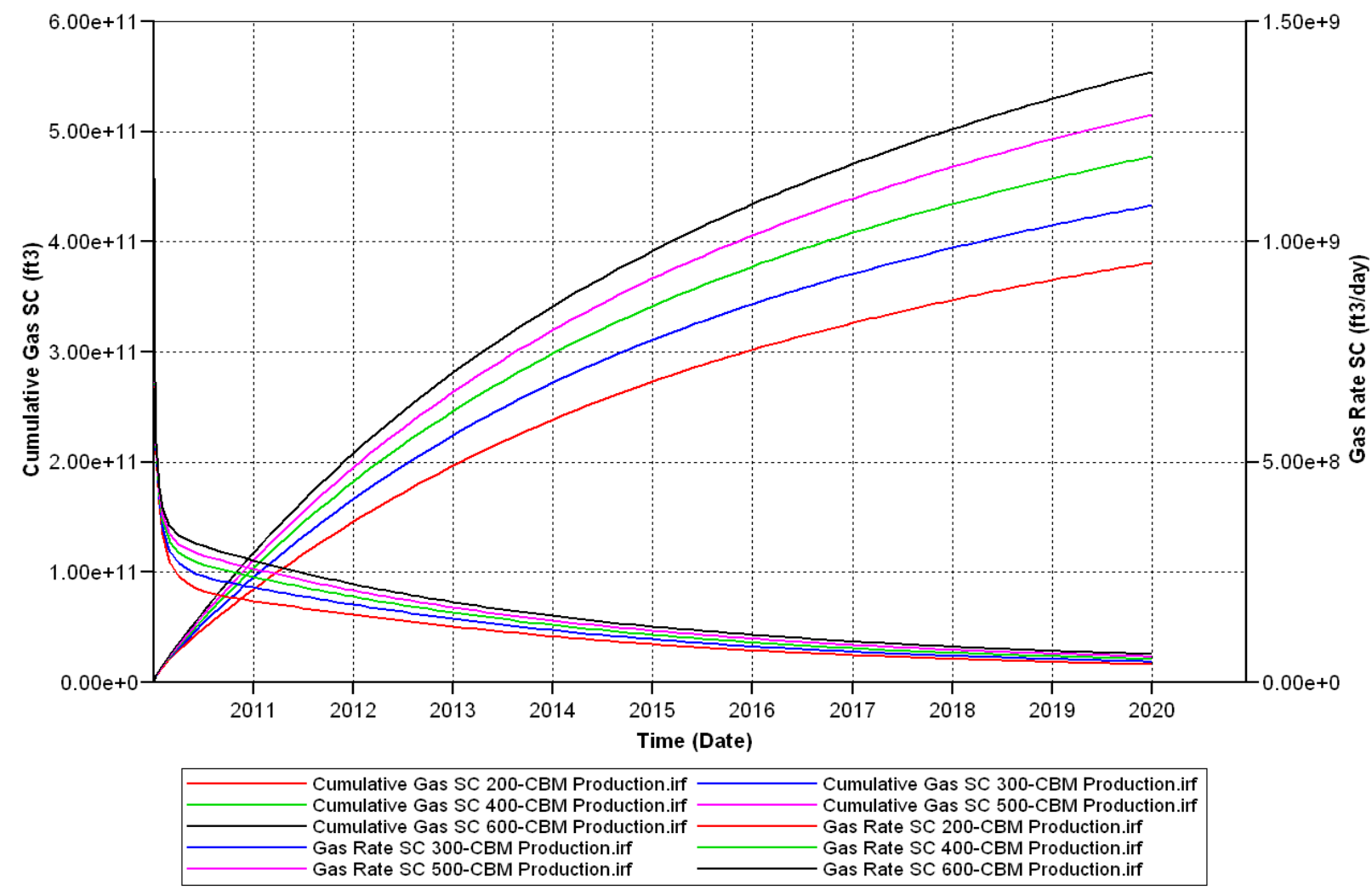

Figure 26 Effect of gas content on cumulative gas and on gas rate for varying gas content of the horizontal well 


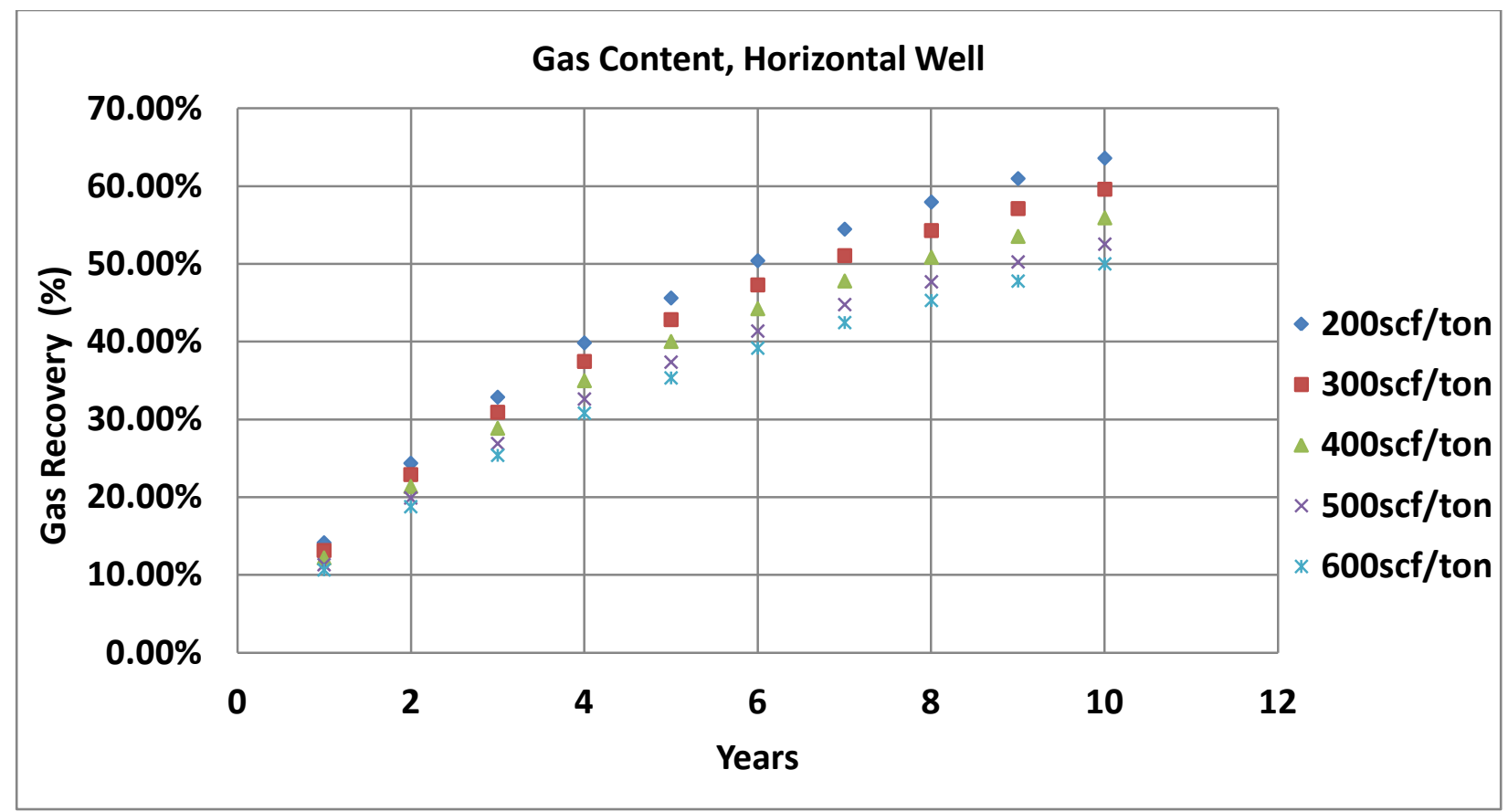

Figure 27 Effect of gas content on gas recovery factor of the horizontal well

Figure 24 through 27 show the cumulative gas production and gas recovery factor of variation of gas content of the vertical well and the horizontal well respectively. The simulation results show that gas production when the gas content increases gradually. As expected, the increase in the matrix gas content increases the gas production rate, since more gas is in storage in adsorbed form. According to the equation 5.1, increasing the gas content will increase the original gas in place in coal matrix.

$G=1359.7 A h \bar{\rho} \bar{G}_{c}$

Where:

$G$ = gas-in-place volume, $\mathrm{scf}$

$\mathrm{A}=$ reservoir area, acres

$\mathrm{h}=$ reservoir thickness, feet

$\bar{\rho}=$ average in-situ rock density at the average in-situ rock composition, $\mathrm{g} / \mathrm{cm}^{3}$

$\bar{G}_{c}=$ average gas content at the average in-situ rock composition, scf/ton 


\subsection{Effect of Desorption Time on CBM Production:}

By definition, the desorption time is the time taken for a methane molecule to desorb from matrix into the fracture. It is the second parameter that we investigated in this study. Values of $1,10,100,200$, and 300 days have been assigned to the desorption time to observe the difference in the production.

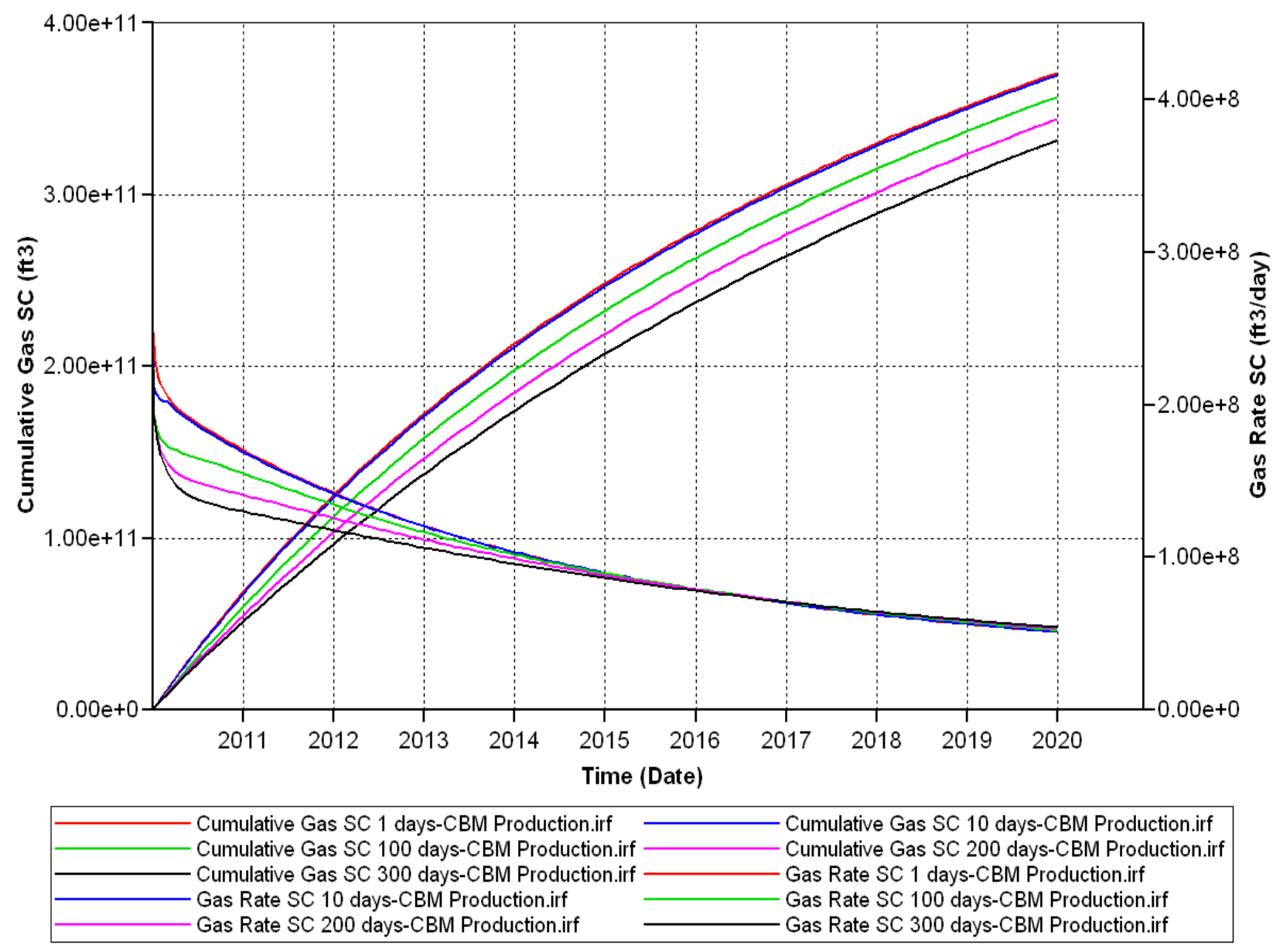

Figure 28 Effect of desorption time on cumulative gas and on gas rate for varying desorption time $(\tau)$ of the vertical well 


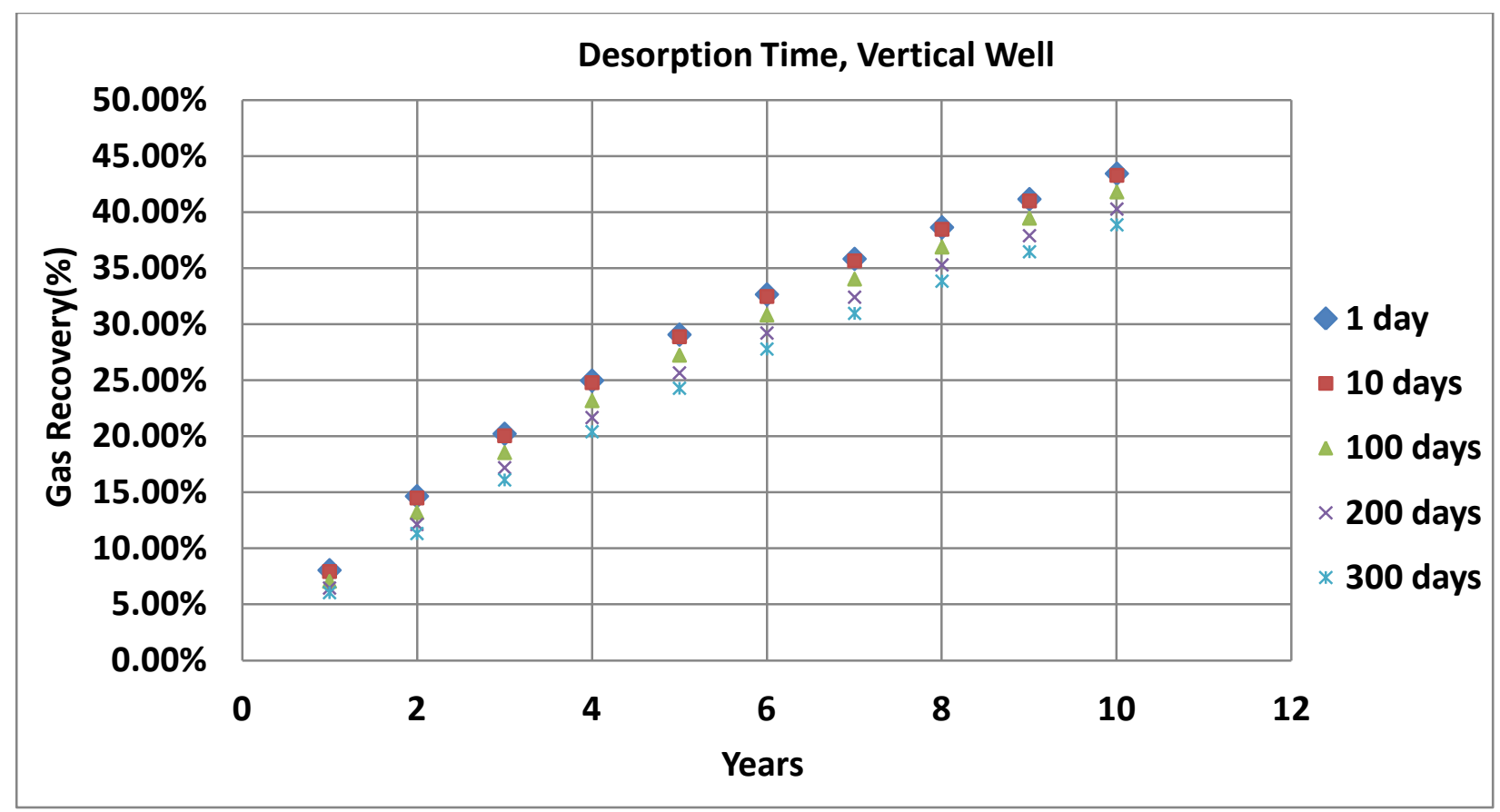

Figure 29 Effect of desorption time on gas recovery factor of the vertical well

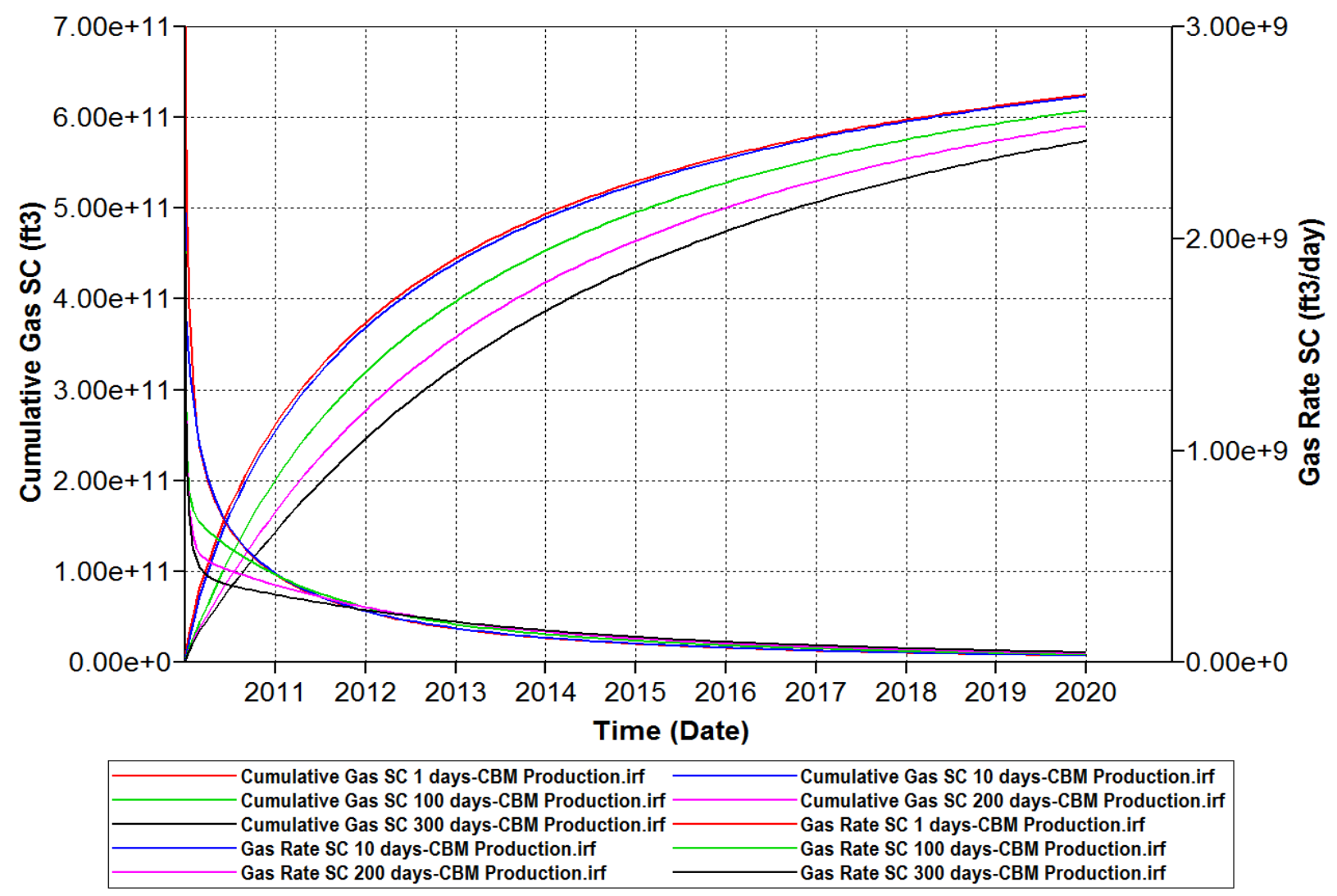

Figure 30 Effect of desorption time on cumulative gas and on gas rate for varying desorption time $(\tau)$ of the horizontal well 


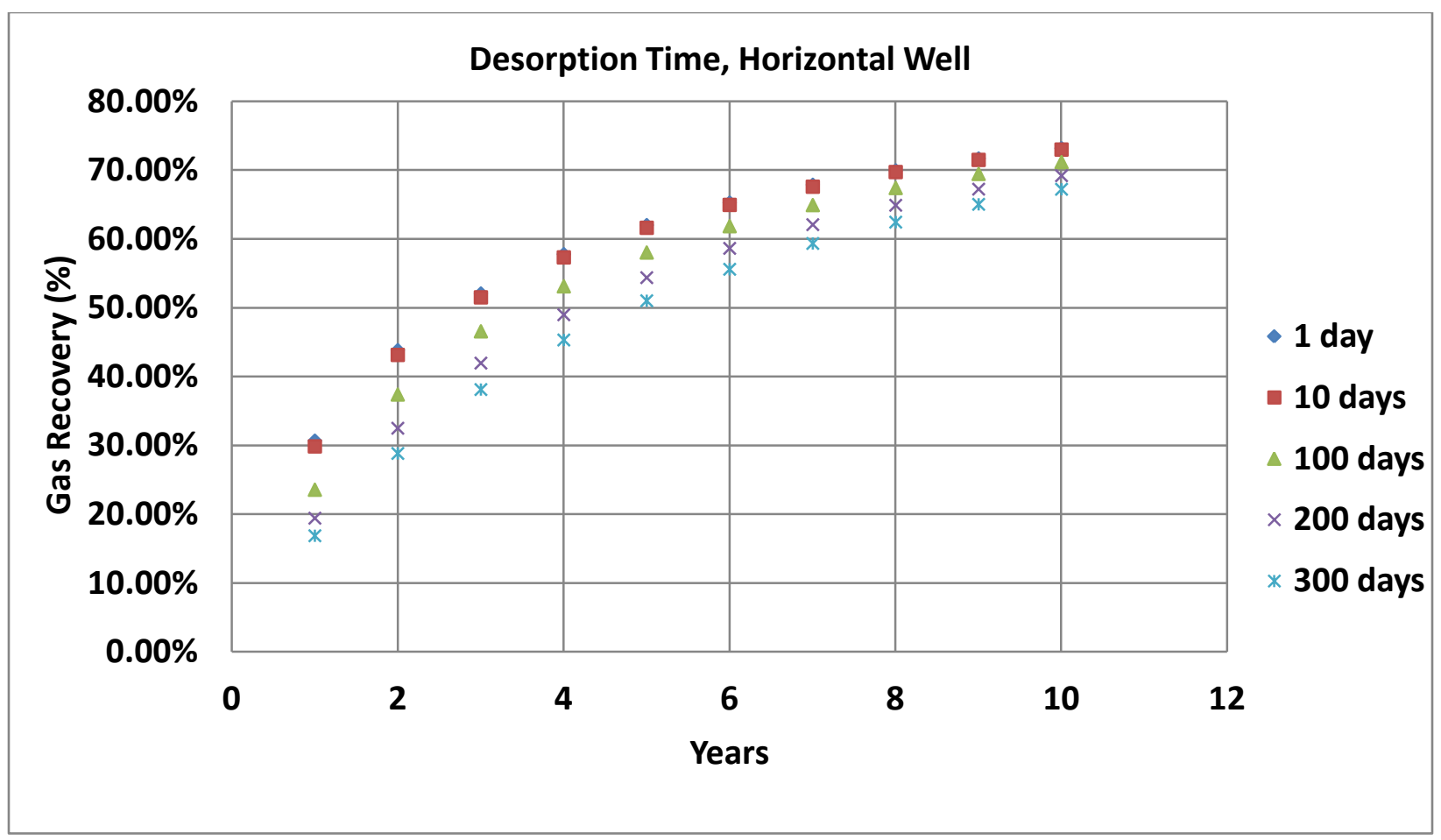

Figure 31 Effect of desorption time on gas recovery factor of the vertical well

The simulation results in Figure 28 through 31 show that desorption time has no enormous effect on the gas production from CBM reservoirs. In other words, it had been observed that the time constant does not have a significant effect on the gas production of CBM reservoirs by itself, because the desorption time indicates how rapidly initial desorption from coal takes place, and does not describe the diffusion process through the coal matrix. Thus, sorption time alone cannot be used as an indicator of coalbed gas production. Also from the results, it is noticed that with small values of desorption time, there will be a rapid increase in the gas production in the first couple of years of production.

\subsection{Effect of Fracture Porosity on CBM Production:}

The porosity by definition is the ratio of the pore volume to the bulk volume. Increasing the coal porosity value will consequently increase the pore volume and the surface gas "which is the adsorbed volume plus the free gas in the matrix pores", and decreases the bulk volume where the gas is sorbed ${ }^{8}$. The fracture in the coal bed is the main conduit part for flow of the methane but does not act as a storage point. Thus, the fracture porosity does not store gas, but is a place for some free gas and water, which will flow into the wellbore after reservoir pressure starts 
decreasing in the first years of the production. For most coal basins throughout the world, coalbeds release their adsorbed gas rapidly and the coal degasification rate is limited by gas flow in the cleats. Five values of the fracture porosity had been investigated in this study which are; $0.02,0.01,0.0075,0.005$ and 0.002 .

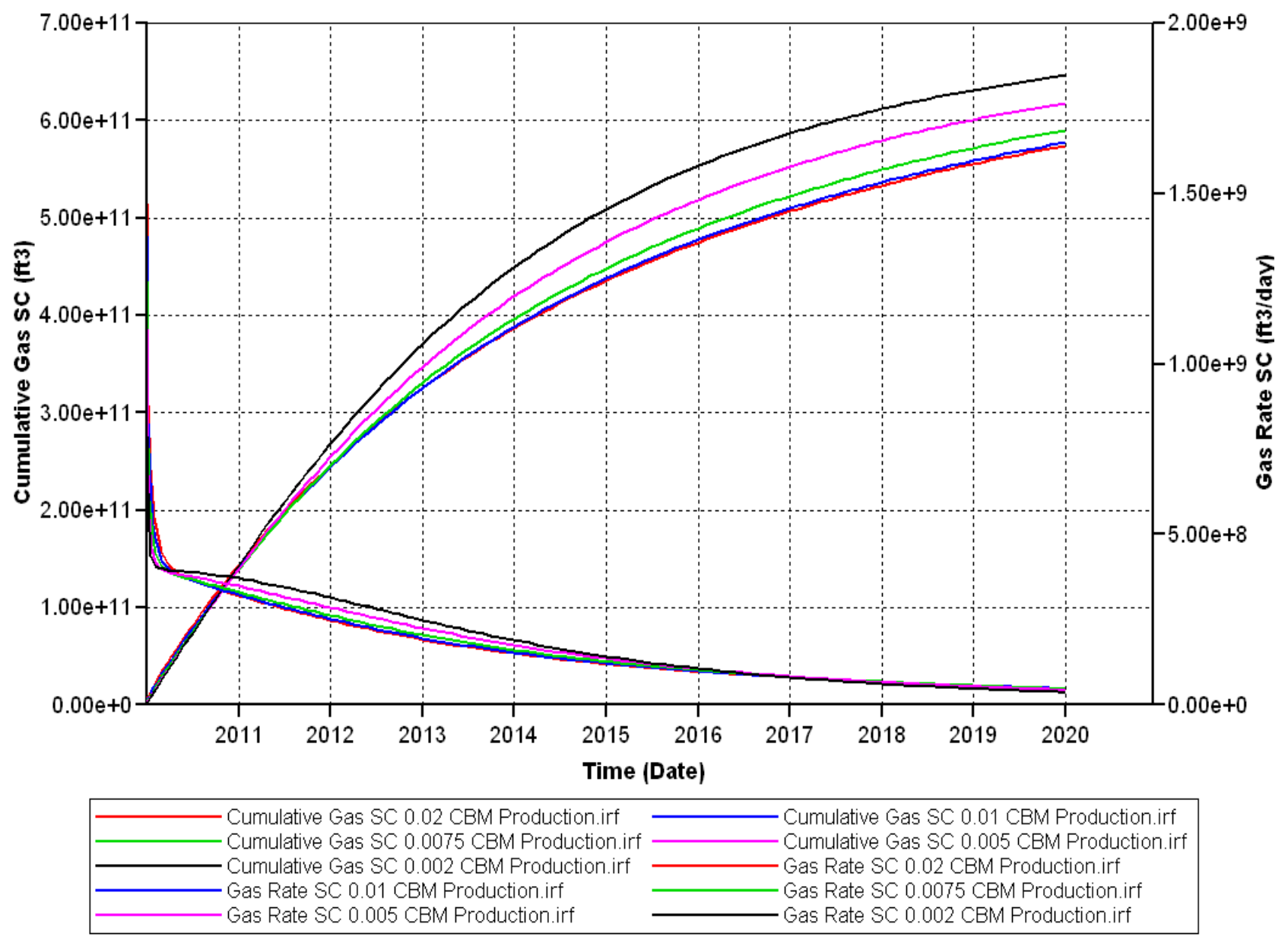

Figure 32: Effect of fracture porosity on cumulative gas and on gas rate for varying cleats porosity of the vertical well 


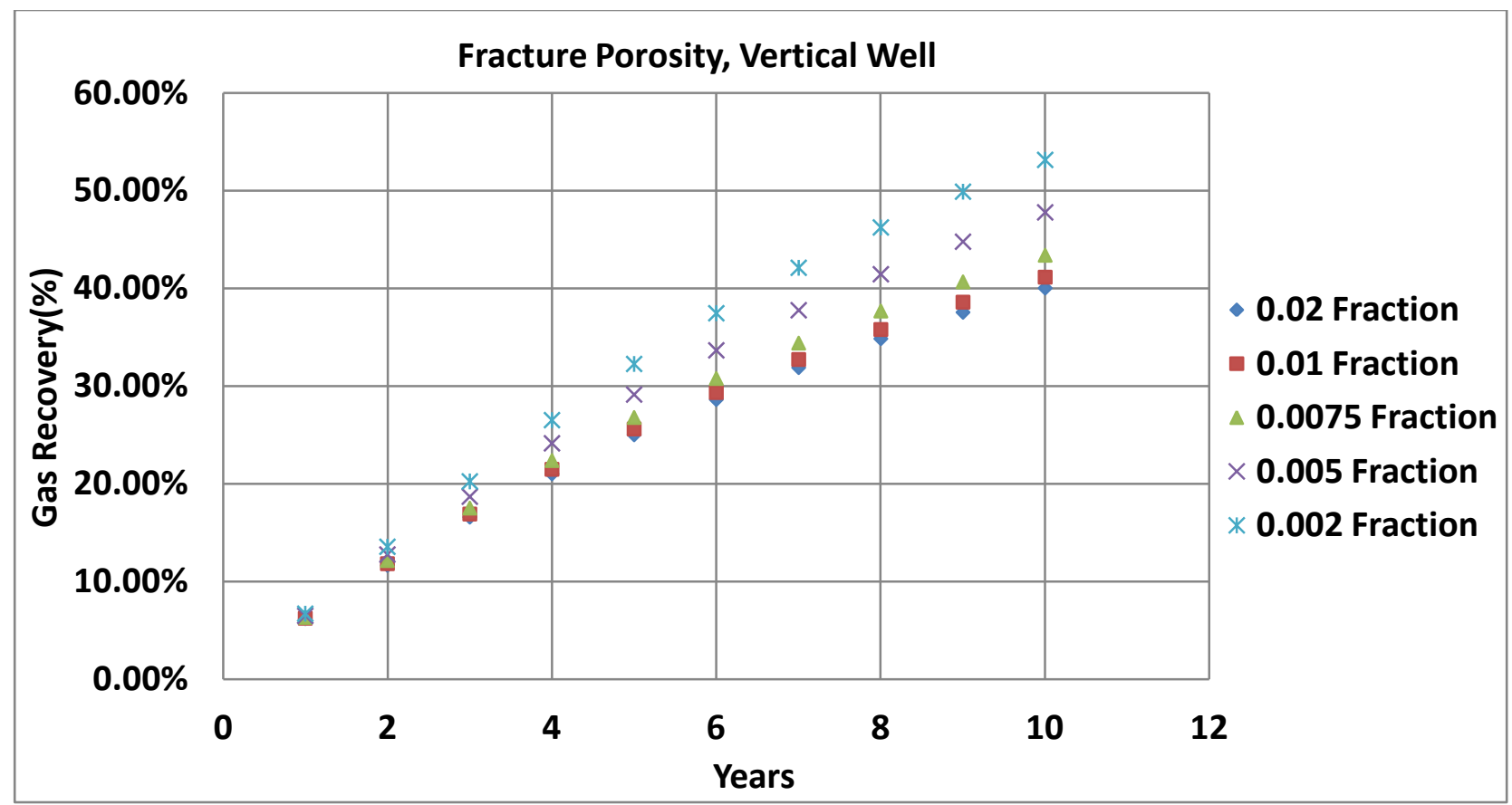

Figure 33: Effect of fracture porosity on gas recovery factor of the vertical well

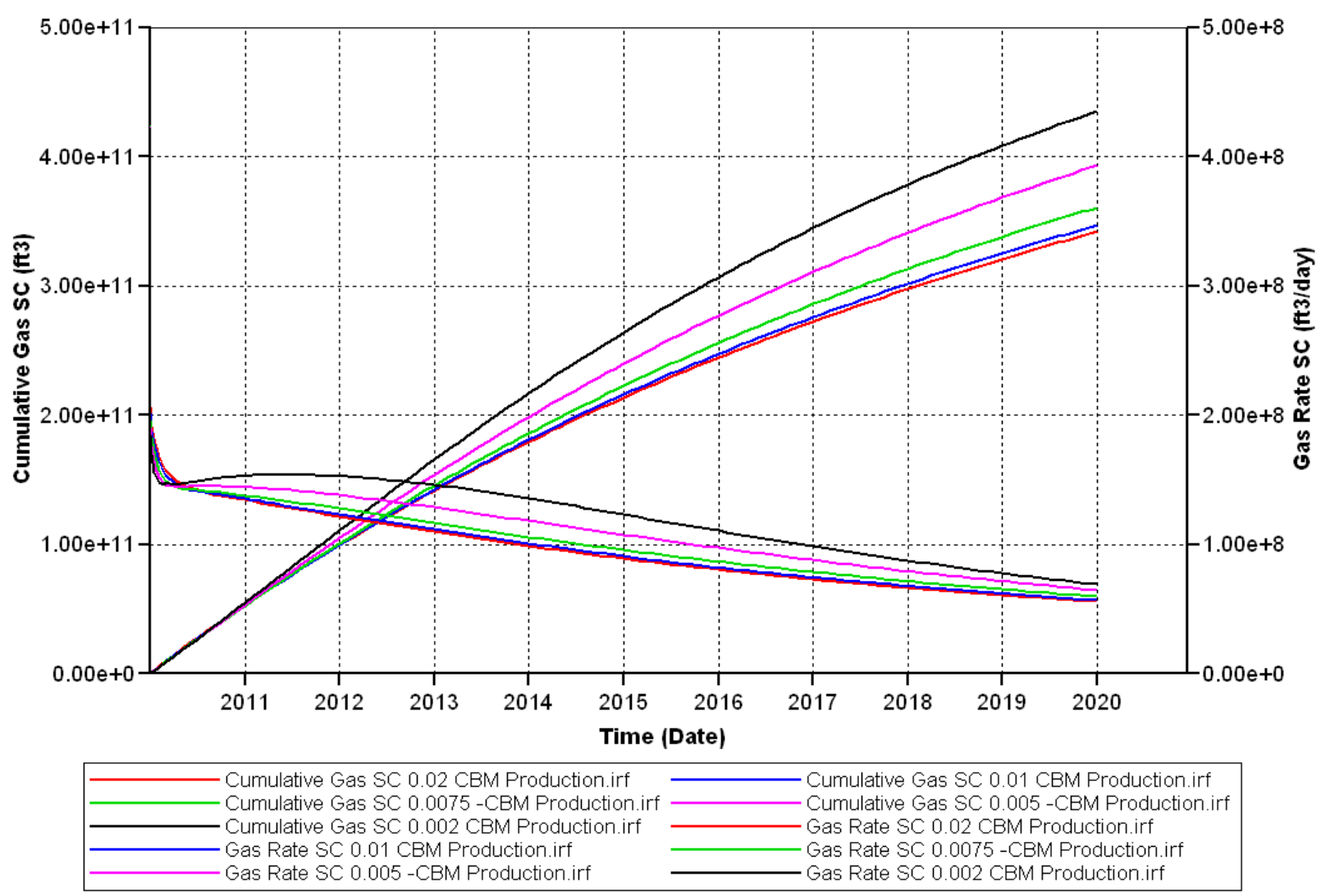

Figure 34: Effect of fracture porosity on cumulative gas and on gas rate for varying cleats porosity of the horizontal well 


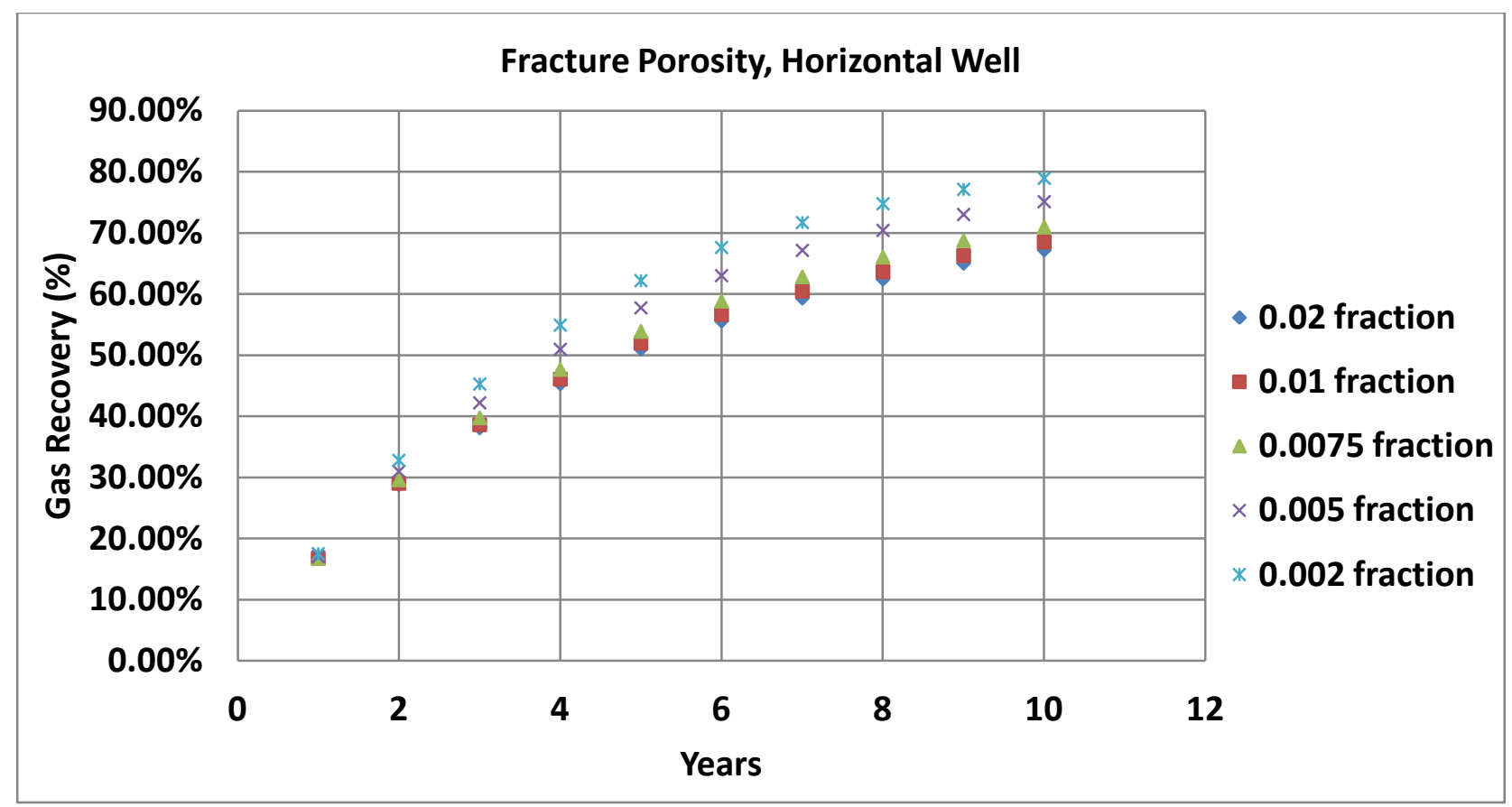

Figure 35: Effect of fracture porosity on gas recovery factor of the horizontal well

The simulation results in Figure 32 through 35 shows that increasing the fracture porosity will decrease the gas production rate. Increasing the coal porosity increases the pore volume and the surface gas and decreases the bulk volume where the gas is sorbed. As a result, decreasing cleats porosity will decrease the amount of water and free gas in the fracture which will give more places for the desorbed gas to produce very quickly.

\subsection{Effect of Fracture Permeability on CBM Production:}

The permeability of the coal is one of the most prevalent factors that affect gas production in CBM reservoirs. In this work, five different values for the fracture permeability were used for simulation designing runs to evaluate their effect on the gas production of CBM reservoirs. The fracture permeability in $\mathrm{i}, \mathrm{j}$ and $\mathrm{k}$ directions have been changed together so as to have the following values: 4, 6, 8, 10 and 12 md. Figure 36 through 39 shows the effect of the fracture permeability on the gas production and recovery factor of the horizontal well and vertical well respectively. 


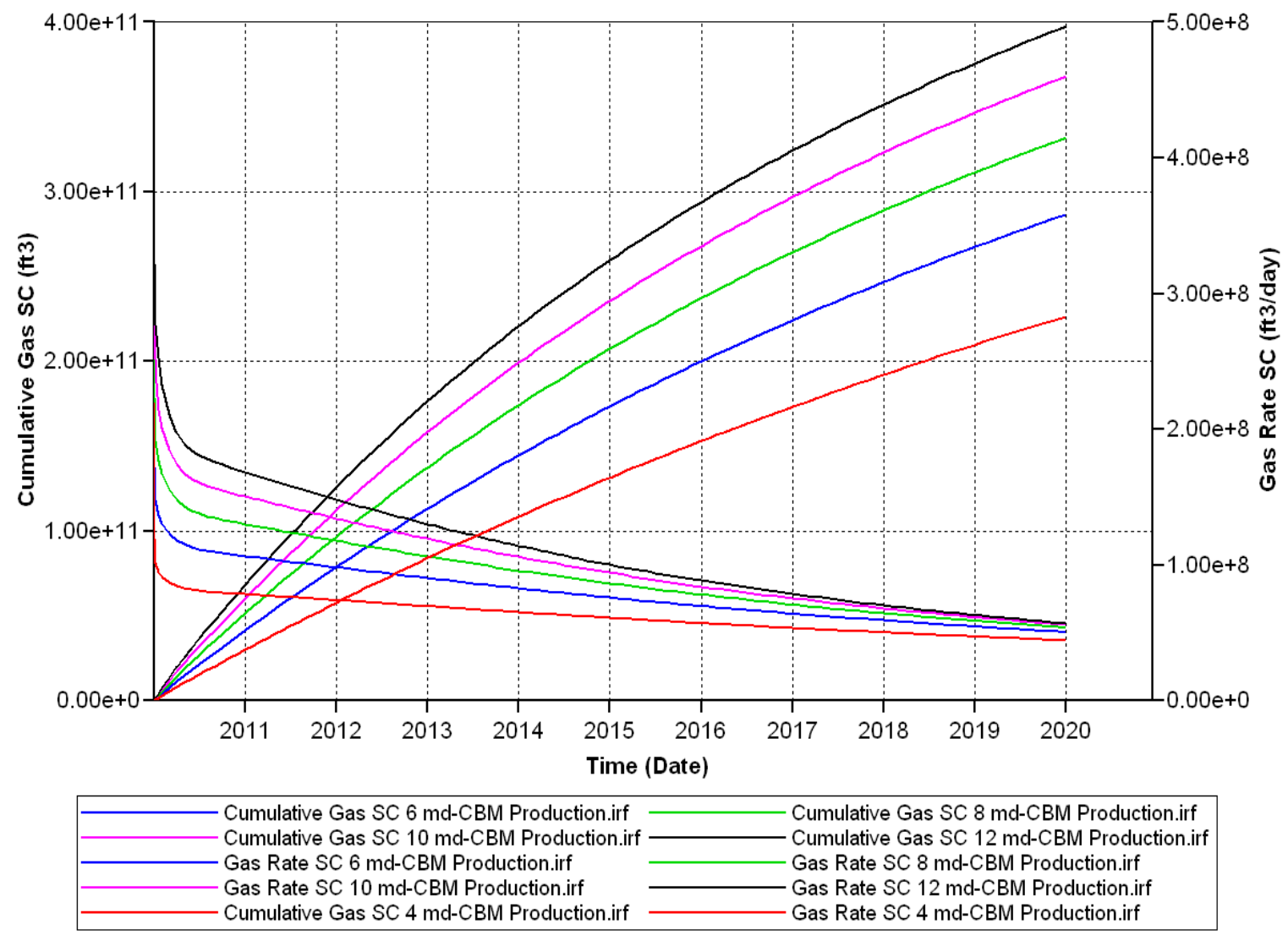

Figure 36 Effect of fracture permeability on cumulative gas and on gas rate for varying cleats permeability of the vertical well

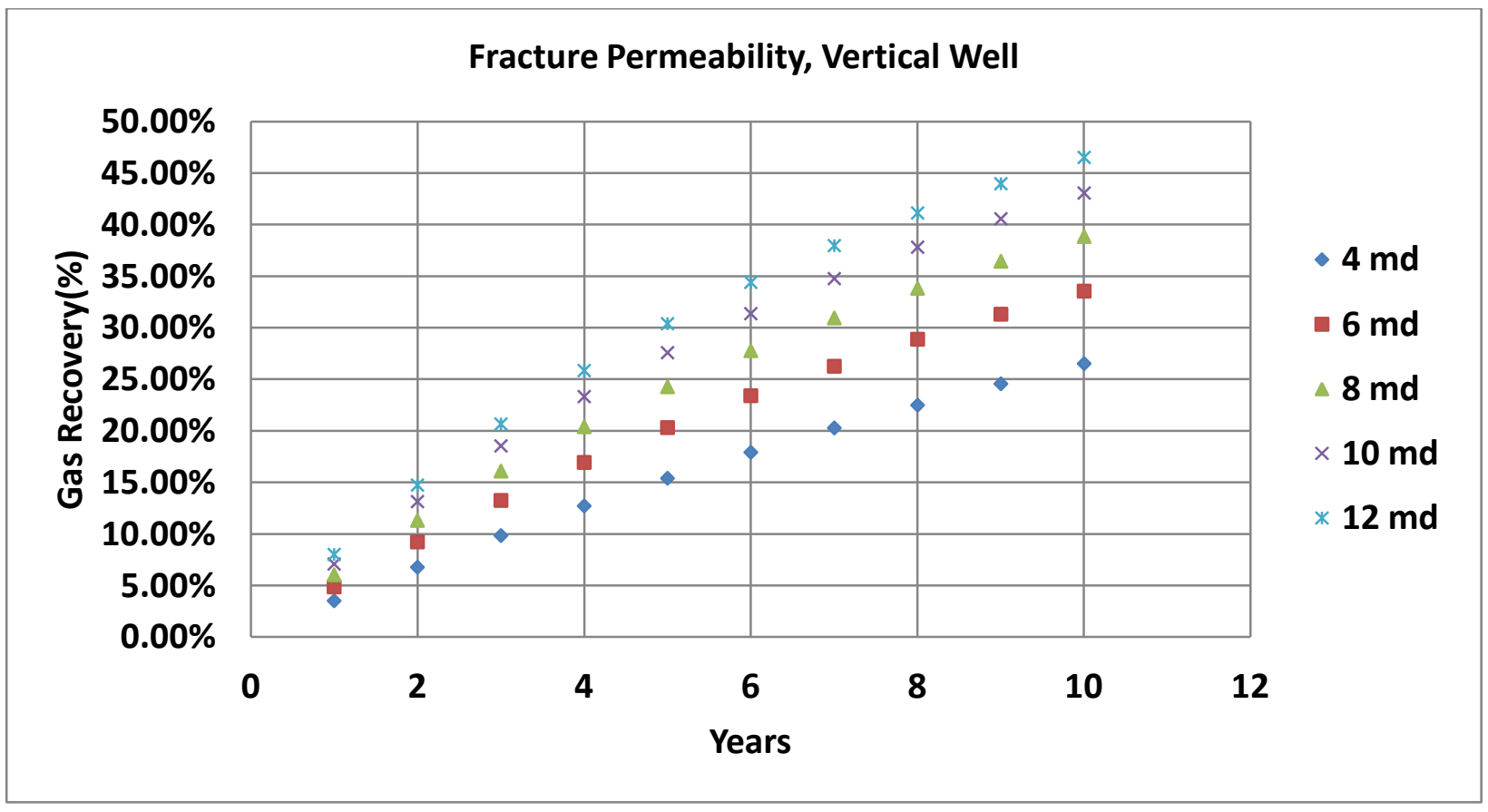

Figure 37 Effect of fracture permeability on gas recovery factor of the vertical well 


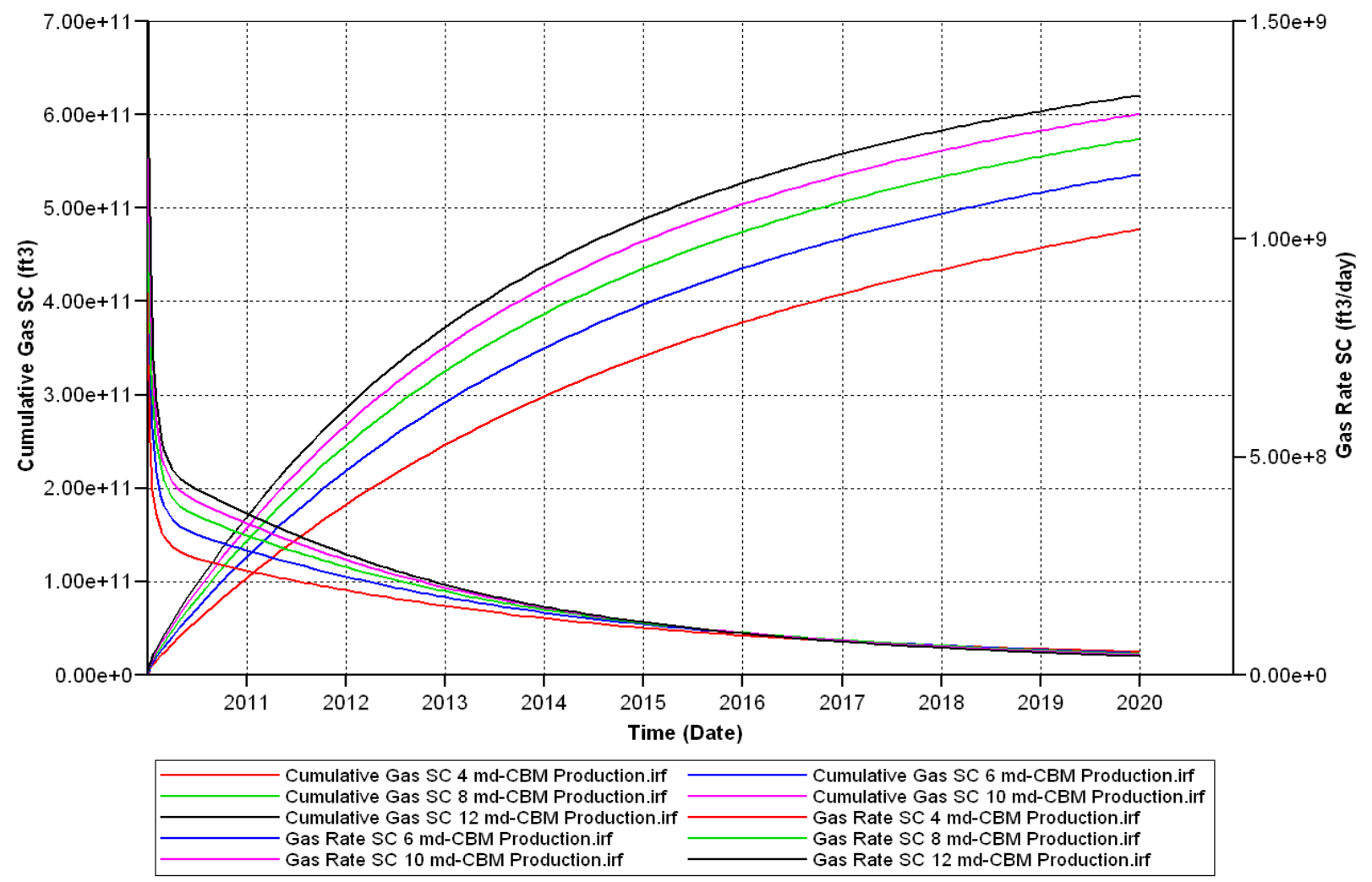

Figure 38 Effect of fracture permeability on cumulative gas and on gas rate for varying cleats permeability of the horizontal well

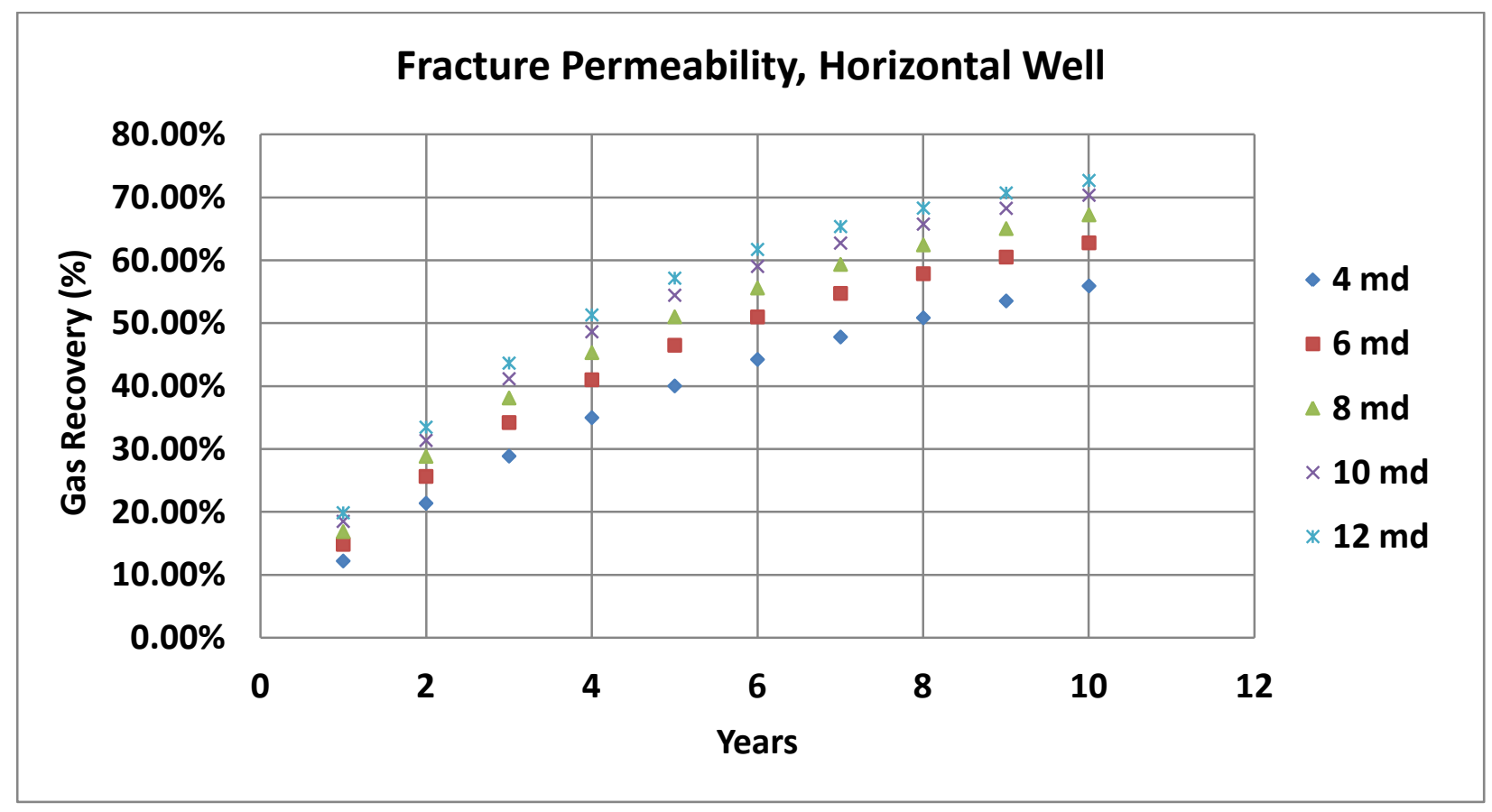

Figure 39 Effect of fracture permeability on gas recovery factor of the horizontal well 
The simulation results show that the gas production increases as the permeability increases. The permeability is acting as the main channel for fluid to flow. As a result, increasing the fracture permeability will increase the ability of the adsorbed gas which comes from the matrix to flow through cleats then toward the wellbore.

\subsection{Effect of Permeability Anisotropy on CBM Production:}

Sensitivity analysis was done for permeability anisotropy in this study. The permeability anisotropy is the ratio of face to butt permeability. It is an important factor for CBM producers, to maximize gas reserves by mitigating its effects. The methane movement in the coal toward the wellbore is dependent on the face and the butt cleats permeabilities. The cleats are longer and generally have wider aperture openings than the butt cleats found approximately perpendicular to them $^{15}$. From a field experience, if a well is drilled perpendicular to face cleats that well will produce 2.5 to 10 times as much methane as that from a well drilled perpendicular to butt cleats ${ }^{15}$. The fracture permeability was changed using four schemes, first by changing only the permeability in the $\mathrm{k}$ direction to a tenth of the original. The second was changing the $\mathrm{j}$ and $\mathrm{k}$ direction to a tenth of the original. The third scheme involved only changing in the $\mathrm{j}$ direction and the forth involved changing the all directions to a tenth of the original. 


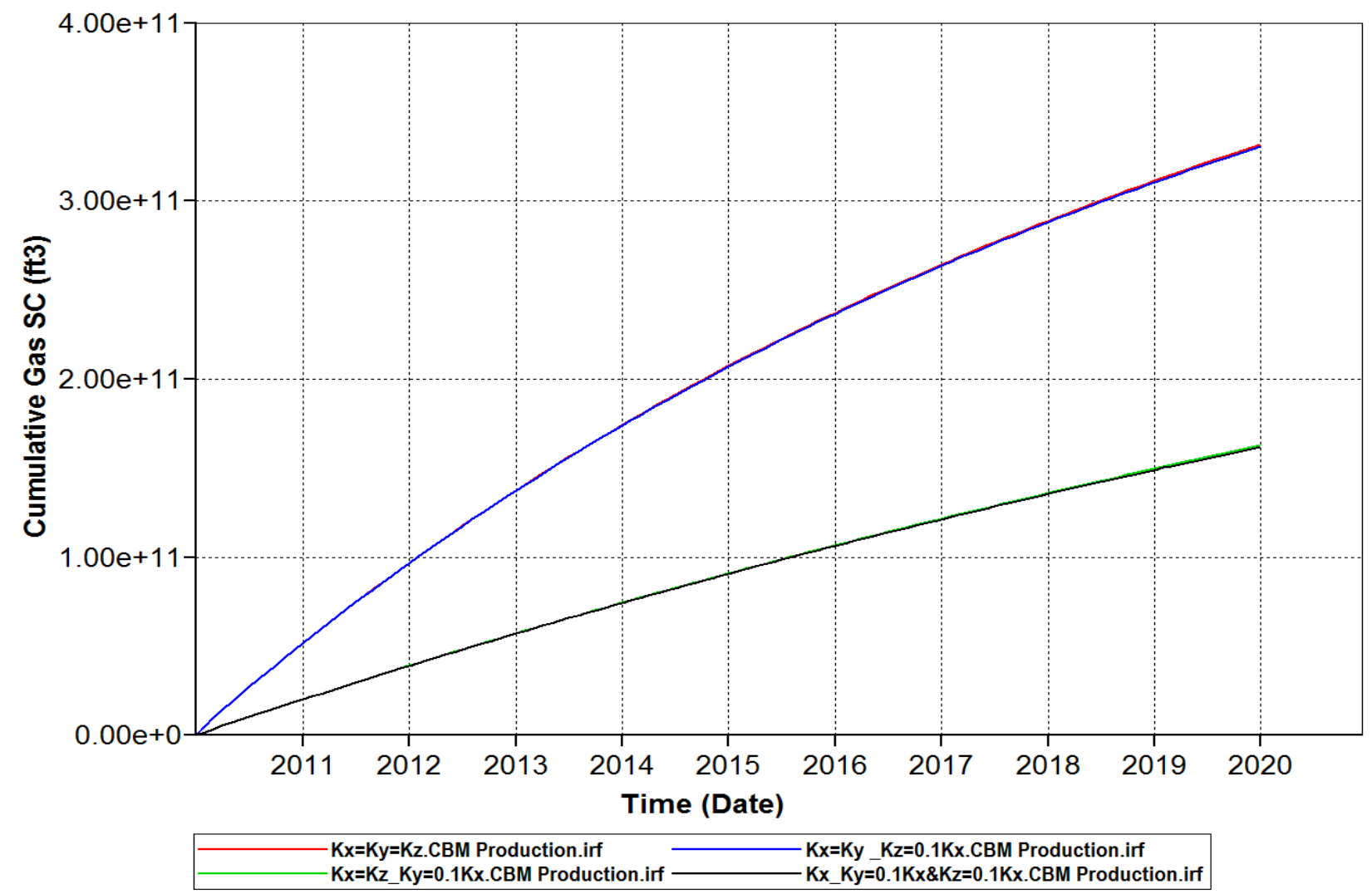

Figure 40 Effect of the permeability anisotropy on the cumulative production from the vertical well

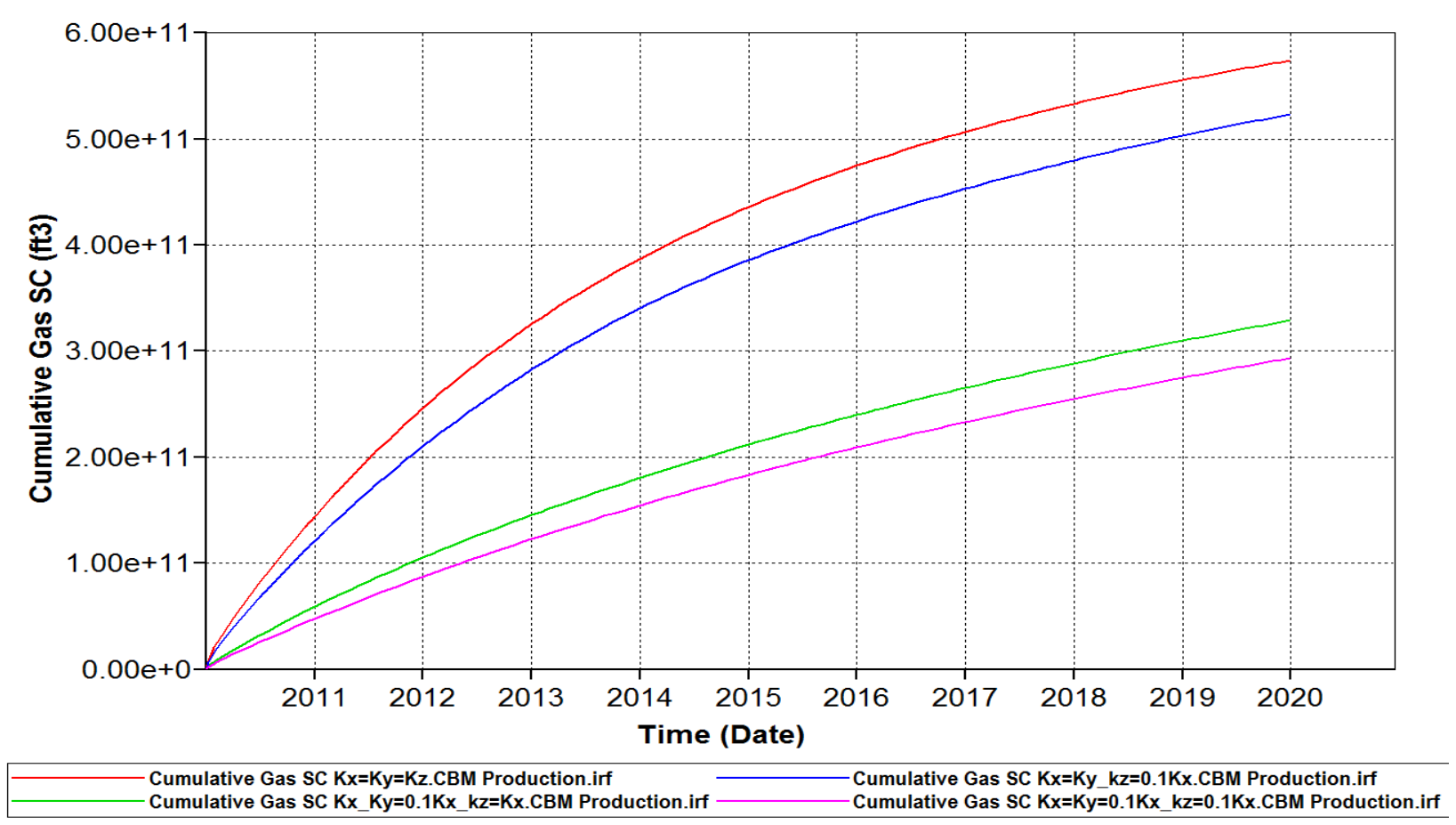

Figure 41 Effect of the permeability anisotropy on the cumulative production from the horizontal well 
The simulation result in Figure 40 of the vertical well shows that there is no change in cumulative production when permeability in $\mathrm{k}$ direction $(\mathrm{z})$ was changed to be $0.1 \mathrm{k}_{\mathrm{x}}$. This is because the flow occurs in $i$ and $j$ direction since the well is drilled vertically. However, the permeability in the $\mathrm{j}$ direction (y) shows that there is a significant effect on production since it is in the direction of low. For the horizontal well the simulation result in Figure 41 shows different results than the vertical well, because the horizontal well is drilled in the middle layer and gas flow is occurring in three directions. Thus, it is clear that changing reservoir permeability in the $\mathrm{i}, \mathrm{j}$ and $\mathrm{k}$ direction give different results.

\subsection{Economic Analysis:}

In this study, cash flow method was used to calculate the NPV. We had calculated the NPV to identify whether drilling a horizontal well is more appropriate decision than drilling a vertical well in thick and deep coal bed methane reservoirs. Furthermore, we calculated the NPV for the different scenarios of changes in reservoir properties to observe their effect on economic analysis. The data that have been used in the economic analysis are listed in Table 5 and 6 . Table -7 shows a sample of the calculation of the vertical well and horizontal well.

Table 5 Drilling cost of the horizontal well

\begin{tabular}{|l|c|l|}
\hline Interest Rate & $\mathbf{1 5}$ & $\%$ \\
\hline Gas Price & $\mathbf{3}$ & \$/MSCF \\
\hline Horizontal Drilling Cost & $\mathbf{3}$ & \$Million \\
\hline Completion Cost & $\mathbf{7 0 0 0 0 0}$ & \$ \\
\hline Operating Cost & $\mathbf{1 3 0 0 0}$ & \$/Month \\
\hline
\end{tabular}

Table 6 Drilling cost of the vertical well

\begin{tabular}{|l|c|l|}
\hline Interest Rate & $\mathbf{1 5}$ & $\%$ \\
\hline Gas Price & $\mathbf{3}$ & \$/MSCF \\
\hline Vertical Drilling Cost & $\mathbf{1 . 4}$ & \$Million \\
\hline Completion Cost & $\mathbf{5 0 0 0 0 0}$ & \$ \\
\hline Operating Cost & $\mathbf{6 0 0 0}$ & \$/Month \\
\hline
\end{tabular}


Table 7 Sample of the calculation and the result of the horizontal well and the vertical Well

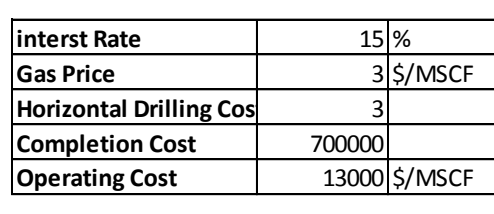

\begin{tabular}{|c|c|c|c|c|c|c|c|c|c|c|c|c|c|}
\hline Time & Years & 0 & 1 & 2 & 3 & 4 & 5 & $6 \mid$ & 7 & 8 & 9 & \multicolumn{2}{|c|}{10 total } \\
\hline Gas Production & SCF/Year & 0 & $1.44 \mathrm{E}+11$ & $1.02 \mathrm{E}+11$ & $7.92 \mathrm{E}+10$ & $6.16 \mathrm{E}+10$ & $4.86 \mathrm{E}+10$ & $3.91 \mathrm{E}+10$ & $3.20 \mathrm{E}+10$ & $2.65 \mathrm{E}+10$ & $2.21 \mathrm{E}+10$ & $1.87 \mathrm{E}+10$ & $5.74 \mathrm{E}+11$ \\
\hline Gas Production & MSCF/Year & & $1.44 \mathrm{E}+08$ & $1.02 \mathrm{E}+08$ & $7.92 \mathrm{E}+07$ & $6.16 \mathrm{E}+07$ & $4.86 \mathrm{E}+07$ & $3.91 \mathrm{E}+07$ & $3.20 \mathrm{E}+07$ & $2.65 \mathrm{E}+07$ & $2.21 \mathrm{E}+07$ & $1.87 \mathrm{E}+07$ & \\
\hline Gas Revenue & SMillion & 0 & 432.17 & 306.65 & 237.74 & 184.70 & 145.95 & 117.27 & 96.06 & 79.41 & 66.41 & 55.98 & 1722.34 \\
\hline Drilling Cost & $\$ M$ & 3 & & & & & & & & & & & \\
\hline Completion Cost & $\$ M$ & 0.7 & & & & & & & & & & & \\
\hline Operating Cost & $\$ M / Y$ & & 0.156 & 0.156 & 0.156 & 0.156 & 0.156 & 0.156 & 0.156 & 0.156 & 0.156 & 0.156 & 1.56 \\
\hline Total Expenses/year & & 3.7 & 0.156 & 0.156 & 0.156 & 0.156 & 0.156 & 0.156 & 0.156 & 0.156 & 0.156 & 0.156 & 5.26 \\
\hline
\end{tabular}

\begin{tabular}{|c|c|c|c|c|c|c|c|c|c|c|c|c|}
\hline profit & \begin{tabular}{|c|}
-3.7 \\
\end{tabular} & 432.02 & 306.49 & 237.58 & \begin{tabular}{|l|l|}
184.55 \\
\end{tabular} & 145.79 & 117.11 & \begin{tabular}{l|l|}
95.90 & \\
\end{tabular} & \begin{tabular}{|l|}
79.26 \\
\end{tabular} & 66.26 & 55.82 & 1717.08 \\
\hline & $\mid-3.7$ & 428.32 & 734.81 & 972.39 & 1156.94 & $\begin{array}{l}1302.73 \\
\end{array}$ & 1419.84 & 1515.74 & 1595.00 & 1661.26 & 1717.08 & \\
\hline & & & & & & & & & & & NPV & 424.435174 \\
\hline
\end{tabular}

\begin{tabular}{|l|c|l|}
\hline interst Rate & 15 & $\%$ \\
\hline Gas Price & 3 & \$/MSCF \\
\hline Vertical Drilling Cost & 1.4 & \$Million \\
\hline Completion Cost & 500000 & \\
\hline Operating Cost & 6000 & \$/MSCF \\
\hline
\end{tabular}

\section{Vertical well-Economic Analysis}

Operating Cost

\begin{tabular}{|c|c|c|c|c|c|c|c|c|c|c|c|c|c|}
\hline \begin{tabular}{|l|} 
Time \\
\end{tabular} & Years & 0 & 1 & $2 \mid$ & 3 & $4 \mid$ & \begin{tabular}{l|}
5 \\
\end{tabular} & \begin{tabular}{l|l|}
6 & \\
\end{tabular} & 7 & 8 & 9 & \multicolumn{2}{|c|}{\begin{tabular}{l|l|}
10 & total \\
\end{tabular}} \\
\hline Gas Production & SCF/Year & 0 & $5.40 E+10$ & $4.67 \mathrm{E}+10$ & $4.21 \mathrm{E}+10$ & $3.77 \mathrm{E}+10$ & $3.39 \mathrm{E}+10$ & $3.05 \mathrm{E}+10$ & $2.76 \mathrm{E}+10$ & $2.50 E+10$ & $2.28 \mathrm{E}+10$ & $2.08 \mathrm{E}+10$ & $3.41 \mathrm{E}+11$ \\
\hline Gas Production & MSCF/Year & & $5.40 E+07$ & $4.67 \mathrm{E}+07$ & $4.21 E+07$ & $3.77 \mathrm{E}+07$ & $3.39 \mathrm{E}+07$ & $3.05 \mathrm{E}+07$ & $2.76 \mathrm{E}+07$ & $2.50 E+07$ & $2.28 \mathrm{E}+07$ & $2.08 \mathrm{E}+07$ & \\
\hline Gas Revenue & \$sMillion & 0 & 162.10 & 140.17 & 126.36 & 113.05 & 101.58 & 91.52 & 82.95 & 75.02 & 68.27 & 62.35 & 1023.36 \\
\hline Drilling Cost & $\$ M$ & 1.4 & & & & & & & & & & & \\
\hline Completion Cost & $\$ M$ & 0.5 & & & & & & & & & & & \\
\hline Operating Cost & $\$ \mathrm{M} / \mathrm{Y}$ & & 0.072 & 0.072 & 0.072 & 0.072 & 0.072 & 0.072 & 0.072 & 0.072 & 0.072 & 0.072 & 0.72 \\
\hline Total Expenses/year & & 1.9 & 0.072 & 0.072 & 0.072 & 0.072 & 0.072 & 0.072 & 0.072 & 0.072 & 0.072 & 0.072 & 2.62 \\
\hline profit & & -1.9 & 162.03 & 140.10 & 126.29 & 112.98 & 101.51 & 91.45 & 82.88 & 74.95 & 68.20 & 62.28 & 1020.74 \\
\hline & & -1.9 & 160.13 & 300.22 & 426.51 & 539.49 & 640.99 & 732.44 & 815.31 & 890.26 & 958.46 & 1020.74 & \\
\hline
\end{tabular}

\begin{tabular}{|l|l|}
\hline NPV & 252.310752 \\
\hline
\end{tabular} 


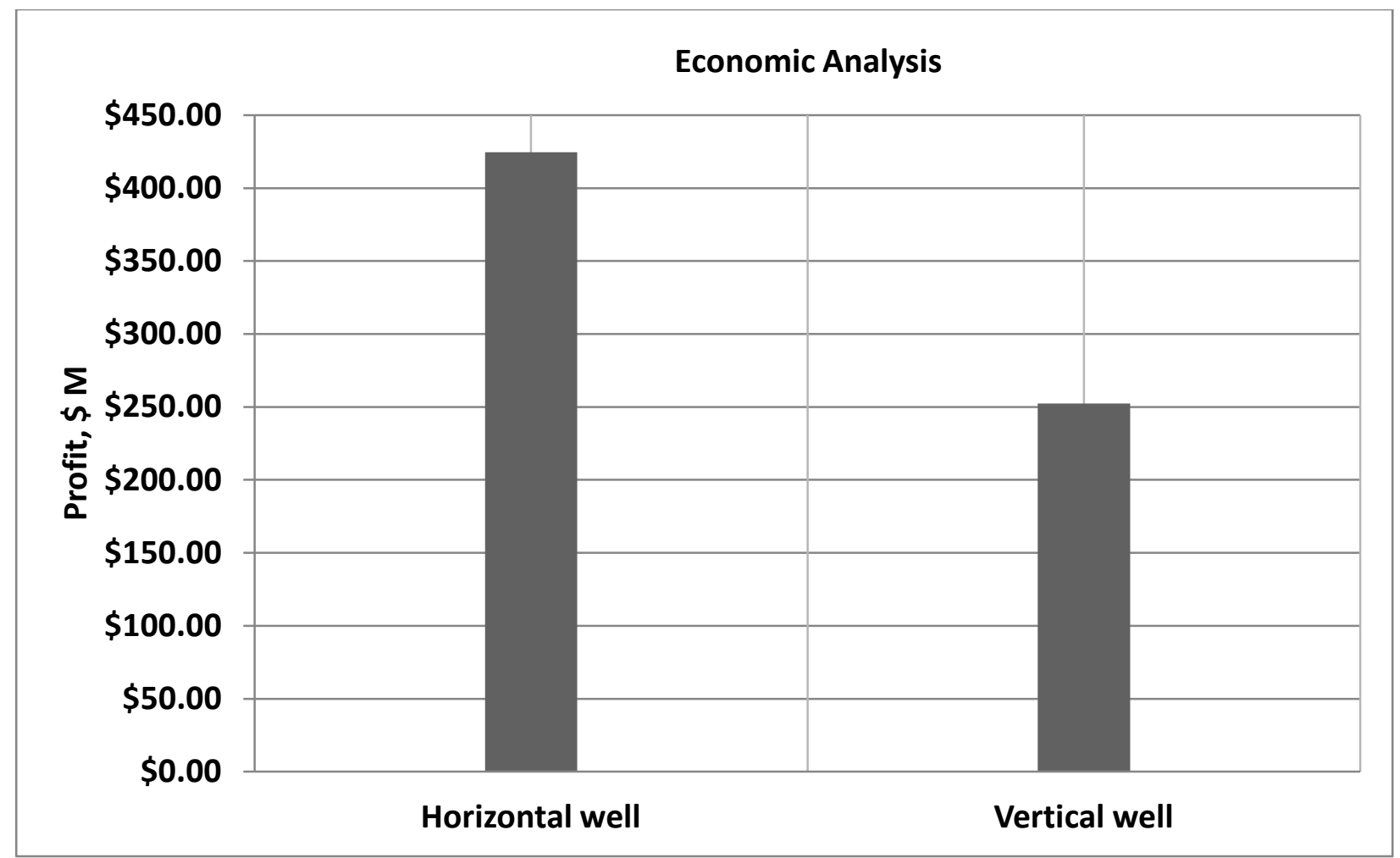

Figure 42 Net Present Value (NPV) result of one vertical well and one horizontal well

According to the results, drilling one horizontal well increases overall profitability by $30 \%$ as compared to the vertical well. Since the drilling cost of a horizontal well is a key factor in making decisions, three extra vertical wells were drilled. Increasing the number of vertical wells was based on drilling cost where the cost of one horizontal well is equal to the cost of four vertical wells in this study. Even though four vertical wells were drilled to increase the production and cut the cost down, the results show that not as much profit can be gained from vertical wells in comparison to the horizontal well with $5000 \mathrm{ft}$ length. Although the gas price has been changed from $3 \$$ to have values of 4,5 , and $6 \$$, the results still show that the horizontal well is more beneficial than multiple vertical wells. 


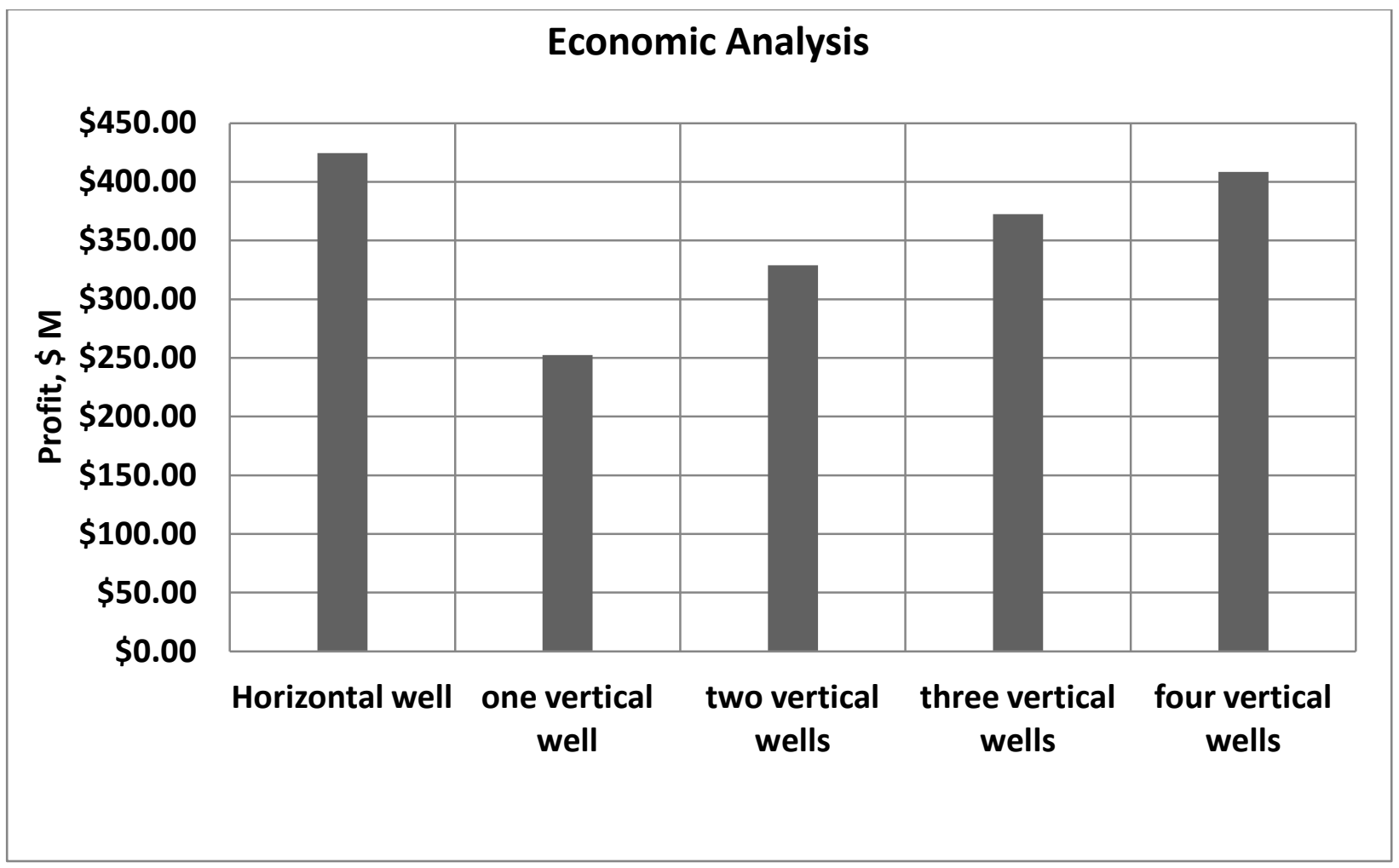

Figure 43 Net Present Value (NPV) result of one Horizontal well and different number of vertical well 


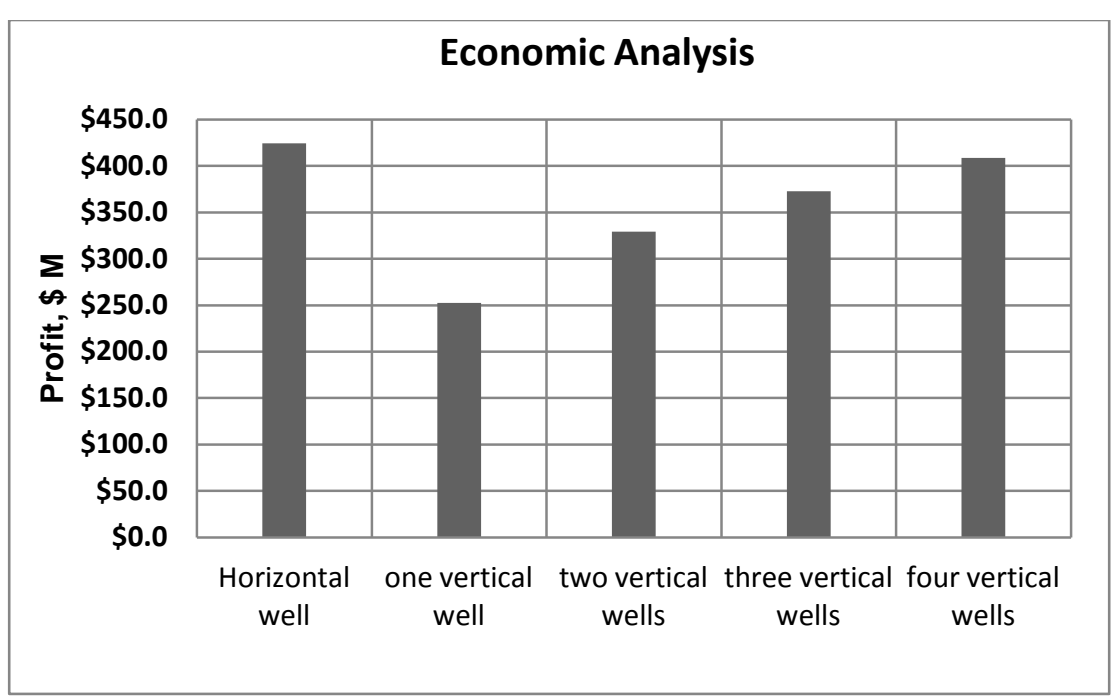

Figure 44 Net Present Value (NPV) of gas price $3 \$$

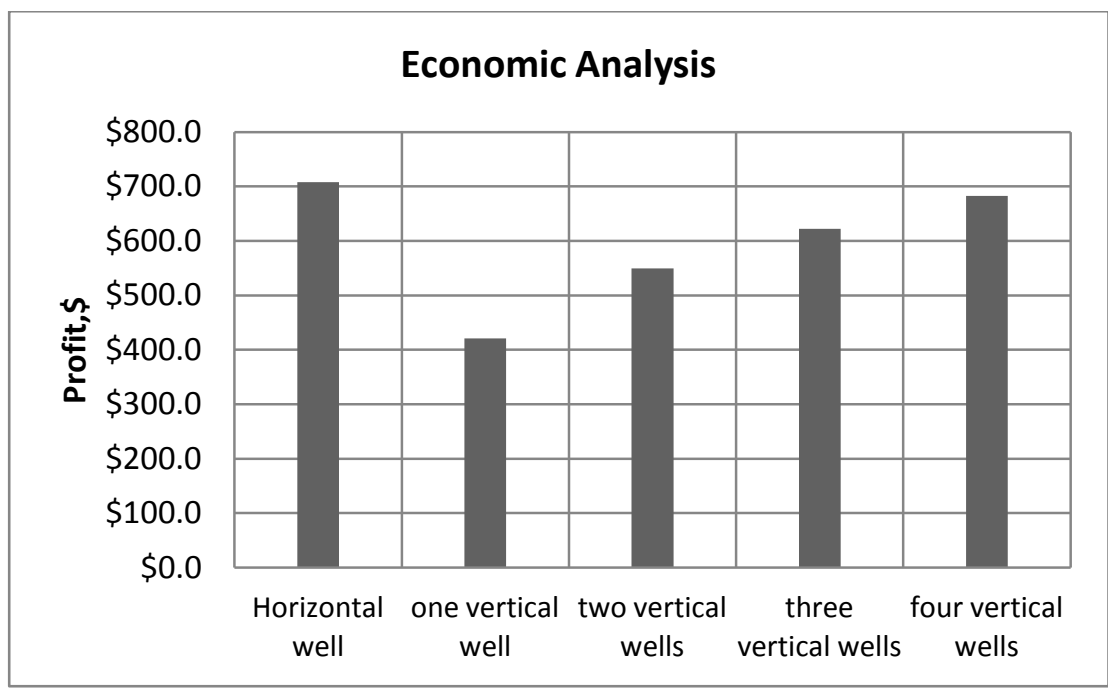

Figure 46 Net Present Value (NPV) of gas price $5 \$$

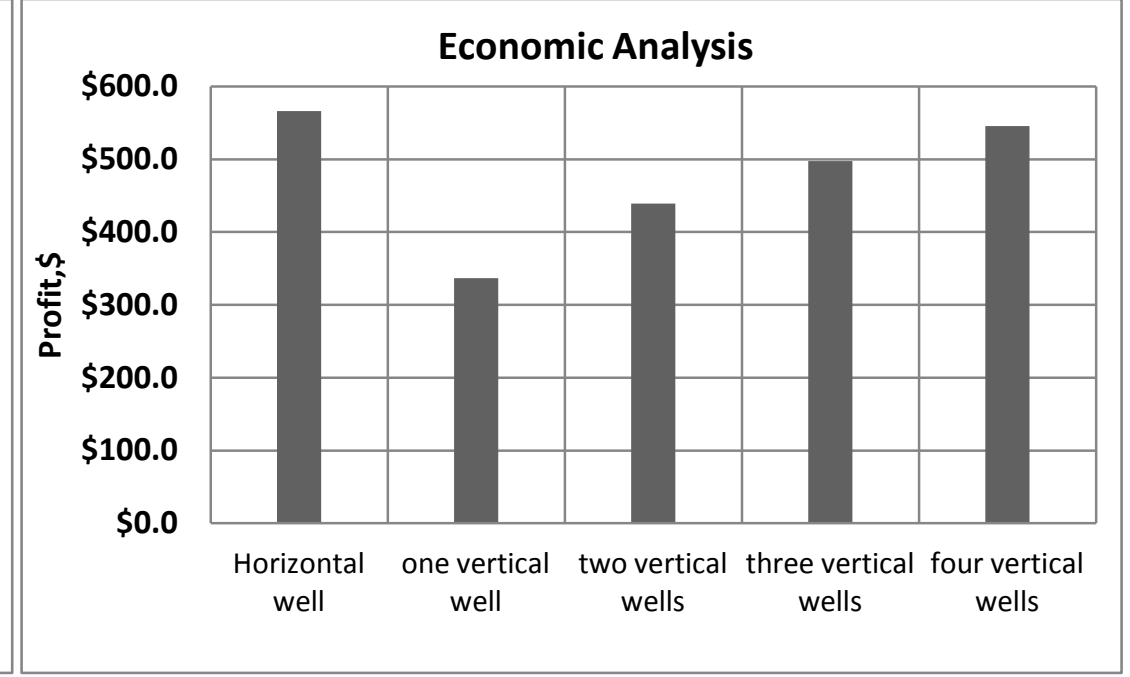

Figure 45 Net Present Value (NPV) of gas price $4 \$$

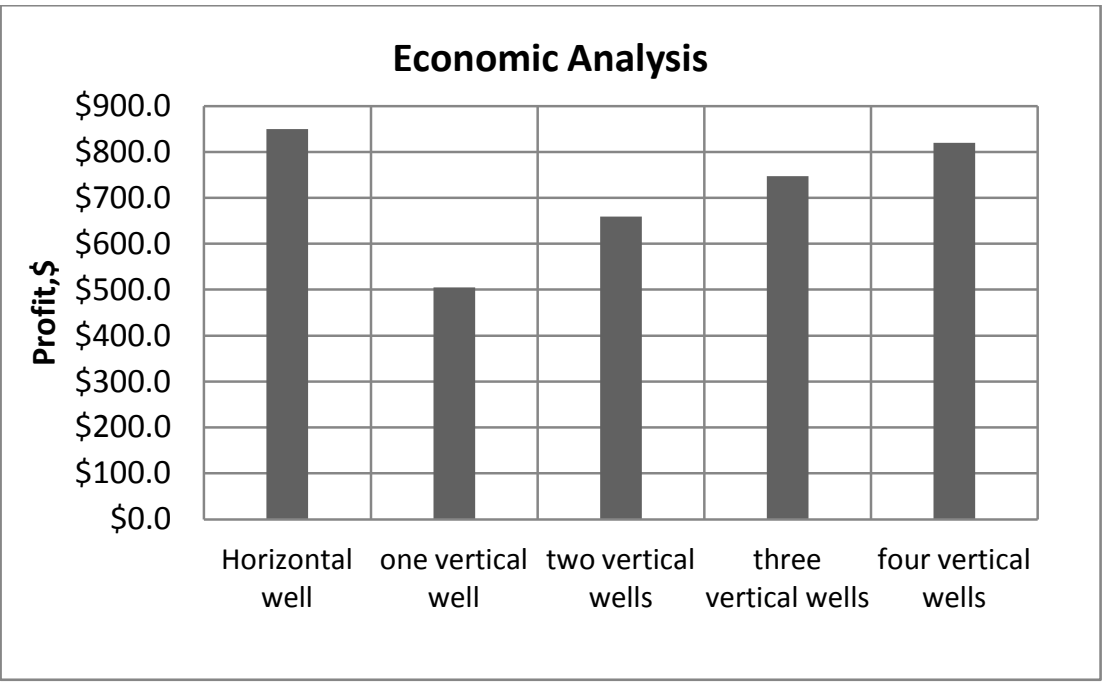

Figure 47 Net Present Value (NPV) of gas price $6 \$$ 


\subsubsection{Economic Analysis of the Desorption time:}

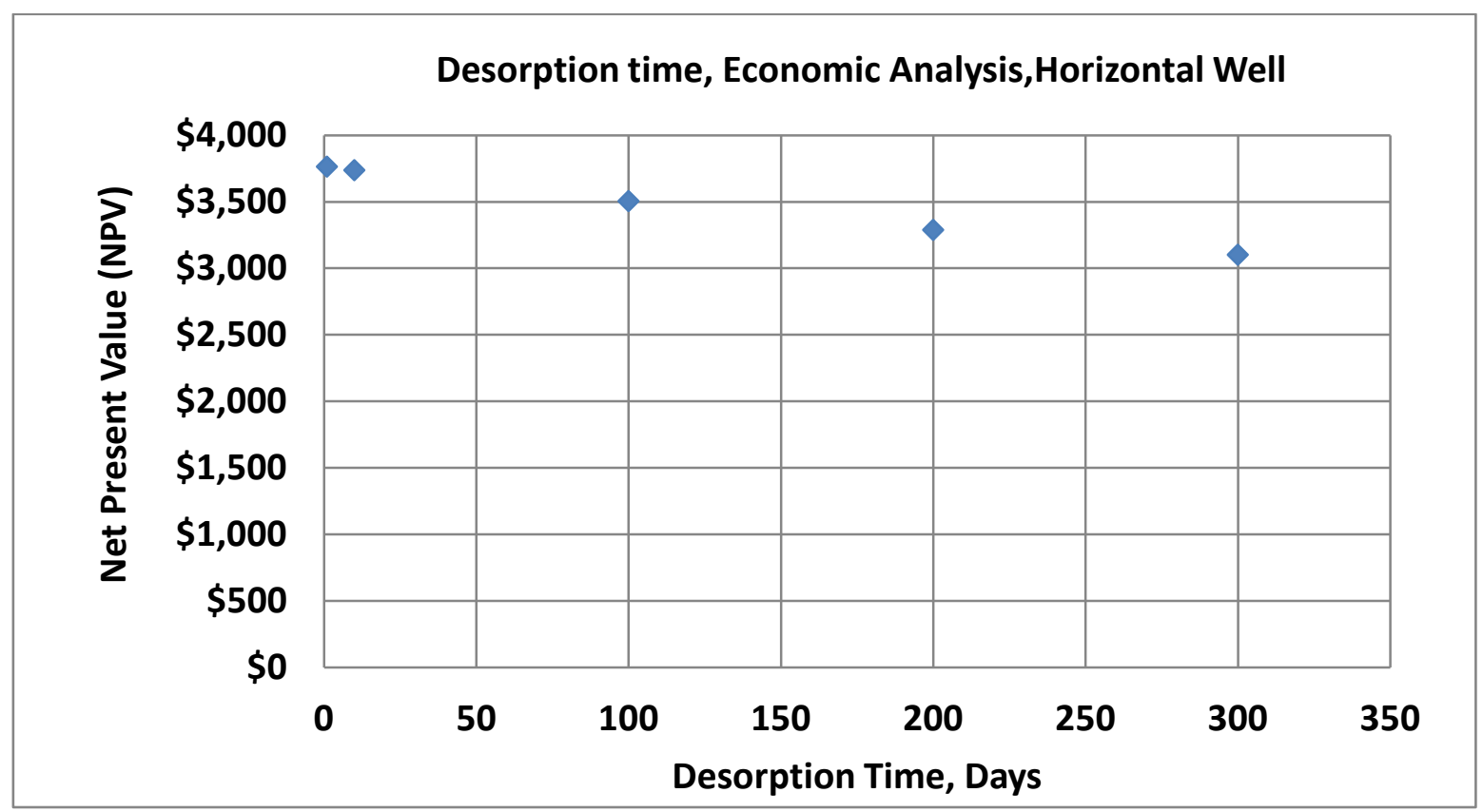

Figure 48 Effect of gas content on NPV of the Horizontal well

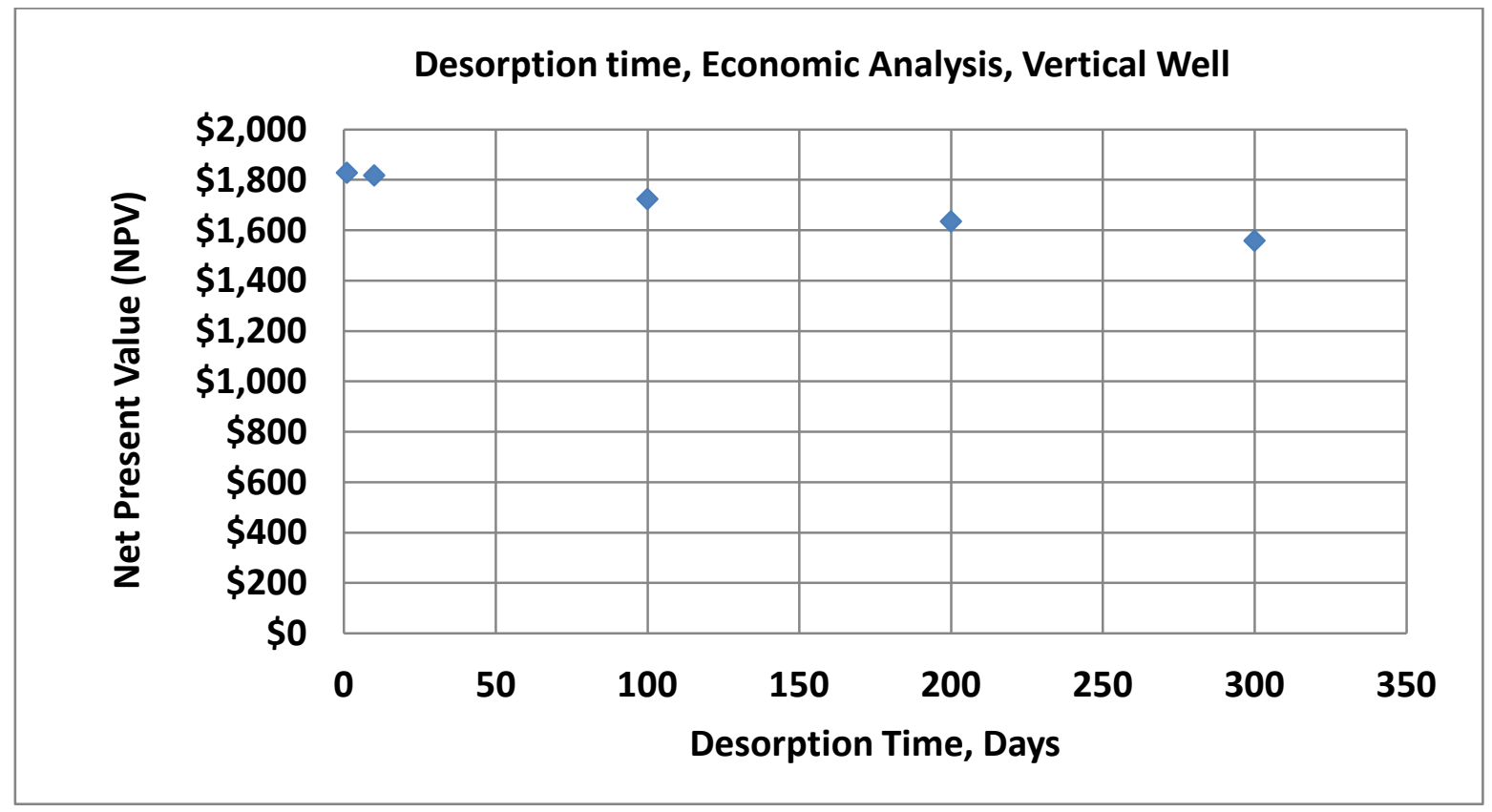

Figure 49 Effect of gas content on NPV of the vertical well

As discussed, the desorption time does not have a significant effect on gas production. The result of the Net Present Value between 1 day to 300 days shows the difference in the NPV. 
However, this difference in NPV is not too much when we consider how big the change in the desorption time to release gas from the matrix.

\subsubsection{Economic Analysis of Gas Content:}

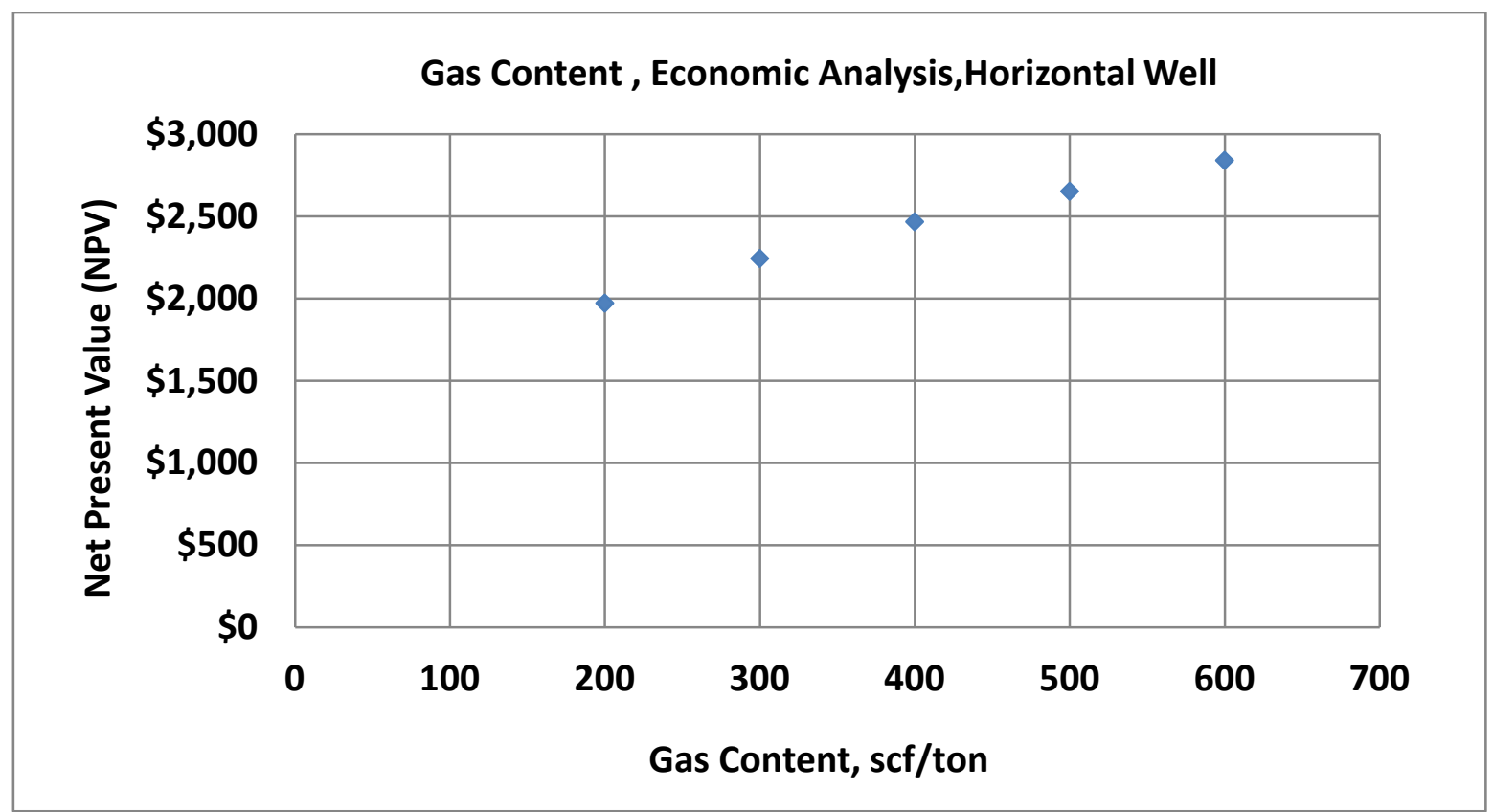

Figure 50 Effect of gas content on NPV of the horizontal well

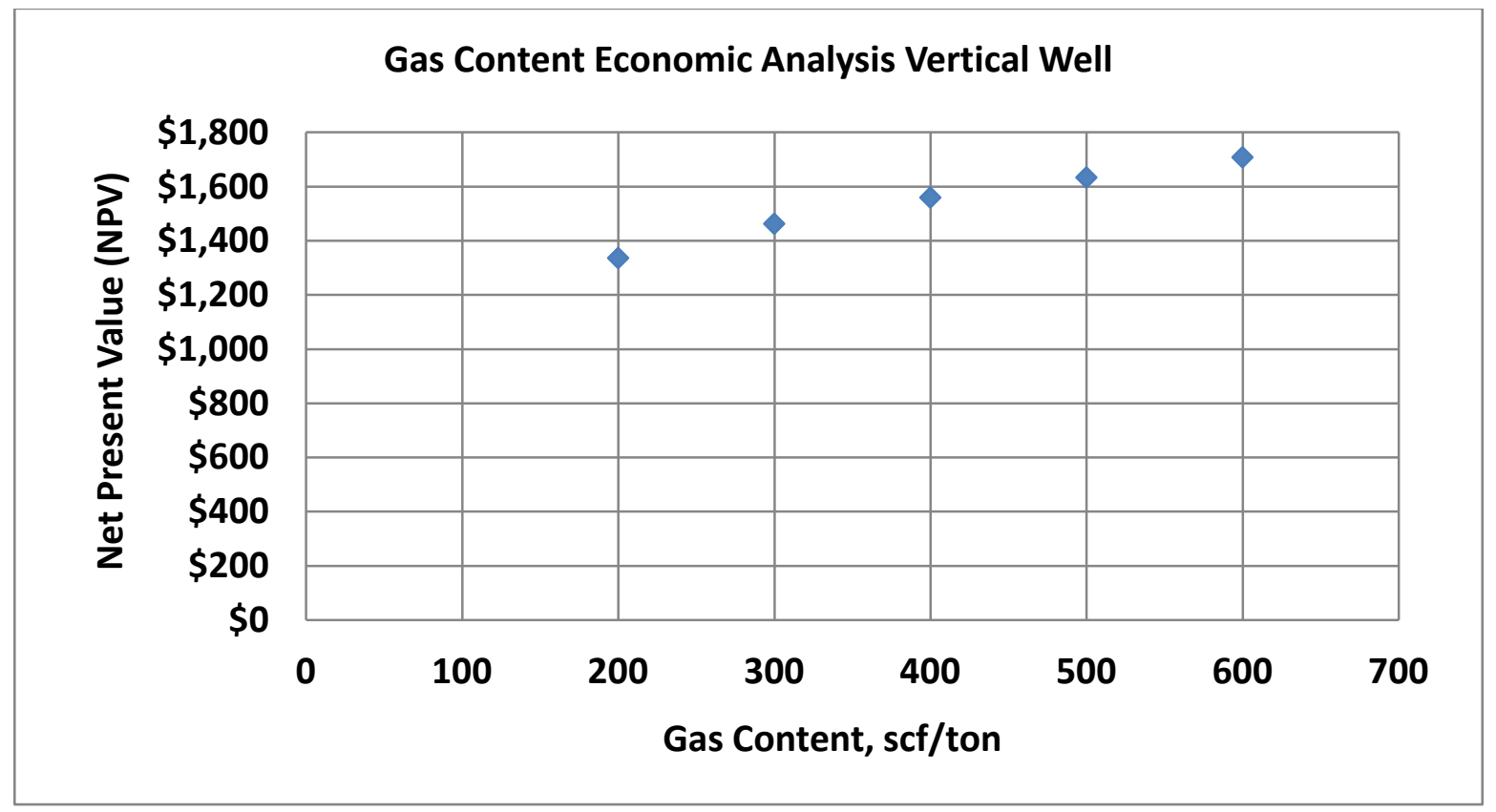

Figure 51 Effect of gas content on NPV of the vertical well 
Gas content is one of the most important factors that show clear effect on the gas production of the coal bed methane. As we can see that increasing the gas content will increase the NPV gradually.

\subsubsection{Economic Analysis of Fracture Permeability:}

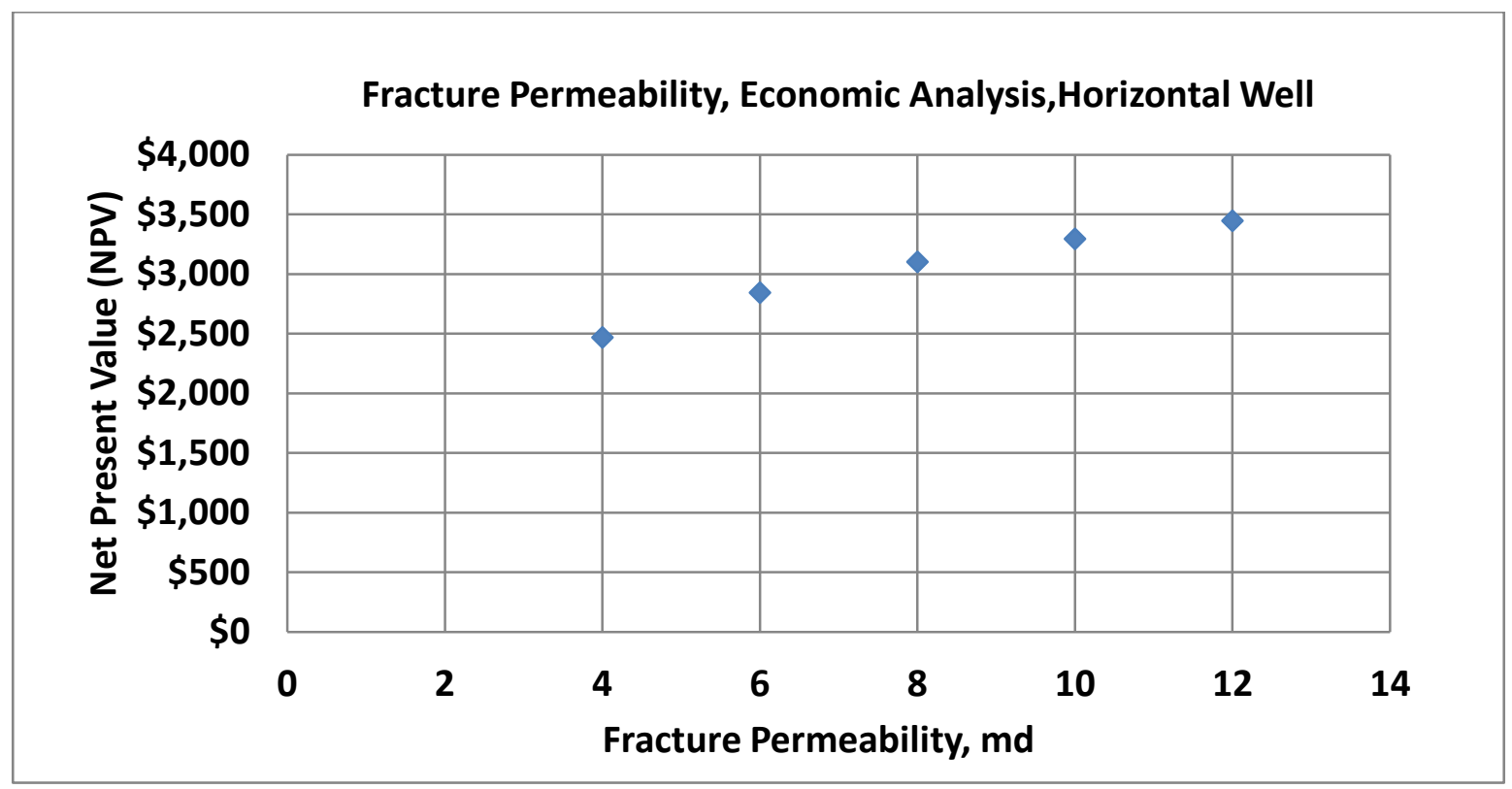

Figure 52 Effect of fracture permeability on NPV of the horizontal

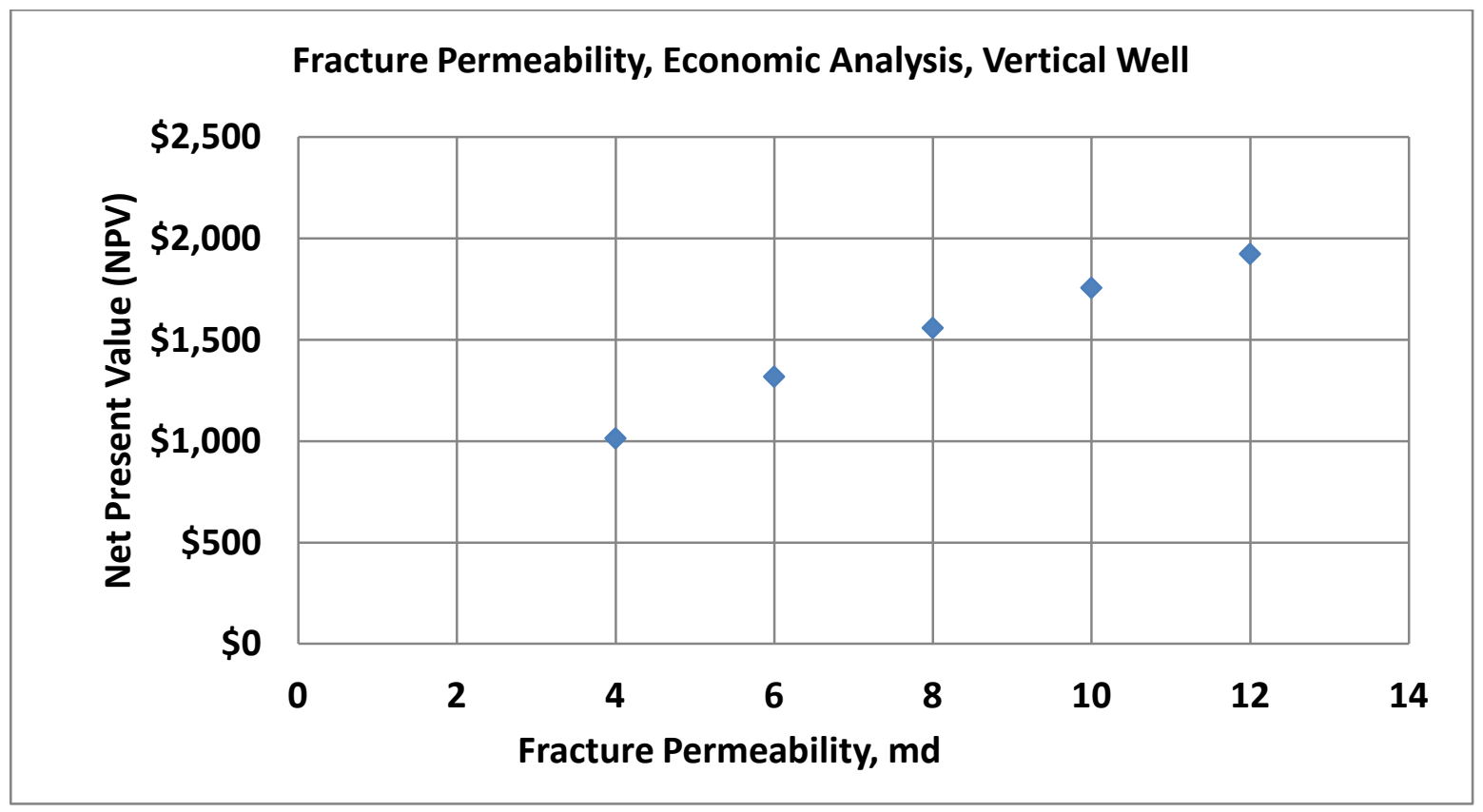

Figure 53 Effect of fracture permeability on NPV of the vertical well 
The fracture permeability has an obvious effect on the gas production from coal bed methane reservoir as discussed earlier. The fracture permeability acts as a specific path for the gas to flow in coal bed. As expected, increase in the fracture permeability increases NPV.

\subsubsection{Economic Analysis of Fracture Porosity:}

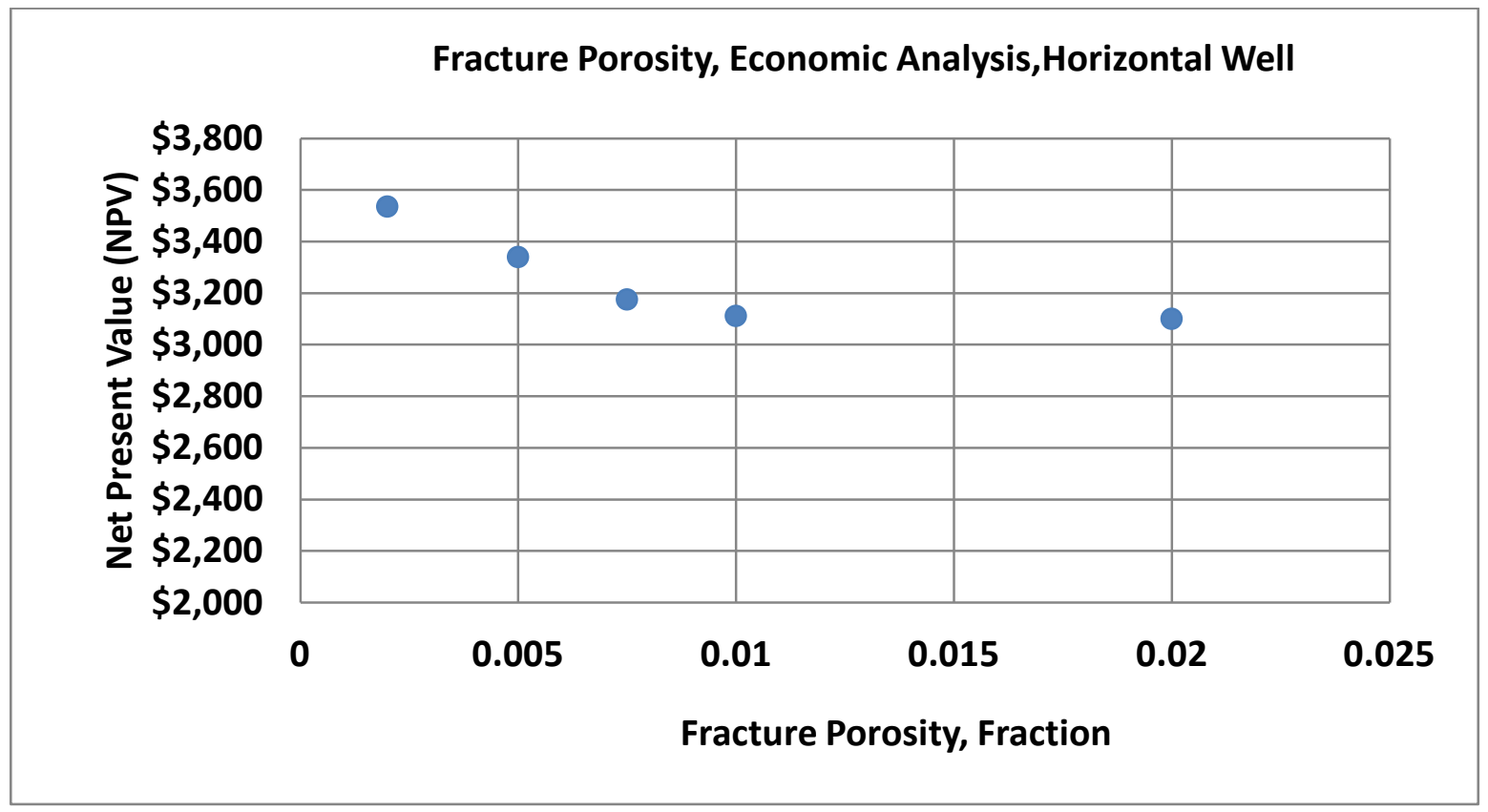

Figure 54 Effect of fracture porosity on NPV of the horizontal well

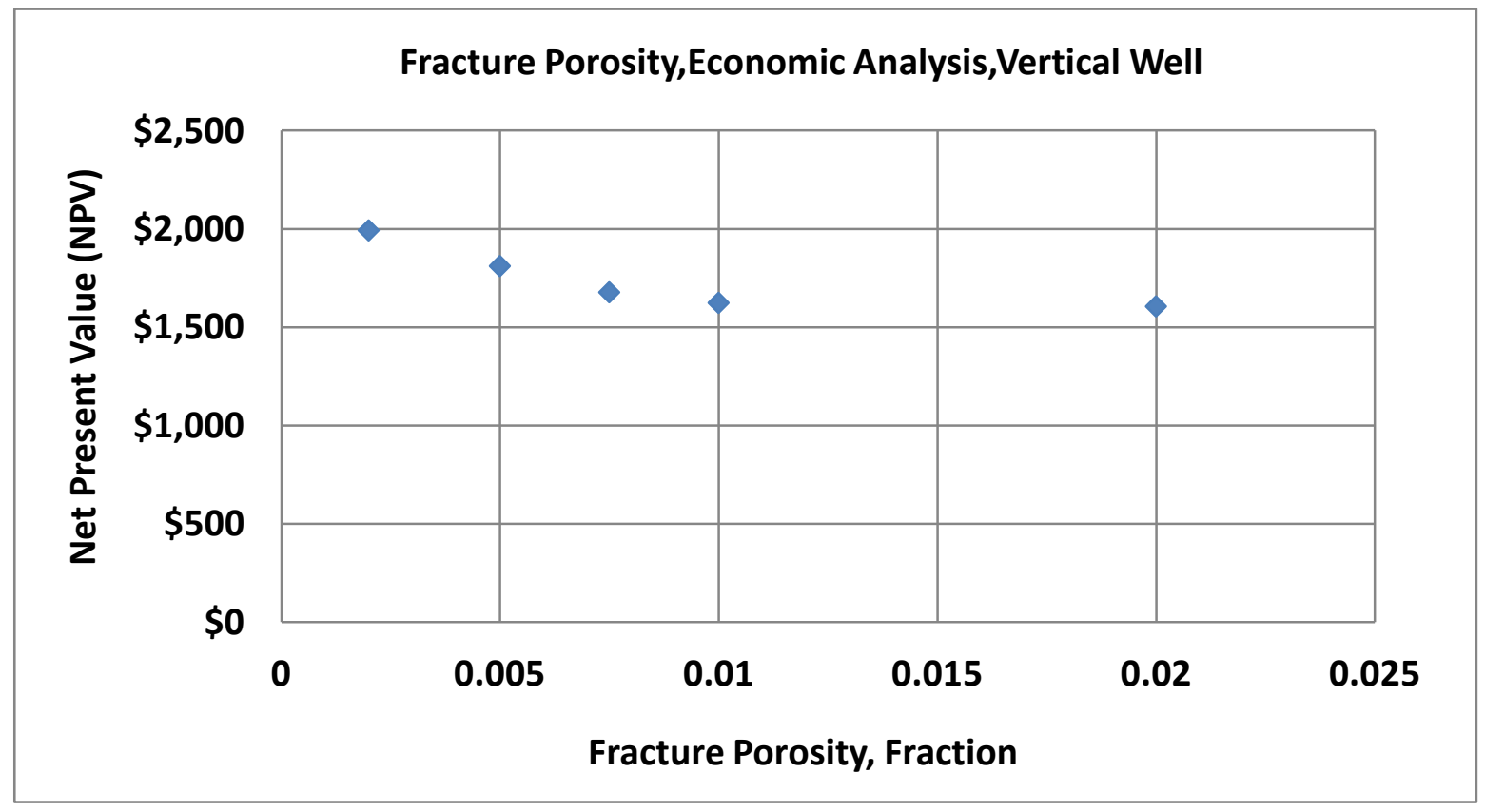

Figure 55 Effect of fracture porosity on NPV of the vertical well 
The fracture porosity as has been discussed is the place to store gas and not a flow conduit. After 10 years from production, the result of NPV shows that increasing the porosity, results in decreasing NPV and gas production as well, but the difference is not significant. 


\section{Chapter 5}

\subsection{Conclusion:}

- From the literature review part we conclude Conventional gas reservoirs are relatively difficult to find but easy to produce, while unconventional gas reservoirs, such as CBM, are easy to find but relatively difficult to produce.

- A parametric study to determine the benefits of drilling pattern in deep and thick CBM reservoirs shows drilling one horizontal well is much better than drilling multiple vertical wells. Horizontal well can improve productivity significantly and also cut down the cost of operation and maintenance.

- Permeability and gas content are the most sensitive parameters that influence the production from deep and thick coal bed methane reservoirs.

- Desorption time has no significant effect on the gas production from deep and thick coal bed methane. It is an important factor that has a small effect on the first years of the production.

- Porosity is another reservoir property which has no significant effect on gas production from CBM reservoirs.

- Increasing the length in the horizontal well increases gas production and recovery factor as well because it is increasing contact with the coal seam and enhancing the productivity of the well. 


\section{Reference:}

1. Stephen, A. Holditch., "The Increasing Role of Unconventional Reservoirs in the Future of the Oil and Gas Business", SPE/Holditch Schlumberger, 2001.

2. Schraufnagel, R. A.,McBane, R. A., "Coalbed Methane - A Decade of Success", paper SPE 28581, Annual Technical Conference and Exhibition, New Orleans, Louisiana, 1994.

3. Andrew, R. Scott., “American Association of Petroleum Geologists”, Program for Annual Convention and Exhibition.

4. Shahab D. Mohaghegh. Nikola Maricic. Chevron Corporation., "A Parametric Study on the Benefits of Drilling Horizontal and Multilateral Wells in Coalbed Methane Reservoir". Paper SPE 96018, West Virginia University, 2005.

5. Michael, J. Economides, Tony Martin., "Modern Fracturing Enhancing Natural Gas Production", University of Houston, TX, 2007.

6. “Coal Information, Kentucky Geological Survey”, University of Kentucky, 1997-2011.

7. "Global petroleum Research institute designs petroleum E\& P Research cooperative Texas Engineering Experiment Station”, Texas A\&M University System.(http://www.google.com/ Coa1 basins)

8. SUNIL, RAMASWAMY., "Selection of best drilling, completion and stimulation methods for coalbed methane reservoirs", Master thesis, Texas A\&M University, 2007.

9. R. J. Bielicki, J. H. Perkins, and F. N. Kissell., "Methane Diffusion Parameters far Sized Coal Particles a Measuring Apparatus and Some PreWary Results”, Pittsburgh Mining and Safety Research Center, Pittsburgh, Pa. Report of investigations 7697, 1972.

10. CMatt, Mavor,Charles, R.Nelson., "Coalbed methane reservoir Gas-In-Place Analysis",gas Research Institute, Chicago, Illinois, USA.1997.

11. Jalal Jalali., "A Coalbed methane simulator designed for the independent producers",Master Thesis, West Virginia University,Morgantown, WV, 2004.

12. C.A.MORA, R.A, WATTENBARGER., "Comparison of Computation Method for CBM Performance", Texas A\&M University, S. MCKETTA El Paso Exploration and Production Company, 2007. 
13. T. Ahmed, A. Centilmen, and B .Roux,Anadarko Petroleum Corp,. "A generalized Material Balance Equation for Coalbed Methane Reservoir", Paper SPE 102638. San Antonio, Texas. 2007.

14. KamalMorad,P.eng;Ray,Mireault,P.E;and,Lisa,Dean,P.Geol.,“coalbedmethane fundamentals", Reservoir engineering for geologists ,October2008.

15. Halliburton.,"Coalbed Methane Principles and Practices". Chapter 4 Reservoir Analysis, June2007 